\title{
BENEFITS OF NEAR-TERM CLOUD LOCATION FORECASTING FOR LARGE SOLAR PV
}

\author{
A Thesis \\ Presented to the \\ Faculty of California Polytechnic State University, \\ San Luis Obispo
}

\author{
In Partial Fulfillment \\ of the Requirements for the Degree \\ Master of Science in Electrical Engineering
}

by

Timothy Robert Rudd

August 2011 
(C) 2011

Timothy Robert Rudd

ALL RIGHTS RESERVED

ii 


\section{COMMITTEE MEMBERSHIP}

TITLE:

Benefits of Near-Term Cloud Location Forecasting for

Large Solar PV

AUTHOR:

Timothy Robert Rudd

DATE SUBMITTED: August 2011

COMMITTEE CHAIR: Dr. Dale Dolan, Professor

COMMITTEE MEMBER: Dr. Ahmad Nafisi, Professor

COMMITTEE MEMBER: Dr. Taufik, Professor 


\section{ABSTRACT \\ Benefits of Near-Term Cloud Location Forecasting for Large Solar PV Timothy Robert Rudd}

As the 'green' energy movement continues to gain momentum, photovoltaic generation is becoming an increasingly popular source for new power generation. The primary focus of this paper is to demonstrate the benefits of close-to real-time cloud sensing for Photovoltaic generation. In order to benefit from this close-to real-time data, a source of cloud cover information is necessary. This paper looks into the potential of point insolation sensors to determine overhead cloud coverage. A look into design considerations and economic challenges of implementing such a monitoring system is included. The benefits of cloud location sensing are examined using computer simulations to target important time-scales and options available to plant operators. Finally, the economics of advanced forecasting options will be examined in order to determine the benefit to plant operators.

Keywords: Energy, Power, Photovoltaic, Renewable, Economics, Cloud, Insolation, Forecast. 


\section{TABLE OF CONTENTS}

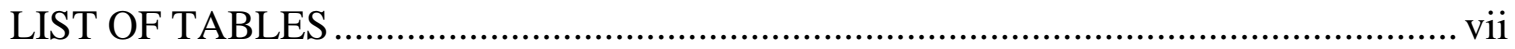

LIST OF FIGURES ................................................................................. viii

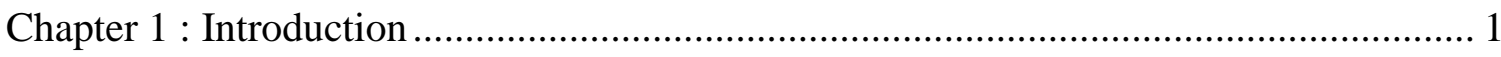

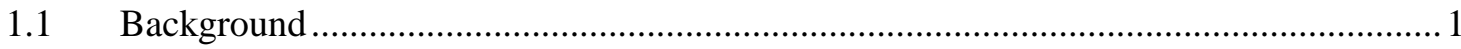

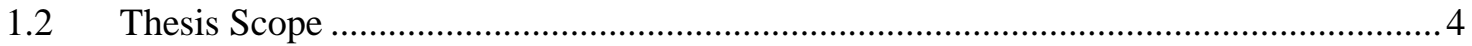

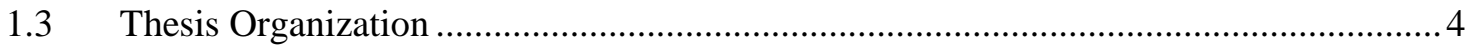

Chapter 2 : Fixed Location Insolation Meters for Cloud Location Forecasting ................ 6

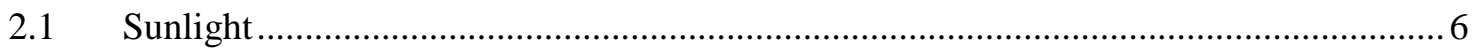

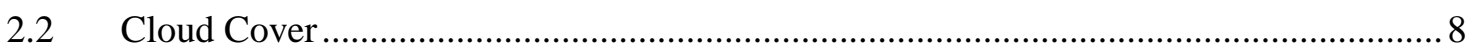

2.3 Fixed Location Insolation Meters for Cloud Location Forecasting ............................. 13

2.4 Characterization of Potential Insolation Meter ......................................................... 19

2.5 Total Sky Imaging for Cloud Location Forecasting ................................................. 22

2.6 Economic Comparison of Insolation Metering and TSI ...........................................28

Chapter 3 : Simulations Demonstrating the Benefits of Near-Term Forecasting ............. 30

3.1 Previous Study into Effects of Loss of PV Generation................................................. 30

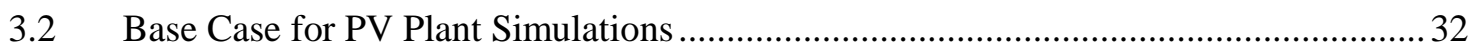

3.3 Individual Scenarios for Ancillary Generation Support............................................. 42

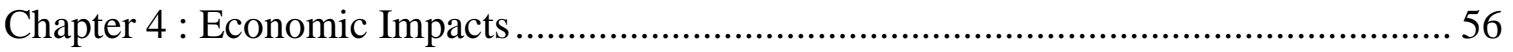

4.1 Potential Economic Benefits for Independent System Operators or PV Plant Operators

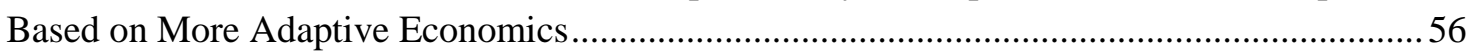

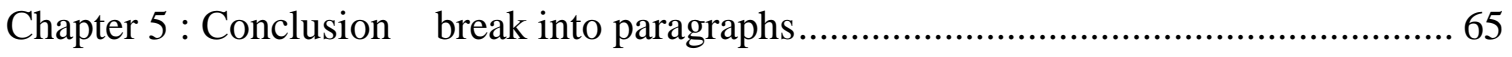

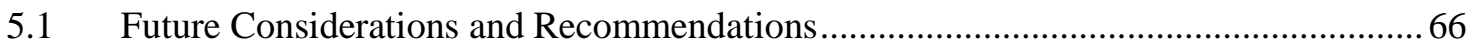

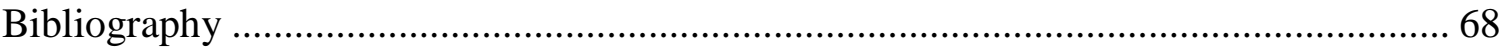

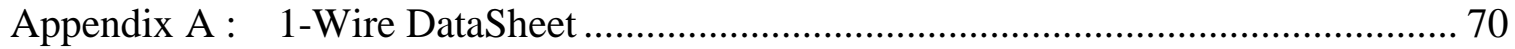

Appendix B : $\quad$ Hobby-Boards Solar Radiation Detector Schematic .............................. 71 
Appendix C： Raw Measurements from Insolation Meter ............................................... 72

Appendix D : PG\&E SCADA Estimated Costs.......................................................... 78 


\section{LIST OF TABLES}

Table 2-1: Estimated Cost per Location of First Solution ........................................... 15

Table 2-2: Estimated Costs for Second Solution .................................................... 16

Table 2-3: Estimated Costs for TSI Solution........................................................ 28

Table 2-4: Estimated Costs for Total Monitoring Solution ....................................... 29

Table 3-1: Frequency Ranges and Corresponding Trip Times [14] ............................. 40

Table 3-2: Observed Minimum Frequency within the Grid ...................................... 40

Table 3-3: Voltage Ranges and Corresponding Trip Times [14] ................................. 41

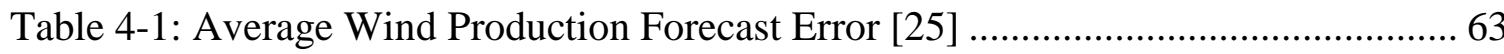

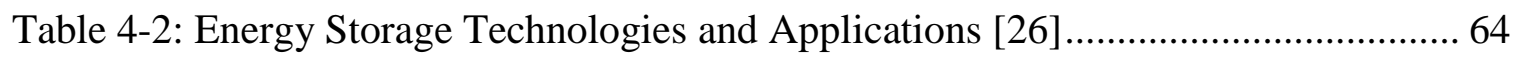

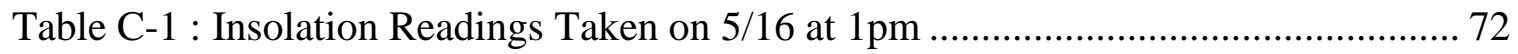

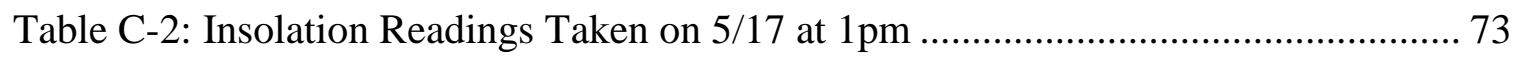

Table C-3: Insolation Readings Taken on 5/18 (1 of 3) .......................................... 74

Table C-4: Insolation Readings Taken on 5/18 (2 of 3) ......................................... 74

Table C-5: Insolation Readings Taken on 5/18 (3 of 3) ........................................... 74

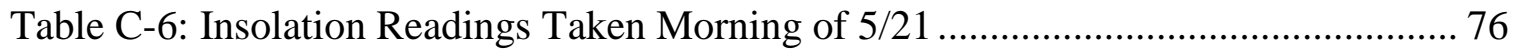

Table C-7: Insolation Readings Taken Evening of 5/24_....................................... 77

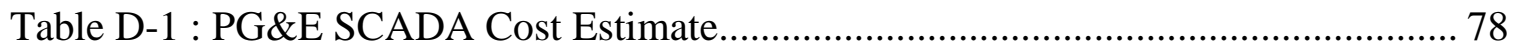

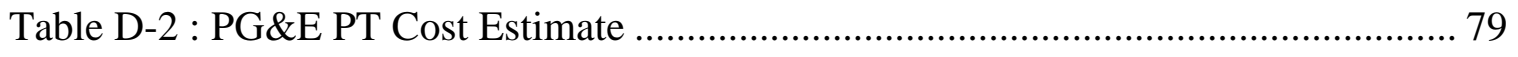




\section{LIST OF FIGURES}

Figure 2-1: Solar Radiation Spectrum[6] .............................................................. 7

Figure 2-2: Irradiance vs Power Output for 30kW System [4]..................................... 10

Figure 2-3: Irradiance vs Power Output for Multi-MW [4]............................................ 11

Figure 2-4: Undetected Potential Cloud Movement ......................................................... 13

Figure 2-5: Proposed Simulation Method for Determining True Path ............................ 18

Figure 2-6: Sensor Testing Circuit........................................................................... 20

Figure 2-7: Insolation Readings for Cloudy vs Sunny Taken on 5/18 ……………........ 21

Figure 2-8: Picture of Total Sky Imager [10] …………….................................... 22

Figure 2-9: Total Sky Imager Raw Image [10] .......................................................... 23

Figure 2-10: Filtered Sky Image to Show Fractional Cloud Coverage (72\%) [10] ......... 24

Figure 2-11: Determining Cloud Motion Vector [9] ................................................... 25

Figure 2-12: Cloud Forecasting [9]........................................................................ 25

Figure 2-13: Cloud Location Predications as Far as a Few Minutes in Advance [9] ....... 26

Figure 2-14: Cloud Forecast Error for 30s ahead [9]................................................ 27

Figure 3-1: Discrete PV Concept [8] ........................................................................ 30

Figure 3-2: Step Reduction in Power Generation, Effect on Frequencies [8] .................. 31

Figure 3-3: Step Reduction in Power Generation, Effect on Voltages[8] ........................ 31

Figure 3-4: Power System with 150MW PV Plant ............................................................. 33

Figure 3-5: Moderate Cloud Ramping Generator Power................................................ 35

Figure 3-6: Moderate Cloud Ramping Bus Voltages ........................................................ 35

Figure 3-7: Moderate Cloud Ramping Bus Frequencies ................................................ 36

Figure 3-8: Quick Cloud Ramping Generator Power ....................................................... 37 
Figure 3-9: Quick Cloud Ramping Bus Voltages ..................................................... 37

Figure 3-10: Quick Cloud Ramping Bus Frequencies .............................................. 38

Figure 3-11: Slow Cloud Ramping Generator Power............................................. 38

Figure 3-12: Slow Cloud Ramping Bus Voltages.................................................... 39

Figure 3-13: Slow Cloud Ramping Bus Frequencies .............................................. 39

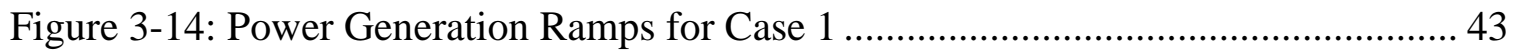

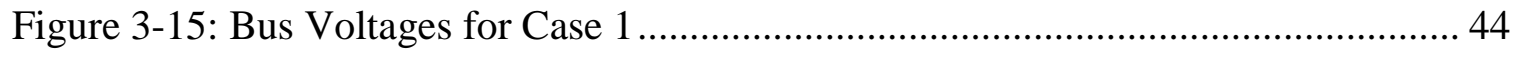

Figure 3-16: Bus Frequencies for Case 1 ........................................................... 44

Figure 3-17: Power Generation Ramps for Case 2 ............................................... 45

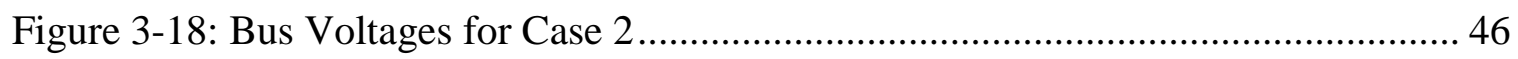

Figure 3-19: Bus Frequencies for Case 2 (Range 99.995 to 100.005)........................... 46

Figure 3-20: Power Generation Ramps for Case 3 ............................................... 47

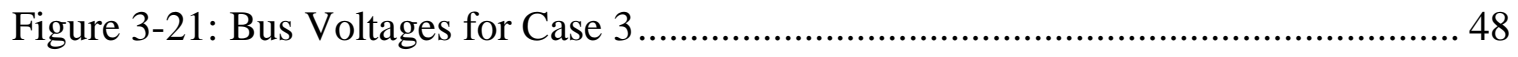

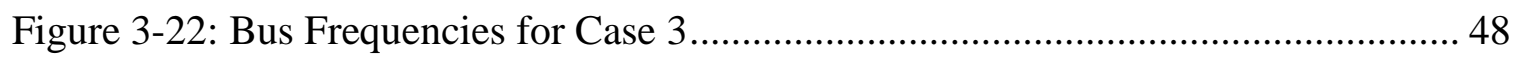

Figure 3-23: Generation Power Ramps for Case 4 ............................................... 49

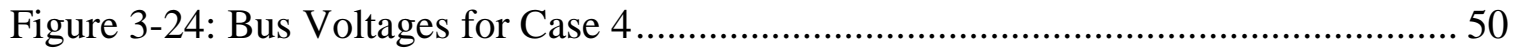

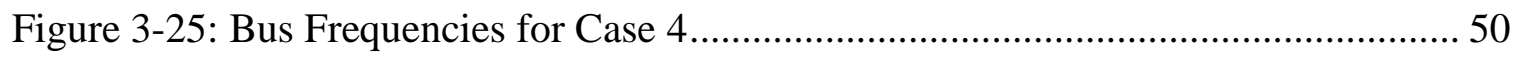

Figure 3-26: Power Generation Ramps for Problematic Case 1 .................................. 51

Figure 3-27: Bus Voltages for Problematic Case 1 (Range: 95 to 105) ......................... 52

Figure 3-28: Bus Frequencies for Problematic Case 1 ............................................ 52

Figure 3-29: Power Generation Ramps for Problematic Case 2 .................................. 53

Figure 3-30: Bus Voltages for Problematic Case 2 ............................................... 54

Figure 3-31: Bus Frequencies for Problematic Case 2 .............................................. 54 
Figure 4-1: Scenarios for Intermittent Renewable Resource Generation [19]

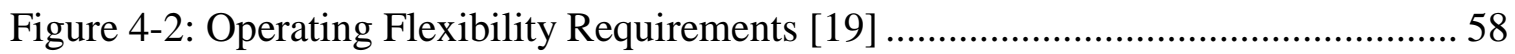

Figure 4-3: Time Scales Relevant to Operating Power Systems [4] ............................. 59

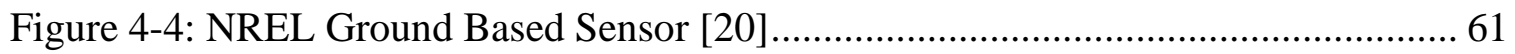

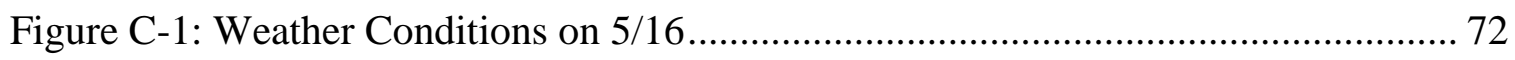

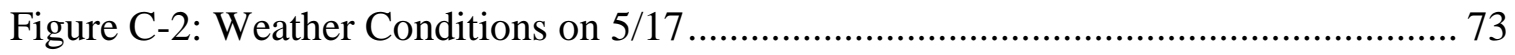

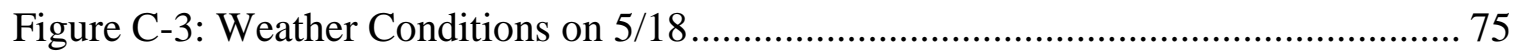

Figure C-4: Weather Conditions on 5/21 (Note Fog Had Already Burned Off) ............. 76

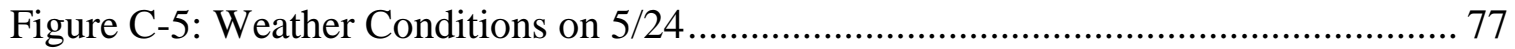




\section{Chapter 1 : Introduction}

\subsection{Background}

The sun is the source of all energy on earth. As an example, plants use photosynthesis to produce nutrients like carbohydrates which are food sources for animals. The idea of harvesting energy from the sun is a concept that dates back thousands of years. Using the sun reliably though, has proven difficult to master. The variability of solar energy and renewable energy in general has proven to be the major challenge of growing renewable generation capacity.

There are many benefits to traditional, large-scale, mechanically-rotating, heavy inertia based generation. Traditionally, mechanically generated power was understood to flow from high-voltage generation sources to lower-voltage based loads. This provided an inherent level of stability for the power grid as power was expected to flow in a unidirectional manner. Solar energy sources do not follow this same pattern as they are often connected close to loads, and are subject to sudden changes in generation due to atmospheric and solar time-based changes.

A recent goal of many developed countries has been to curtail the use of limited supply fossil fuels in a "sustainable" fashion. This phenomenon has gone so far as to change the way many consumers think about their global environmental footprint. In a world-leading effort to promote "green" or earth-friendly pursuits, the state of California passed Assembly Bill 32 (AB32): Global Warming Solutions Act and former governor Arnold Schwarzenegger signed Executive Order S-14-08. The assembly bill was passed in an effort to reduce the statewide level of greenhouse gas emissions. The executive 
order mandates that all retailers of electricity meet 33 percent of their total load with renewable sources of energy by the year 2020 [1,2].

Many utilities are seeking to meet this demand for clean energy with wind farms and photovoltaic solar plants. Meeting such a large target for renewable energy is not something that can be done as simply as adding more renewable generation and taking off-line old fuel based generators. Doing this would leave system extremely vulnerable to the natural transient conditions of renewable energy sources. Instead, it is necessary to research and implement methods of protecting and controlling the electrical grid from the variability of renewable power production.

This demand will be met by in a number of ways. One way is distributed generation, where small or medium-scale PV arrays are connected to the power system at the distribution level. These PV generators are typically owned by energy customers, and produce relatively small amounts of power, i.e. less than 10MW. An example of medium-scale would be the newly installed 5MW Sunset Reservoir Solar Project in San Francisco owned by Recurrent Energy [3]. Such PV arrays are typically installed by customers seeking to reduce long-term economic expenditures with a large up-front payment. In addition, the demand will need to be met by the category of PV generation that is large-scale generation. These plants interface with the power system at the transmission level and produce output power in the 10's to 100's of MW range. Recent advances in photovoltaic efficiencies, as well as government ordered support and incentives have made implementing and operating large-scale PV plants a more feasible solution for investors. An advantage of large-scale PV plant inverters is the time-delayed smoothing response of the power output to transients in the system. 
The variability of solar radiation affects all sizes of PV installations, but the ramifications of losing large-scale generation are much more significant to operators of the power system than their small-scale counterparts. This is true in spite of the fact that the changes in output power are quicker than their large-scale counterparts. The total magnitude of power loss is much less catastrophic on the distribution level where the magnitude of generation is typically in line with the size of loads on the respective distribution feeder.

Insolation is the measure of solar radiation that is received at a specific location and time, commonly expressed as average irradiance in $\mathrm{W} / \mathrm{m}^{2}$. Variations in insolation result from two primary factors: time of day, and cloud coverage. Clouds are one of the biggest obstacles to the flourishing of PV generation. They represent the source of most unpredictable rapid changes in the output of PV plants. There are many factors that influence the time it takes a cloud to pass a given point including the cloud size, height, and speed. The time it takes for an entire PV plant to be shaded by passing clouds is on the order of minutes [4].

Being able to predict the passing of a cloud over a given plant would be an incredibly useful bit of knowledge for both utility and PV plant operators. The primary advantage for PV plant operators would be the ability to more accurately forecast a day's generation capacity. In its current form, PV managers use day-out forecasts to more-or-less guess what their generation will be. Unfortunately, these predictions are subject to strong economic pressures. When a PV plant does not meet its target generation it is penalized for underproduction, but the opposite scenario of over-producing is not adequately lucrative. The benefit for system operators comes primarily from being able to avoid 
voltage instability during cloud-induced power drops by bringing other generation within the system online.

\subsection{Thesis Scope}

The primary focus of this paper is to demonstrate the benefits of close-to real-time cloud sensing for Photovoltaic generation. In order to benefit from this close-to real-time data, a source of cloud cover information is necessary. This paper will look into the potential of point insolation sensors to determine overhead cloud coverage. A look into design considerations and economic challenges of implementing such a monitoring system will be included. The benefits of cloud location sensing will be examined using computer simulations to target important time-scales and options available to plant operators. Finally, the economics of advanced forecasting options will be looked into for the benefit of the plant operators.

\subsection{Thesis Organization}

Chapter one of this thesis provides a background on PV generation by introducing the need for addressing and understanding the reliability and variability of renewable energy.

Chapter two provides more background on the nature and effects of meteorological changes to PV power generation. It also contains a discussion concerning the use of solar insolation meters at fixed locations to forecast the movement and changes of clouds. The economics of a few solutions will be examined. Finally, it will compare insolation based readings with a sky image based readings for forecasting.

Chapter three of this thesis goes into case specific simulations demonstrating the benefits of near-term cloud location forecasting. It contains a discussion on the ramifications of loss of generation, as well as the effects of bringing other generation 
sources online. The stability of the system is analyzed from the perspective of voltage and frequency stability.

Chapter four discusses the economic challenges facing intermittent renewable energy sources, and the need for new economic structuring for solar renewable energy.

The thesis is finally concluded in Chapter five with a summary of the results obtained in chapters two through four. In the end, propositions for future studies relating to the inherent uncertainty and variability of renewable power and generation are recommended. 


\section{Chapter 2 : Fixed Location Insolation Meters for Cloud Location Forecasting}

There are many advantages and disadvantages to the use of photovoltaic solar energy. The most common advantages include their solid-state nature, ease of installation, ease of operation, ease of maintenance, no need for a fuel delivery system, and the ability to be modularized. Common disadvantages for PV energy plants include the high cost of generation, large environmental impact in the case of a large centralized PV plant, and relatively low conversion efficiencies for terrestrial solar energy. Aside from these disadvantages, an even larger detriment to PV energy lies in the inherent variability of solar radiation, or solar insolation, with respect to many different factors. The three largest factors affecting the insolation at a specific location are the time of day, season of the year, and meteorological or atmospheric conditions. To understand the reasons behind changes in solar irradiance and how this effects PV generated power, it is necessary to understand the basics of sunlight, and clouds.

\subsection{Sunlight}

The solar energy that is received on earth is a product of a massive thermonuclear fusion reaction that is the sun. The sun's primary constituent, hydrogen, is constantly being converted to helium in this reaction. The energy produced via the conversion of mass to energy comes from the relation $E=\mathrm{mc}^{2}$. Stemming from this massive reaction, the energy dissipates uniformly and makes its way to earth [5].

As sunlight makes its way through the earth's atmosphere it can be absorbed, scattered or make its way unaffected to the surface of the earth. Water vapor, ozone, oxygen, and carbon dioxide all play large roles in the absorption of sunlight whether visible, infra-red, or ultra-violet. Figure 2-1 below shows the effects of the atmosphere 
on extra-terrestrial solar radiation. Note how the sunlight at the top of the atmosphere is significantly altered by the time it makes its way to sea level.

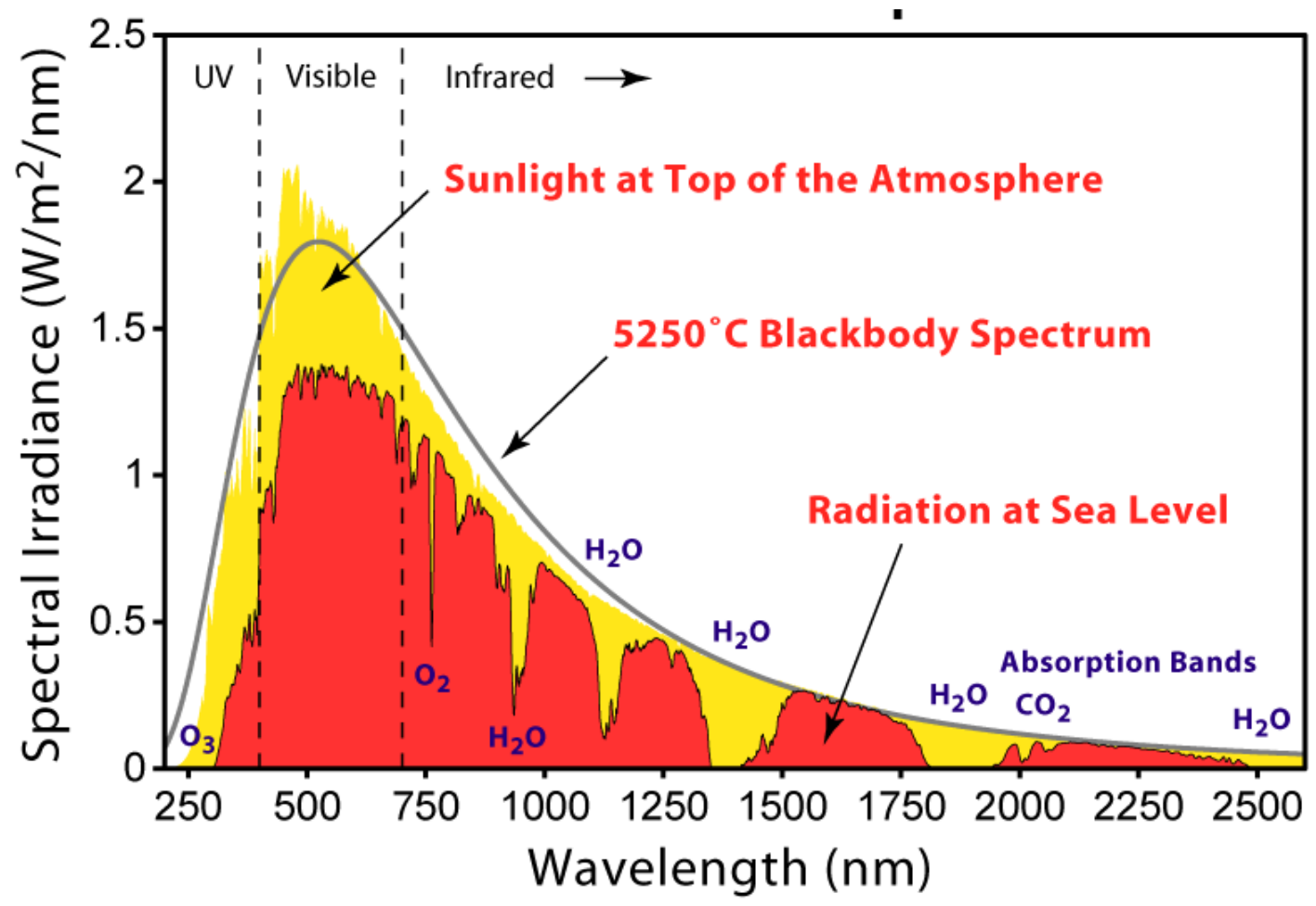

Figure 2-1: Solar Radiation Spectrum[6]

The amount of solar radiation that makes its way to the earth is a function of the length of a particular path to the surface of the earth. The light at the top of the atmosphere is commonly referred to as air mass $=0(\mathrm{AM} 0)$, and sea level as air mass = 1(AM 1). The intensity of solar radiation is reduced from $1367 \mathrm{~W} / \mathrm{m}^{2}$, the solar constant for earth, to roughly $1000 \mathrm{~W} / \mathrm{m}^{2}$ from AM 0 to AM 1, a difference of almost $30 \%$ [5]. The unit for this power density of sunlight is irradiance in $\mathrm{W} / \mathrm{m}^{2}$. This is an instantaneous measure of intensity of the sun. The integral of power density over a period of time, typically a day, is energy density, known as irradiation. Irradiation is commonly expressed in $\mathrm{kWh} / \mathrm{m}^{2}$. The most common way of quantifying irradiation is by 
using peak sun hours (PSH). PSH are the number of equivalent hours at an irradiance of $1000 \mathrm{~W} / \mathrm{m}^{2}$ based on the entire day's irradiance levels [5]. Due to higher levels of dispersion around sunrise and sunset, the actual irradiance is less than the irradiance around solar noon, or when the sun is normal to the earth's surface. Therefore the PSH are always less than the number of hours of daylight for terrestrial applications. According to a study done at Lawrence Berkeley National Laboratory, the periods of time around sunrise and sunset typically incur 10 to 13 percent changes in photovoltaic output over a time period roughly every 15 minutes [4].

In addition to daily changes in irradiance, the earth is also subject to seasonal changes. In revolving around the sun one time per year, the earth follows an elliptical path. The earth has in inclination angle of $23.45^{\circ}$ to its polar axis [5]. For this reason, the sun is lower in the winter than the summer, and there is more daylight in the summer than the winter. This pertains to both the northern and southern hemispheres, at their respective summer and winter seasons. Both of these differences between seasons play a large role in power output of PV plants.

Of the total solar energy that makes its way to the surface of the earth, only a small fraction of that energy is converted into electrical energy by current photovoltaic panels. Common photovoltaic modules have efficiencies in the range of 5 to19 percent, while high-end and cost-prohibitive modules have efficiencies around 35 percent. Panels with higher efficiencies are typically used in extra-terrestrial applications.

\subsection{Cloud Cover}

Meteorology is the scientific study of the atmosphere. Variables to the study of meteorology include, but are not limited to: temperature, air pressure, water vapor, and 
time. Clouds are typically the result of rising air that reaches its dew-point temperature, saturating the air. This water vapor then condenses on dust, ice, or salt to form a cloud [7].

As previously mentioned, the greatest obstacle to predictable solar irradiance levels is the variability of meteorological and atmospheric conditions, or cloud cover. The changes in irradiance at a specific location caused by a passing cloud can surpass 60 percent of the peak irradiance on the time-order of a few seconds. For a larger system, the effects are dependent on the size of the PV array, the size, height, and movement of the clouds. For a PV plant with a rated capacity of $100 \mathrm{MW}$, the time it takes for cloud cover to entirely cover an un-shaded facility would be on the order of a minute [4].

Changes in PV plant output due to clouds are quite different from changes due to the position of the sun. Changes due to the position of the sun are predictable, uniform, and correlate well with other PV plants, whereas changes in cloud cover are specific to a particular location and do not carry-over to other, even nearby, locales. Also, clouds bring about varying levels of insolation within large PV plants. This results in a common scenario where part of a large plant may be completely unobstructed while another area may have significant shading. This variation of insolation over the area of the PV plant leads to the concept of PV plant 'smoothing'. Studies of large PV plant impacts and effects are few and far between. Much of this is due to the small number of large PV plants installed compared to the relatively high number of proposed large PV plants. One of the premier studies out of Lawrence Berkeley National Labs substantiated a concept that had been mentioned only a few times before, namely, 'smoothing'. Smoothing is the effect that occurs when sudden spikes of solar irradiance occur over a large PV plant with 
many panels and inverters [4]. The power output does not vary with the same immediacy as it would over a small number of PV panels. There is an inherent delay and dampening of the effects of localized irradiance changes. Figures 2-2 and 2-3 demonstrate this effect on two different power plants, one $30 \mathrm{~kW}$ and one multi-Megawatt plant. The dashed lines are the output of an insolation meter and the solid lines correspond to the power output of the plant.

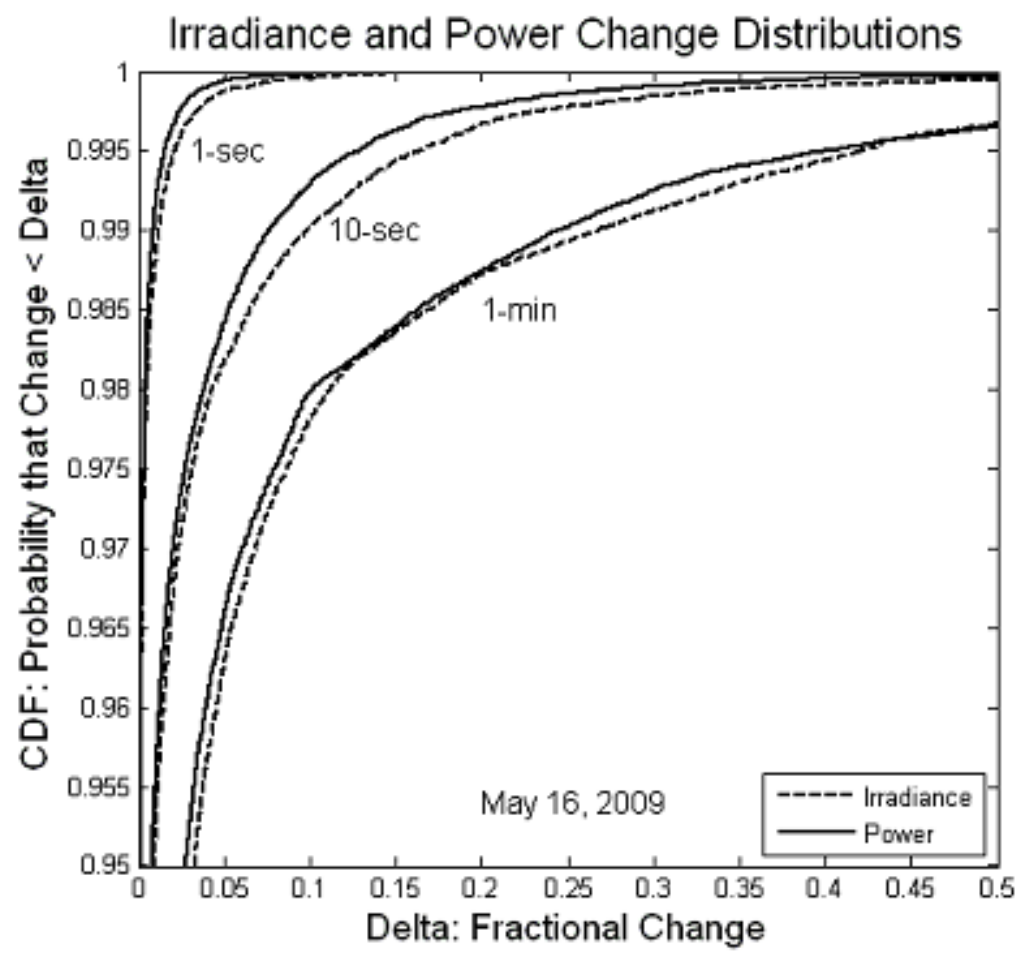

Figure 2-2: Irradiance vs Power Output for 30kW System [4] 


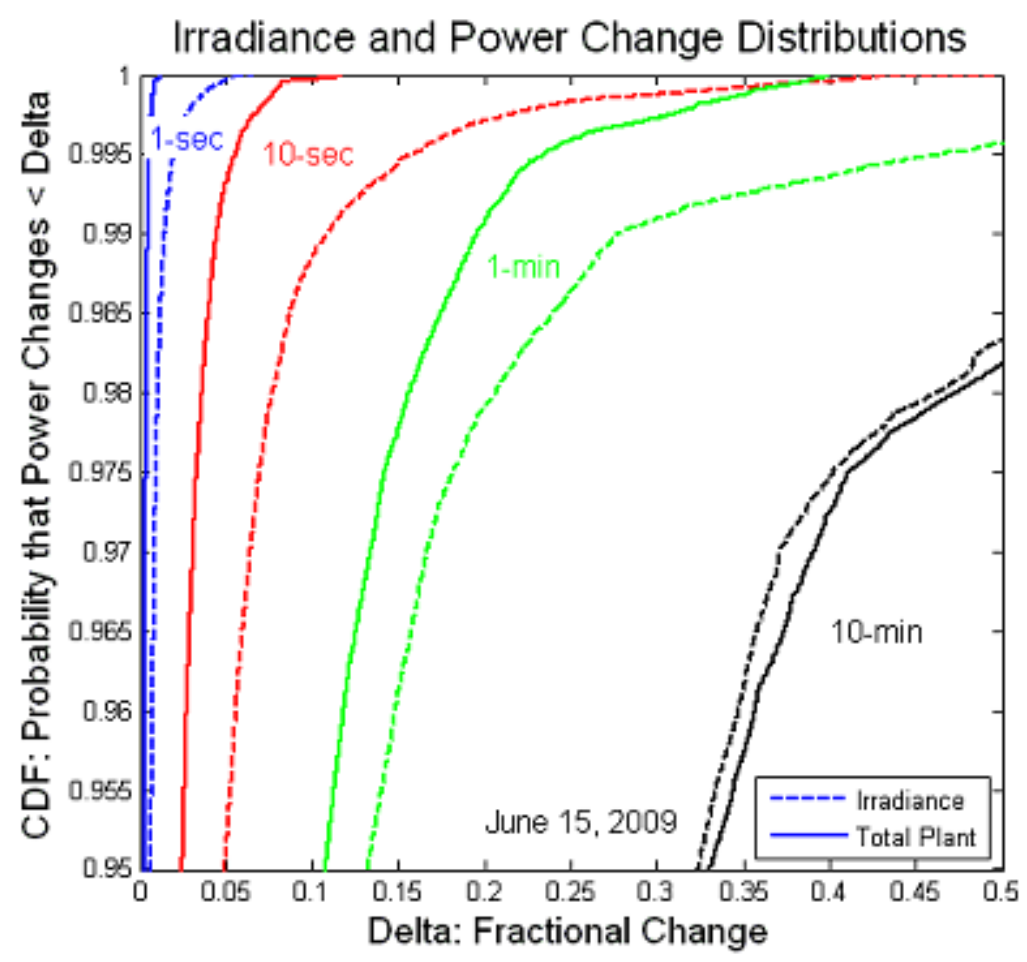

Figure 2-3: Irradiance vs Power Output for Multi-MW [4]

In comparing these two scenarios, $30 \mathrm{~kW}$ and multi-MW, it is interesting to note that as the time scale for irradiance grows versus the observed fractional change in irradiance, the systems' responses are more in-line. That is, the longer the power ramp, the higher correlation there is between the point sensor and the total plant output. More specific scenarios have been studied at a 13.2 MW facility in Nevada. It was found in one case that a $75 \%$ ramp in insolation over a 10 second period resulted in only a $20 \%$ reduction in power output over the same period. A more exaggerated ramp of negative $80 \%$ in one minute led to only a $50 \%$ total power reduction. A negative ramp of $75 \%$ recorded by an insolation meter over 10 minutes manifested itself in only a $65 \%$ percent change in output power [4]. 
Another important bit of information gleaned from the Berkeley labs study is the time scale involved in power output ramps for multi-MW power systems. Whereas smaller PV plants are capable of dropping output on the order of a few seconds, larger PV plants have time scales on the order of minutes [4].

It can be seen that knowing where and when clouds of various sizes will cover a solar facility would be an extremely useful tool. The most common tools for judging weather conditions available to plant operators today change based on the size of the facility. For plants fewer than 5MW, John Hostetter at REC Solar installs weather monitoring stations consisting of: pyranometers to measure ambient light, wind speed detection, ambient temperature thermometers, and cell temperature thermometers. These weather stations are rather minimally useful in prediction and are instead used simply for service monitoring. For facilities larger than those being installed by REC Solar, greater than 5MW, other solar firms are making significant investments in weather stations including radar measurements costing from a few hundred thousand to over a million US dollars [8].

Current forecasts for large PV plant output capacity are made based upon primarily radar and satellite imagery available to the plant operators. Radar and satellite are the most commonly used tools by PV operators. On their own, both radar and satellite forecasts have big downsides. For radar systems, the cost as well as the range covered is prohibitive. Similarly for satellite, the cost is prohibitive. The benefit of radar over satellite is the resolution of imagery that is available. The benefit of satellite over radar is the range covered. Satellites are capable of producing images with diameters on the order of 1000 's of miles, while radar is limited to roughly 60 miles reliably. 


\subsection{Fixed Location Insolation Meters for Cloud Location Forecasting}

There are many things to consider when determining how to predict the expected output of a PV plant based on insolation observed at various points throughout the system. In an effort to produce reliable and more cost-effective predictions, fixed location insolation metering will be examined. One of the most difficult things to develop is the methodology for tracking the clouds with a large number of insolation meters.

The first associated challenge is determining the optimum spacing for the sensors within the network to avoid any aliasing effects and get an accurate picture of the possible cloud location. In order to determine the spacing of sensors you need to start with a base of acceptable power loss without being detected by insolation meters. As insolation meters can only give readings for insolation at a fixed location, there is a significant amount of uncertainty that would arise between two adjacent meters. Figure 2-4 demonstrates this principle graphically.

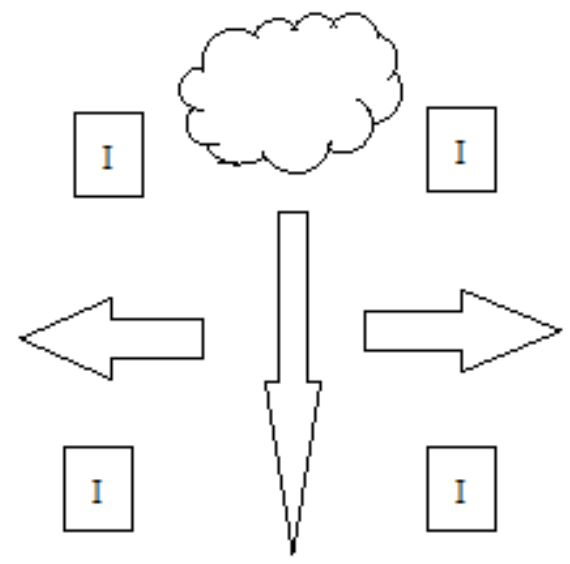

Figure 2-4: Undetected Potential Cloud Movement 
As an example, the sizing of the Topaz Solar Farm will be used to determine solar sensor spacing. For the sake of this example, a maximum undetected loss of $10 \%$ operating capacity will be used. Topaz Solar Farm is in the initial stages of building a 550MW facility over roughly 3800 acres, approximately 6 square miles. Ten percent of this area corresponds to a cloud area of 380 acres or 1,538,000 square meters. Assuming a square layout, each length of the concerned cloud coverage would be $1240 \mathrm{~m}$. To be able to recreate an image based upon these considerations the sensors need to be spaced twice as densely, or at least as close as $620 \mathrm{~m}$. As the maximum acceptable undetected loss decreases, the spacing of the sensors decreases. Similarly, fewer sensors will be needed to determine the location of clouds if a larger loss of generation capacity is acceptable.

The maximum amount of potential operating loss depends heavily upon the conditions of the power grid at the location of a proposed plant. Where generation capacity is abundant, higher losses without ancillary or backup generation may be acceptable. Where loads are more prevalent, generation capacity will be crucial.

The next factor to determine is the distance these sensors need to be away from the plant in all directions. This corresponds to the time-frame associated with the cloud location. As a longer prediction time-frame is desired by both plant operators and the ISO, the distance from the plant needs to similarly increase. If a 15 minute preview is wanted, and the quickest cloud taken into consideration moves at 30mph (reasonable for the Central Coast), then the sensors need to go out to a distance of 7.5 miles, or $12 \mathrm{~km}$. This corresponds to 20 adjacent sensors spaced at $620 \mathrm{~m}$. 
As can be seen, the number of sensors is not trivial, and will manifest itself greatly in the proposed cost of such a solution. Fixing a price point on a cloud tracking solution like fixed location insolation meters may appear trivial at first glance, but is in fact rather complex. There are a very large number of isolated sensors required in order to pull off such a feat. In its most simple form, all that would be required is the correct number of solar sensors, miles and miles of Ethernet cables with appropriate repeaters as necessary, and a computer with a 1-wire input to accumulate the respective data from each of the insolation meters.

The first solution to be examined would work only in an environment with a heavy amount of distributed generation lines available. The biggest challenge to the idea lies in the accumulation of data over ranges of approximately 15 mile diameters, as previously calculated. At PG\&E similar challenges in data accumulation are met for the purpose of Supervisory Control and Data Acquisition (SCADA). SCADA is used to provide realtime information to engineers and operators that is extremely helpful in providing a high level of service reliability. The estimated costs per location are provided below in Table $2-1$.

Table 2-1: Estimated Cost per Location of First Solution

\begin{tabular}{|c|c|c|}
\hline Item & Description & Unit Cost (\$) \\
\hline Solar Diode + 1-Wire & Hobby Boards Set-up & $30.00[9]$ \\
\hline Bluewave BGY890 & $890-960 \mathrm{MHz}$ Directional Antenna with Mount & $50.00[10]$ \\
\hline MDS EL805-BO & $902-928 \mathrm{MHz}$ Radio and Range Extender & $600.00[10]$ \\
\hline Enclosure & $18 " x 16 " x 10 "$ & $50.00[10]$ \\
\hline Lightning Arrestor & & 50.00 \\
\hline PT & Distribution Voltage Potential Transformer & 900.00 \\
\hline Pipe & & 25.00 \\
\hline Cables & & 65.00 \\
\hline Total Cost & & $1,740.00$ \\
\hline
\end{tabular}


The costs in this table are based upon both independent research as well as a PG\&E prepared cost estimate for the purpose of installing SCADA at new switch locations. This document, with sensitive information withheld, can be found in the Appendix.

As you can see, this solution relies upon distribution power using a potential transformer to transform to a standard voltage of $120 \mathrm{~V}$. The advantage of such a system comes in the form of reliability, only losing power in the event of a faulted circuit. Unfortunately, finding a locale with such a heavy penetration of distribution voltage power lines and also conducive to large PV is not a likely scenario. Following the voltage transformation, a dc power supply may be used to power both the radio and the sensor device. As the sensor takes it measurements, the measurements are in-turn sent to a receiver where the information can be processed.

A second solution that will be examined uses a similar set-up as road-side Call Boxes. The solution uses a $20 \mathrm{~W}$ solar panel to provide a trickle charge to a $12 \mathrm{~V} 12 \mathrm{AH}$ Battery. Table 2-2 gives the estimated costs for this solution.

Table 2-2: Estimated Costs for Second Solution

\begin{tabular}{|c|c|c|}
\hline Item & Description & Unit Cost (\$) \\
\hline Solar Diode + 1-Wire & Hobby Boards Set-up & $30.00[9]$ \\
\hline Blue Wave BGY890 & $890-960 \mathrm{MHz}$ Direction Antenna with Mount & $50.00[10]$ \\
\hline MDS EL805-BO & $902-928 \mathrm{MHz}$ Radio and Range Extender & $600.00[10]$ \\
\hline Enclosure & $18 " x 16 " x 10 "$ & $50.00[10]$ \\
\hline Battery & $12 \mathrm{~V} \mathrm{12AH}$ & 75.00 \\
\hline Lightning Arrestor & & 50.00 \\
\hline Pipe & & 25.00 \\
\hline Cables & & 65.00 \\
\hline Alps AP-NB20W & 20W Solar Panel & $150.00[10]$ \\
\hline
\end{tabular}




\begin{tabular}{|c|c|c|}
\hline Morning Star SS-6-12V & 12V PWN Charge Controller & $40.00[10]$ \\
\hline Total Cost & & $1,145.00$ \\
\hline
\end{tabular}

As you can see, there are a couple reasons this could be considered a better option. First, the cost of implementing this solution is less than the first primarily due to the lack of a costly potential transformer. In addition, there is no longer any reliance upon the grid for power, as power is stored in a localized battery.

The best method to quantify the predicted path of the cloud would be to utilize an occupancy grid, similar to the ones used by autonomous robots in determining their surroundings. Instead of the sensor moving as it does with an autonomous robot to characterize fixed surroundings, the solar sensor would be fixed and determining the moving location of clouds. Uncertainty exists not only in the size of the cloud but also in the shape of the cloud as it moves through the sky. As varying levels of solar insolation are recorded at multiple sensors, the probability of cloud coverage in a specific location can be updated. Figure 2-5 graphically suggests how this proposed method would work. The initial readings determine a cloud that encompasses those locations, as the second readings come in, the model determines what the likely location for the cloud is, and will be. 

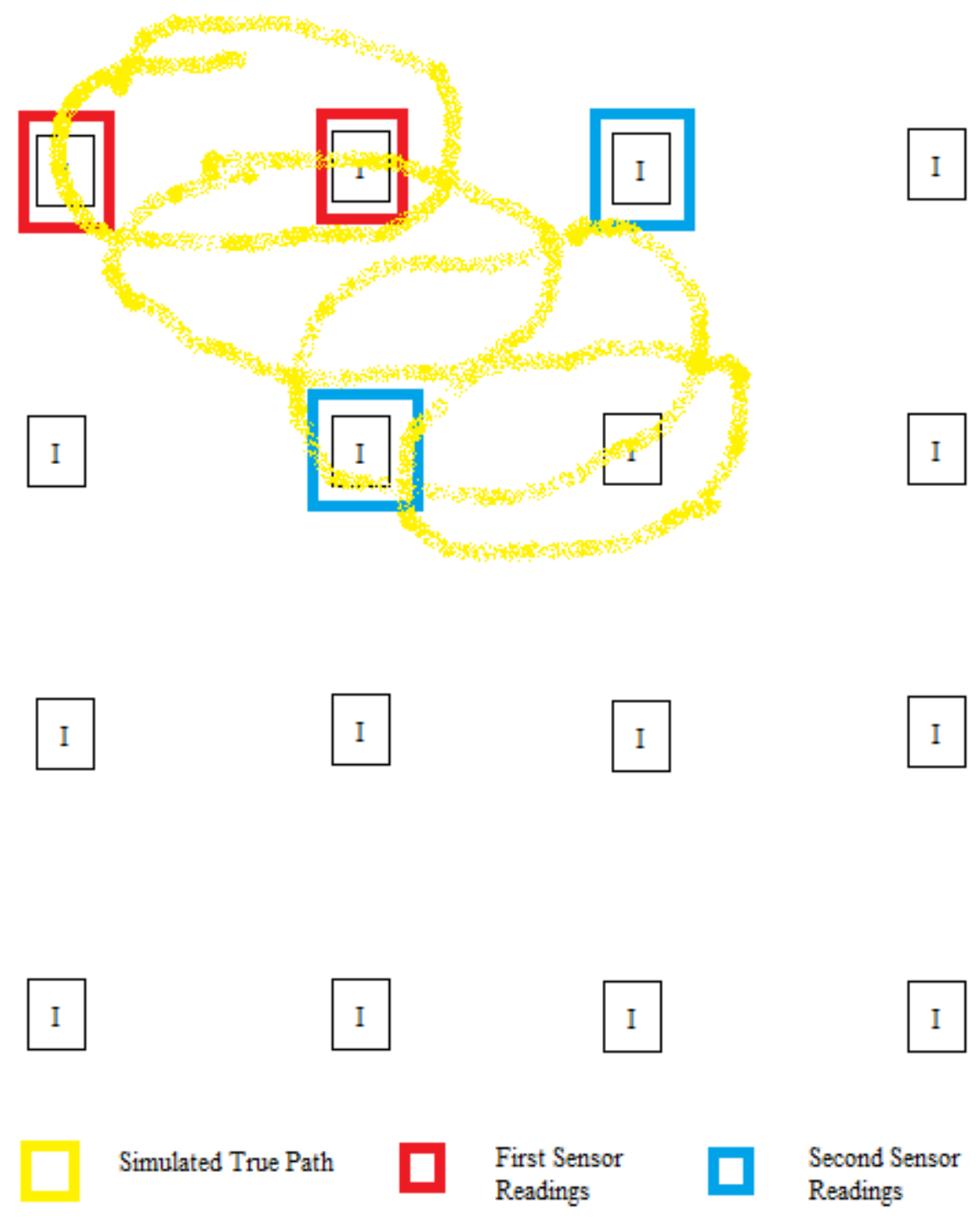

Figure 2-5: Proposed Simulation Method for Determining True Path

In order to combat the high number of sensors required, one could also look into other options concerning placement and density of solar sensors. A possible way to reduce the number of sensors would be to coordinate time-stamped data with other real time observations whether that is satellite imagery, wind speed, or wind direction. Also, 
having real-time plant generation levels can help ensure that predictions are being met, and if they are not, they could be used to calibrate the predictions.

\subsection{Characterization of Potential Insolation Meter}

An important piece to this large puzzle of cloud location forecasting is the insolation meter that will be used. From an economics and usability stand-point, a Maxim 1-Wire network was chosen to accumulate data. 1-Wire Networks are useful in that each device connected to the network is uniquely identified by a 64bit ROM ID. This allows adding however many sensors and not worrying about possible cloned sensor issues. It is also useful as it is capable of receiving power over Ethernet instead of requiring a stand-alone energy source, though this may not be practical for field application as seen in the previously mentioned estimated costs.

The kit chosen included both the 1-Wire A/D adapter and a photo diode in order to be able to time-stamp values of solar insolation that were encountered. Testing of the circuit was performed over a one week period in which all-forms of useful insolation readings could be obtained. A picture of the set-up used is shown in Figure 2-6. 


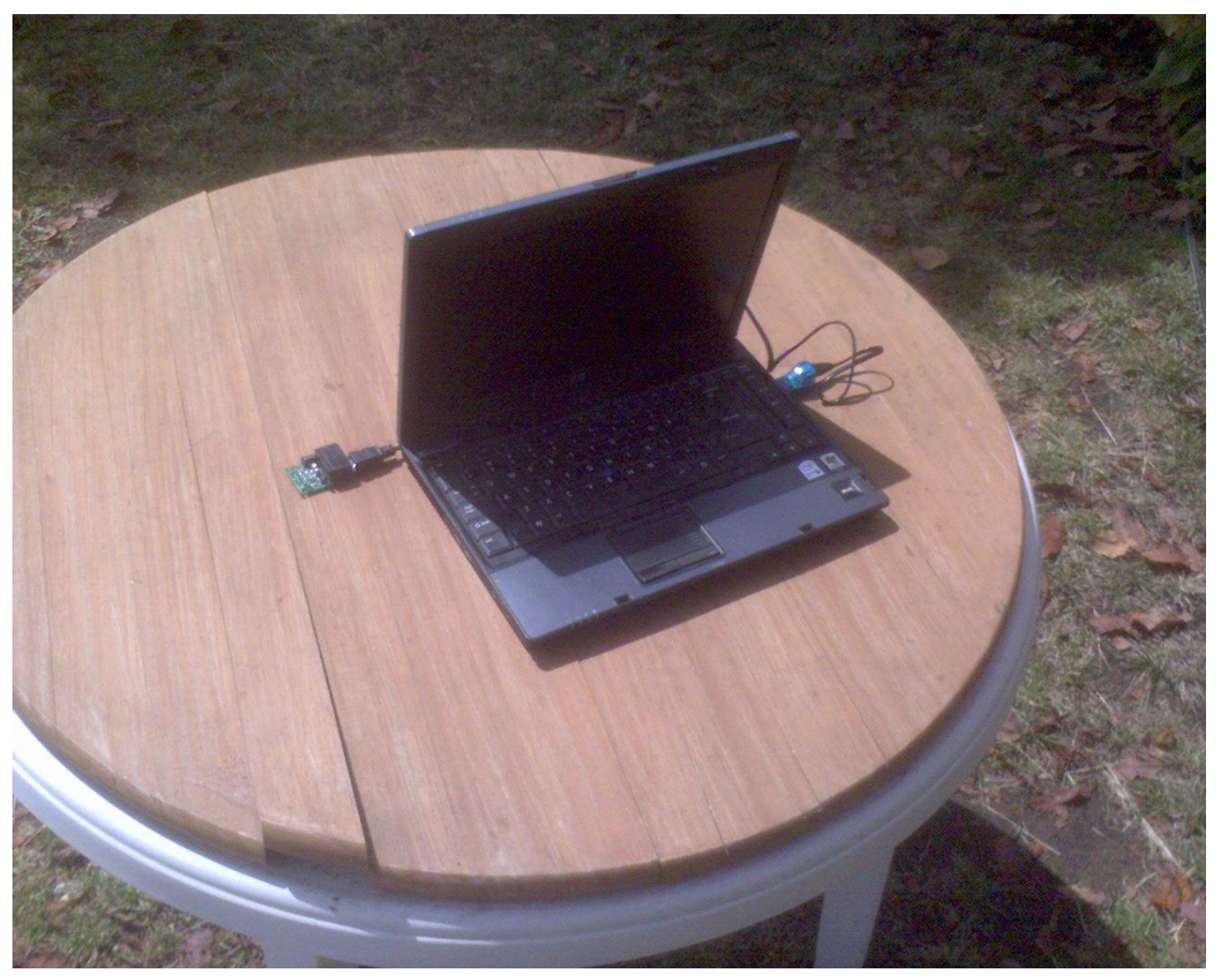

Figure 2-6: Sensor Testing Circuit

Appendix $\mathrm{C}$ includes the raw measurements taken over the week-long period.

The freeware utility 'LogTemp for Dallas 1-Wire sensors' was used to record the values from the 1-Wire A/D. This program allows for input from any number of connected devices, and allows the user to compare time stamped data from the various locations easily. The most useful data was compiled on May $18^{\text {th }}$ where it was possible to characterize the sensor based upon moving clouds. A careful analysis of the data shows a range from $60.05 \mathrm{mV}$ to $245.69 \mathrm{mV}$. Based on these values, thresholds for levels of insolation can be established. With simultaneous observation of weather conditions, it 
was noted that at roughly $100 \mathrm{mV}$, the cloud cover limited any direct solar irradiance, shading the entire local area.

Using a value of $100 \mathrm{mV}$ as a threshold, levels of insolation can be deemed cloudy or not. Figure 2-7 shows how this threshold could work based upon values of insolation taken on May $18^{\text {th }}$.

\begin{tabular}{|c|c|c|}
\hline 18.05.11 13:14:55 & 4A,000000F1E 49826.S & Solar $=43 \%, V$ sens $=107.65 \mathrm{~m}^{\prime}$ \\
\hline 18.05.11 13:15:12 & 4A,000000F1E49826-S & Solar $=70 \%, V$ sens $=175.63 \mathrm{~m}^{4}$ \\
\hline 3.05.11 13:15:28 & 4A.000000F1E49826-S & Solar $=41 \%, V$ sens $=103.74 \mathrm{~m}^{4}$ \\
\hline 18.05.11 13:15:45 & 4A,000000F1E49826-S & Solar $=46 \%, V$ sens $=114.73 \mathrm{~m}^{4}$ \\
\hline 18.05.11 13:16:01 & 4A.000000F1E49826-S & Solar $=52 \%, V_{\text {sens }}=129.01 \mathrm{n}$ \\
\hline 18.05.11 13:16:17 & 4A,000000F1E49826-S & Solar $=45 \%$, Vsens $=112.04 \mathrm{~m}$ \\
\hline 18.05.11 13:16:34 & 4A,000000F1E49826.S & Solar $=52 \%, V$ sens $=129.01 \mathrm{~m}$ \\
\hline 18.05.11 13:16:50 & 44,000000F $1 E 49826 \cdot 5$ & Solar $=39 \%, \mathrm{~V}$ sens $=97.52 \mathrm{~m}$ \\
\hline 18.05.11 13:17:07 & 4A,000000F1E49826.S & Solar $=37 \%, V$ sens $=92.64 \mathrm{mV}$ \\
\hline 18.05.11 13:17:23 & 4A,000000F1E49826-S & Solar $=33 \%, V$ sens $=81.65 \mathrm{ml}$ \\
\hline 18.05.11 13:17:40 & 4A,000000F1E49826-S & Solar $=27 \%, V_{\text {sen }}=68.10 \mathrm{ml}$ \\
\hline 18.05.11 13:17:56 & 4A.000000F1E49826-S & Solar $=26 \%, V$ sens $=6$ \\
\hline 18.05.11 13:18:12 & 4A,000000F1E49826-S & Solar $=27 \%$, Vsens $=66.27$ \\
\hline 18.05.11 13:18:29 & DOF1E49826-S & Solar $=27 \%$, Vser \\
\hline 18.05.11 13:18:45 & 4A,000000F1E49826.S & Solar $=25 \%$, Vser \\
\hline 18.05.11 13:19:02 & 00F1E49826-S & Solar $=25 \%$, Vse \\
\hline 18.05.11 13:19:18 & DOF1E 49826.S & Solar $=24 \%, 1$ \\
\hline 18.05.11 13:19:34 & $26 \cdot 5$ & $24 \%$ \\
\hline 111 & 6.S & \\
\hline 113 & 44,00 & 3 \\
\hline .1713 & $4 A, C$ & $\mathrm{mi}$ \\
\hline 18.05.11 13.20.40 & $4 \mathrm{~A}, 00$ & $64 \mathrm{mv}$ \\
\hline 5.111 & $44,000000 F$ & Solar $=2$ \\
\hline 18.05.11 13.21:13 & 4A,000000F1E $49826 \cdot S$ & Solar $=28 \%$, Vser \\
\hline 18.05.11 13:21:29 & 4A,000000F1E 49826.S & Solat $=29 \%$, Vset \\
\hline 18.05.11 13:21:46 & 4A,000000F1E49826-S & Solar $=30 \%, V$ sens $=76.16 \mathrm{ml}$ \\
\hline 18.05.11 13.22:02 & 4A,000000F1E49826.S & Solar $=32 \%, V$ sens $=80.43 \mathrm{ml}$ \\
\hline 18.05.11 13.22:19 & 4A.000000F1E49826.S & Solar $=34 \%, V$ sens $=84.58 \mathrm{mV}$ \\
\hline 18.05.11 13.22:35 & 4A,000000F1E49826-S & Solar $=36 \%$, Vsens $=89.83 \mathrm{ml}$ \\
\hline 18.05 .1113 .22 .52 & 4A,000000F1E49826-S & Solar $=36 \%, V_{\text {sen }}=90.81 \mathrm{ml}$ \\
\hline 18.05.11 13.23:08 & 4A.000000F1E49826-S & Solar $=36 \%, V$ sens $=90.44 \mathrm{ml}$ \\
\hline 18.05.11 13:23:24 & 4A,000000F1E49826-S & Solar $=35 \%, V$ sens $=88.73 \mathrm{~m}^{\prime}$ \\
\hline & 4A,000000F1E49826-S & Solar $=36 \%$, Vsens $=90.32$ \\
\hline
\end{tabular}

Figure 2-7: Insolation Readings for Cloudy vs Sunny Taken on 5/18

The values surrounded by red are greater than $100 \mathrm{mV}$, while the values surrounded by blue are less than $100 \mathrm{mV}$.

It would be possible to increase the number of thresholds beyond one hard limit at $100 \mathrm{mV}$, but doing so will greatly increase the size of computed data. 


\subsection{Total Sky Imaging for Cloud Location Forecasting}

At the University of California in San Diego, using Total Sky Imaging (TSI) is being researched for applications related to efficiently controlling PV systems. The test-subject for their system is their own campus smart grid that hopes to have up to $3 \mathrm{MW}$ of PV online in the near future. They are attempting to use Total Sky Imaging to create an accurate model for cloud location forecasting, and implement it within a larger PV control system [11].

TSIs work by providing a series of time-stamped images of current cloud cover conditions. These images are taken by a camera facing down onto a hemispherical mirror. Figure 2-8 shows an example of a TSI. Current generation TSI are capable of producing an image with up to a 3.5 mile diameter [12]. An obvious disadvantage of TSI is that it requires a good deal of open space around it, or it requires placement above low lying obstacles.

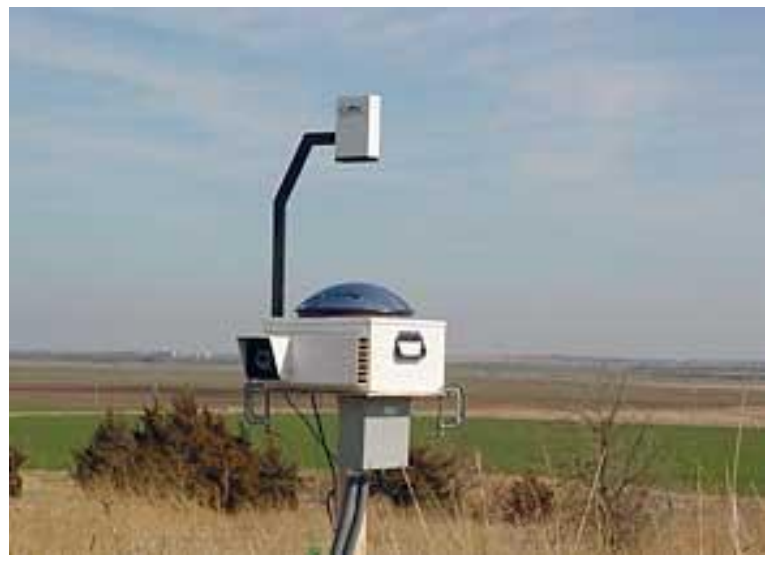

Figure 2-8: Picture of Total Sky Imager [13]

In their studies at UCSD they have chosen to take images at 30 second intervals and process them to determine the amount of cloud cover. Figures 2-9, and 2-10 demonstrate this action. 


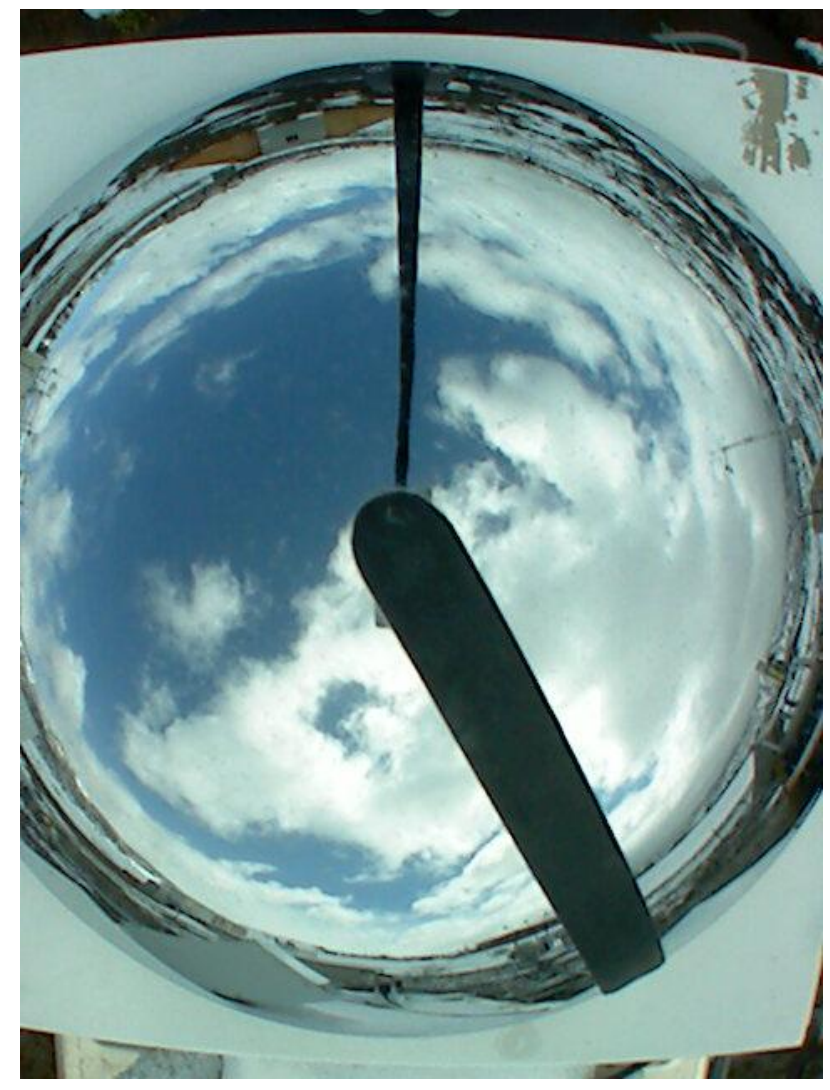

Figure 2-9: Total Sky Imager Raw Image [13] 


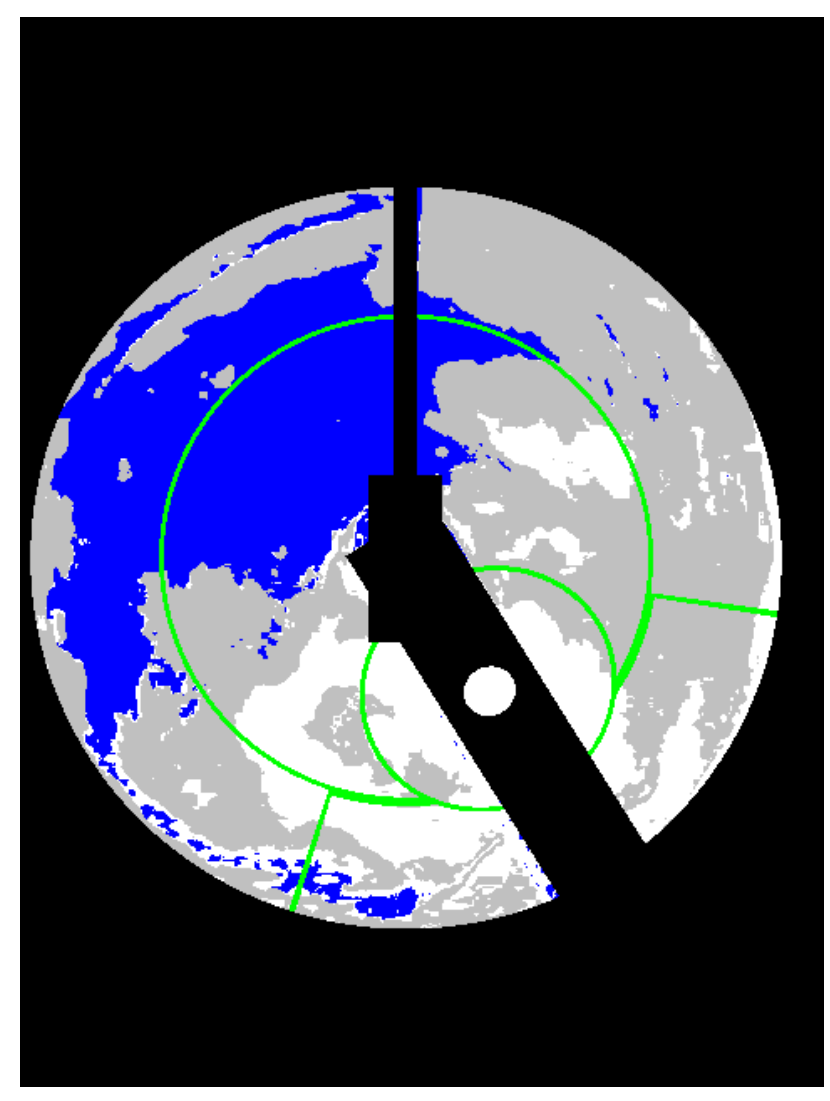

Figure 2-10: Filtered Sky Image to Show Fractional Cloud Coverage (72\%) [13]

In addition, the images are then cross correlated in order to create cloud motion vectors. These vectors are then applied to the sky image to determine the most likely path of the cloud. Figures 2-11 -14 show how this concept works through in various phases. 

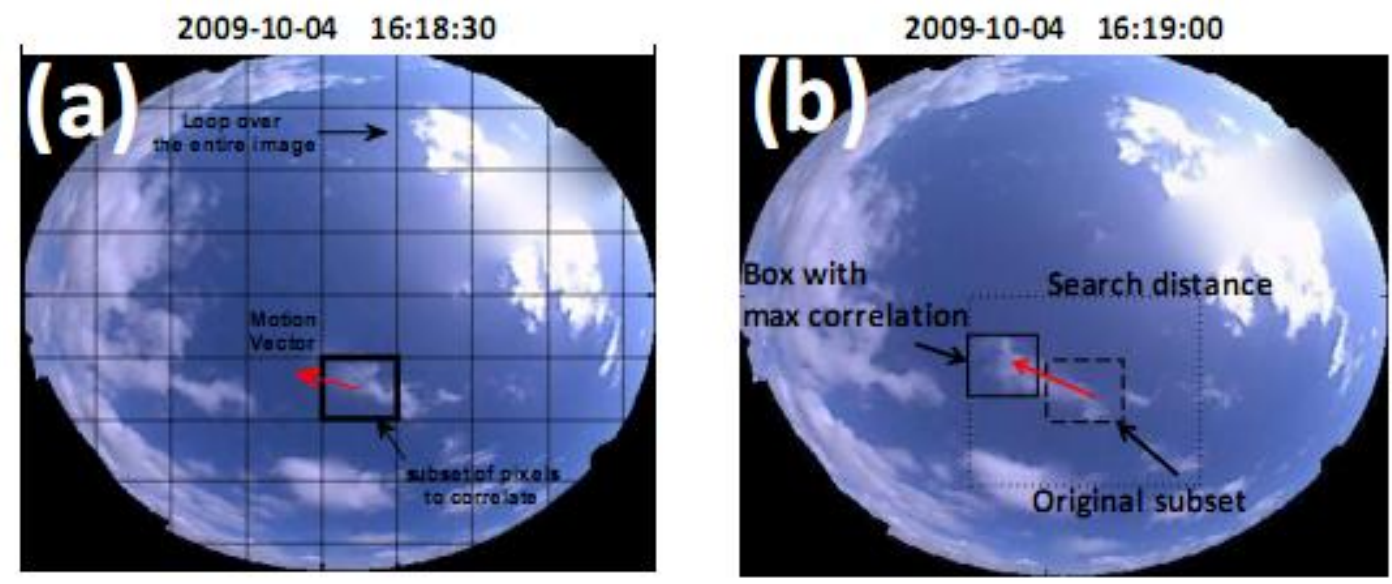

Figure 2-11: Determining Cloud Motion Vector [9]

(a) 10:49:00

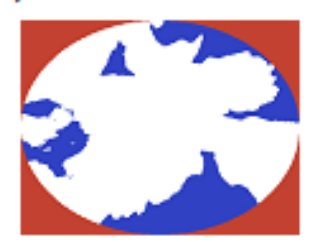

(b)

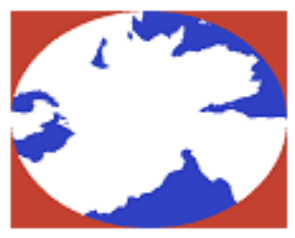

(c)

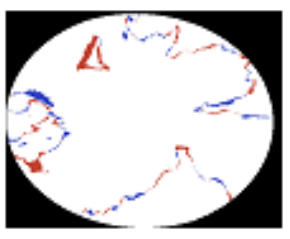

The forecast cloud cover is produced by advecting the cloud decision image (a) in the direction of the motion vector. To determine accuracy, the future image(b) is compared to the forecast (a) to determine the forecast error . Blue and red colors in (c) shows the forecast errors ( blue: forecast cloudy and but actually clear; red: forecast clear but actually cloudy) and white marks accurate forecasts.

Figure 2-12: Cloud Forecasting [12] 


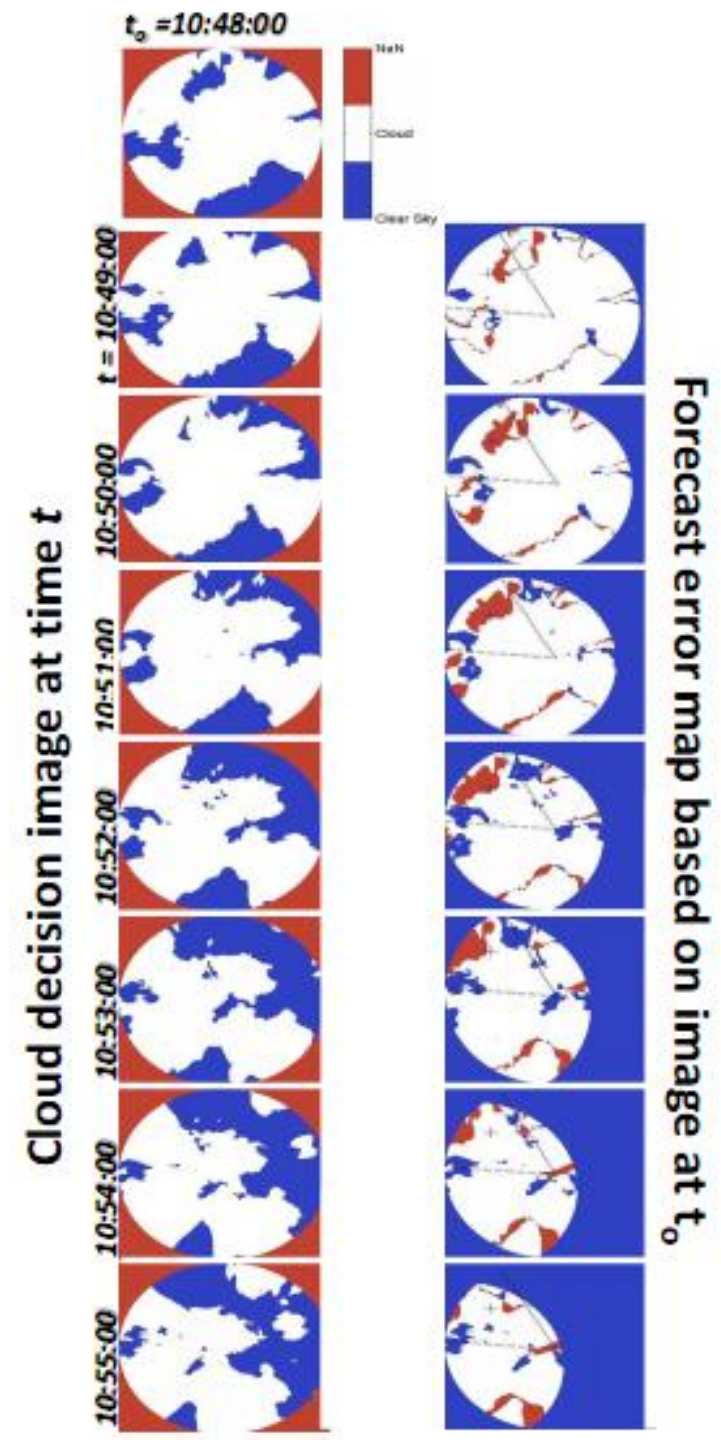

Figure 2-13: Cloud Location Predications as Far as a Few Minutes in Advance [12] 

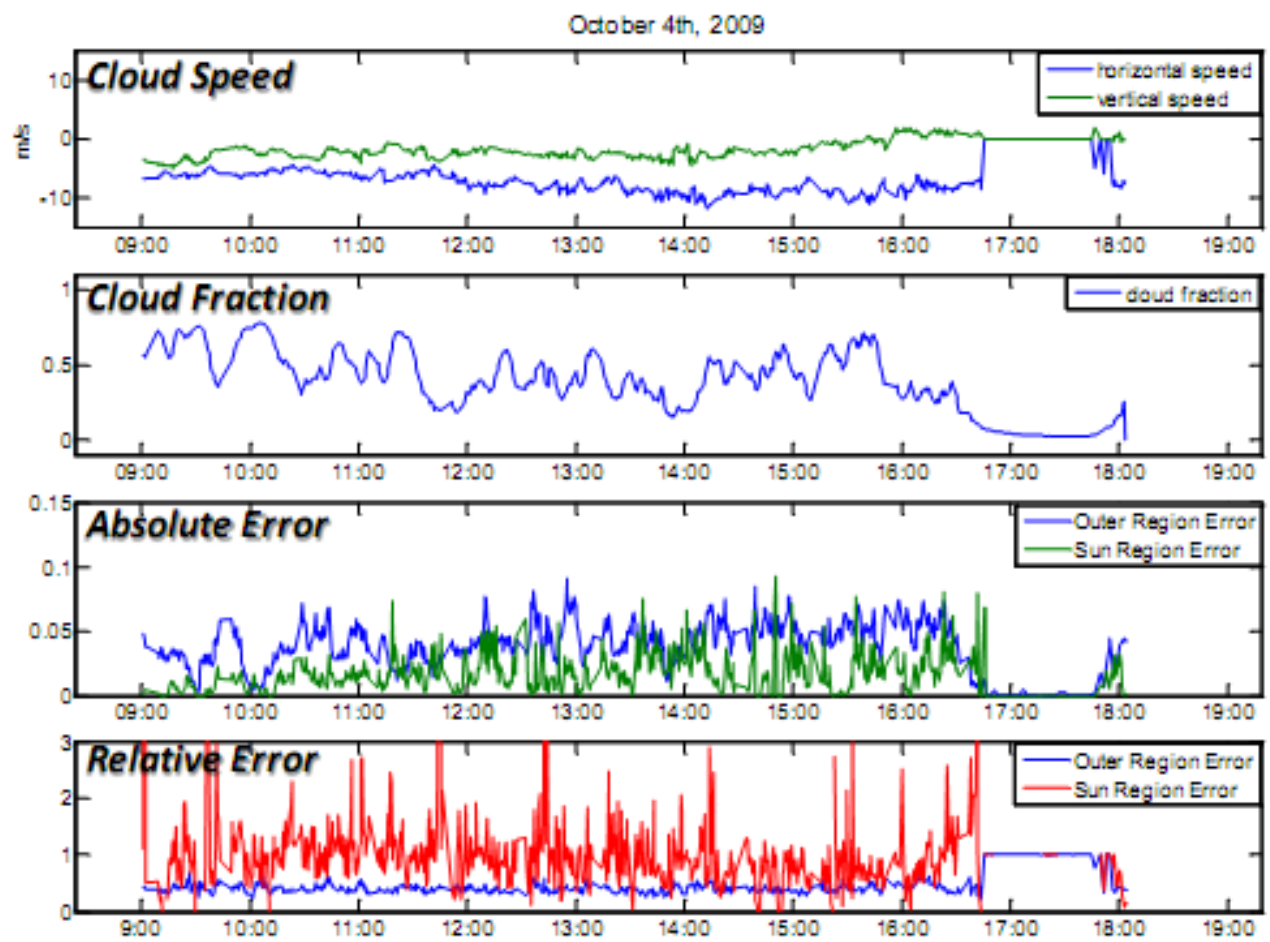

A time series plot of cloud forecast error for 30 seconds ahead is shown above with cloud speed and cloud fraction. Absolute error is defined as the ratio of number of mismatched pixels to number of available pixels. Relative error is the ratio of number of mismatched pixels after advection to number of mismatched pixels before advection. For cloud forecast minutes ahead, cloud decision image at initial time $t_{0}$ is advected and overlapped with cloud decision image at time t. Images below show the forecast error for 1 to 7 minutes ahead.

Figure 2-14: Cloud Forecast Error for 30s ahead [12]

An advantage of TSI over fixed location insolation meters is the resolution involved.

The amount of uncertainty between meters is significantly reduced due to the nature of photographic imagery compared to solar insolation meters which are only capable of accounting for the area directly above them.

In order for a system with TSI to be effective for large PV, it would also need to be implemented within a grid similar to that of the proposed fixed location insolation meters. This is because the 3.5 mile range is simply not large enough to predict cloud coverage more than a couple of minutes in advance of real-time, as seen in Figures 2-13 and 2-14, 
and demonstrated in the earlier example. This would become even more obvious for PV plants on the order of 100 times the size of the UCSD system.

A third solution, in addition to the two aforementioned insolation metering solutions, is determining the cost of implementing a TSI based forecasting grid. This option takes advantage of the larger diameter of coverage of the TSI, and in-turn requires fewer locations from which to record values. Table 2-3 gives this estimate.

Table 2-3: Estimated Costs for TSI Solution

\begin{tabular}{|c|c|c|}
\hline Item & Description & Unit Cost (\$) \\
\hline Solar Diode + 1-Wire & Hobby Boards Set-up & $30.00[9]$ \\
\hline Blue Wave BGY890 & $890-960 \mathrm{MHz}$ Direction Antenna with Mount & $50.00[10]$ \\
\hline MDS EL805-BO & $902-928 \mathrm{MHz}$ Radio and Range Extender & $600.00[10]$ \\
\hline Enclosure & $18^{\prime \prime} 16 " x 10 "$ & $50.00[10]$ \\
\hline PT & Distribution Voltage Potential Transformer & 900.00 \\
\hline Lightning Arrestor & & 50.00 \\
\hline Pipe & & 25.00 \\
\hline Cables & Total Sky Imager Research Unit & 65.00 \\
\hline TSI & & $12,000.00[14]$ \\
\hline Total Cost & & $13,770.00$ \\
\hline
\end{tabular}

As you can see the total cost for each site is significantly higher using this option. Also, due to the high cost of the TSI unit compared with the rest of the equipment, only the potential transformer based solution is examined. A similarly devised solar/batterybased solution would be near the same total cost per location.

\subsection{Economic Comparison of Insolation Metering and TSI}

The number of locations required for each potential solution can be computed as follows. The number of sensors for the first two solutions that rely upon fixed location solar sensors can be calculated using the values derived in Chapter 2. To cover an area of $12 \mathrm{~km} \times 12 \mathrm{~km}$, corresponding to the newly planned Topaz Solar Farm, with a spacing of 
$620 \mathrm{~m}$ between the sensors, roughly 400 monitoring stations are required. For the case using TSIs the number of sensors is reduced based upon the larger coverage area. The $3.5 \mathrm{mi}$ diameter of the images produced by the TSI corresponds to $5.63 \mathrm{~km}$. Using values on the conservative side, this would require 9 TSI based monitoring stations.

Using these values, the total estimated cost for the monitoring stations for each solution can be calculated. The results are shown in Table 2-4 below.

Table 2-4: Estimated Costs for Total Monitoring Solution

\begin{tabular}{|l|cr|r|}
\hline Solution & \multicolumn{2}{|c|}{ Cost Per Location } & \multicolumn{1}{l|}{ Total Cost } \\
\hline PT Based Insolation Metering & $\$$ & $1,740.00$ & $\$ 696,000.00$ \\
\hline Solar Based Insolation Metering & $\$$ & $1,145.00$ & $\$ 458,000.00$ \\
\hline TSI Based Monitoring & $\$$ & $13,770.00$ & $\$ 123,930.00$ \\
\hline
\end{tabular}

As you can see, for a location this large, the more economical choice is the TSI based solution. This is due to a number of factors, primarily the density of sensors and coverage diameter. As previously mentioned, the spacing of sensors for the fixed location insolation meters depends on the maximum allowable error in cloud sizing. As this value is allowed to increase, the spacing density can similarly increase. Also, the size of the plant plays a large role. As the plant size decreases, a significantly smaller number of sensors will be required for both solutions. 


\section{Chapter 3 : Simulations Demonstrating the Benefits of Near-Term Forecasting}

In order to demonstrate the merits of near-term forecasting, as previously described, a simulation test circuit must be designed.

\subsection{Previous Study into Effects of Loss of PV Generation}

Previously studies concerning the effects of loss of PV generation on a power system have been incomplete [15]. For these studies, discrete losses of power generation were taken into account rather than continuous power ramps. Figure $3-1$ shows the $60 \mathrm{MW}$ Power Plant Generator that was connected to a larger and generic power grid.

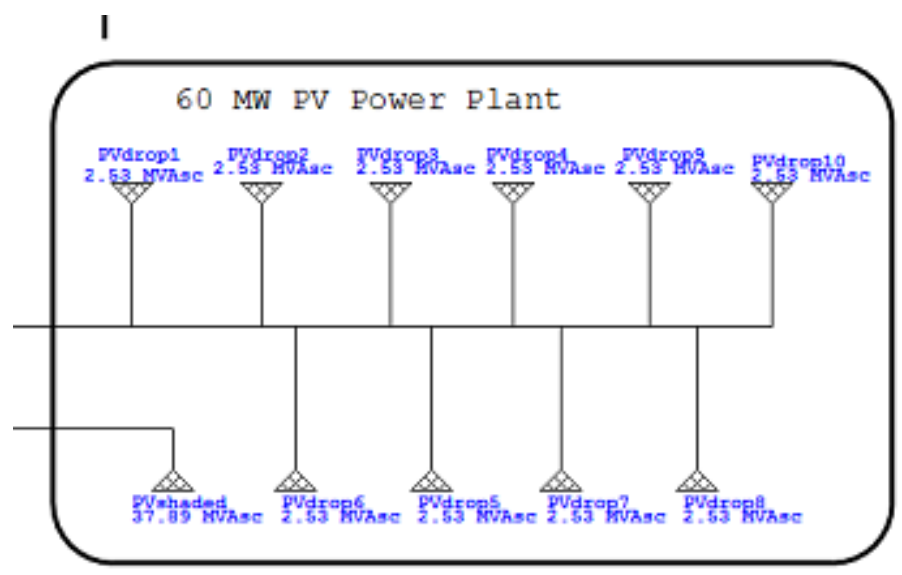

Figure 3-1: Discrete PV Concept [15]

The method used was to drop one of the 'PVdrop' elements from Figure 3-1 every second over a period of $10 \mathrm{~s}$, in order to simulate the shading of a PV array to $60 \%$ of its original generation capacity. The harsh nature in which the generators were removed from the system resulted in unrealistic frequency and voltage characteristics as seen in Figure 3-2 and 3-3. 


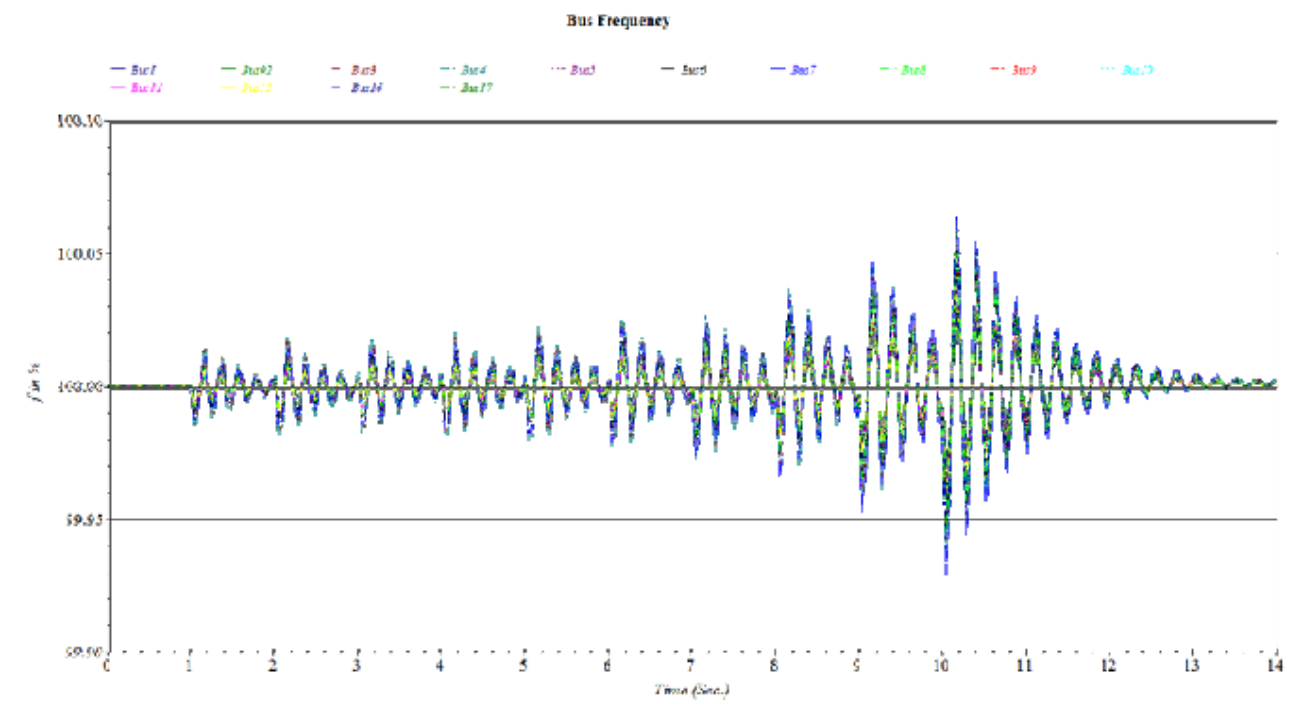

Figure 3-2: Step Reduction in Power Generation, Effect on Frequencies [15]

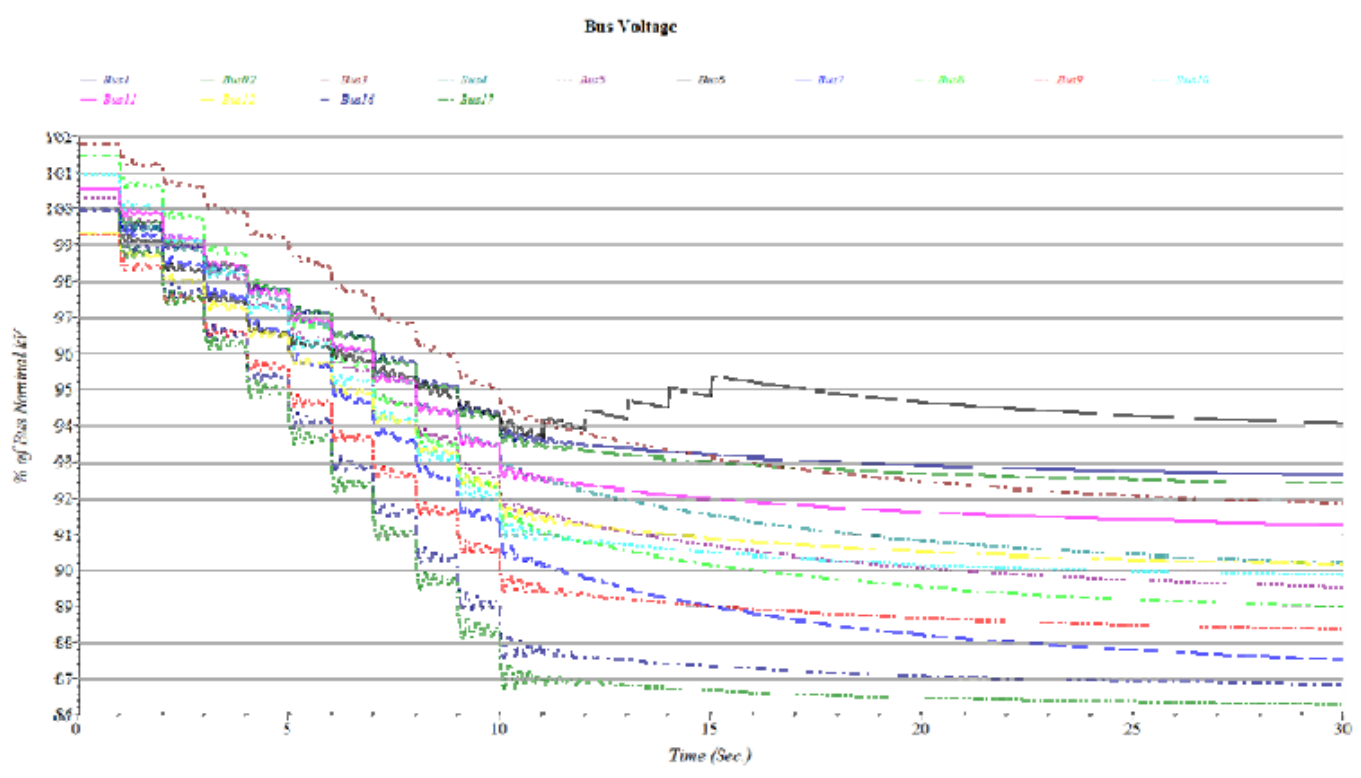

Figure 3-3: Step Reduction in Power Generation, Effect on Voltages [15]

As can be seen in Figure 3-2 and 3-3, there is a ringing taking place with the removal of generation in an instantaneous fashion. As the ringing was not allowed to dampen before further generation was removed, the ringing continued adding to itself, growing 
unrealistically over the period of time. This will be shown to be the case in the following example of a continuous loss of generation.

This was not the only oversight the study failed to include. In addition, the study failed to include the effects of ancillary generation in the power grid.

\subsection{Base Case for PV Plant Simulations}

Figure 3-4 shows the test circuit modified for a continuous power generation ramping scheme. It is based upon the steady-state circuit used in the previous study, changing only the amount of power generated, and type of power generation. 


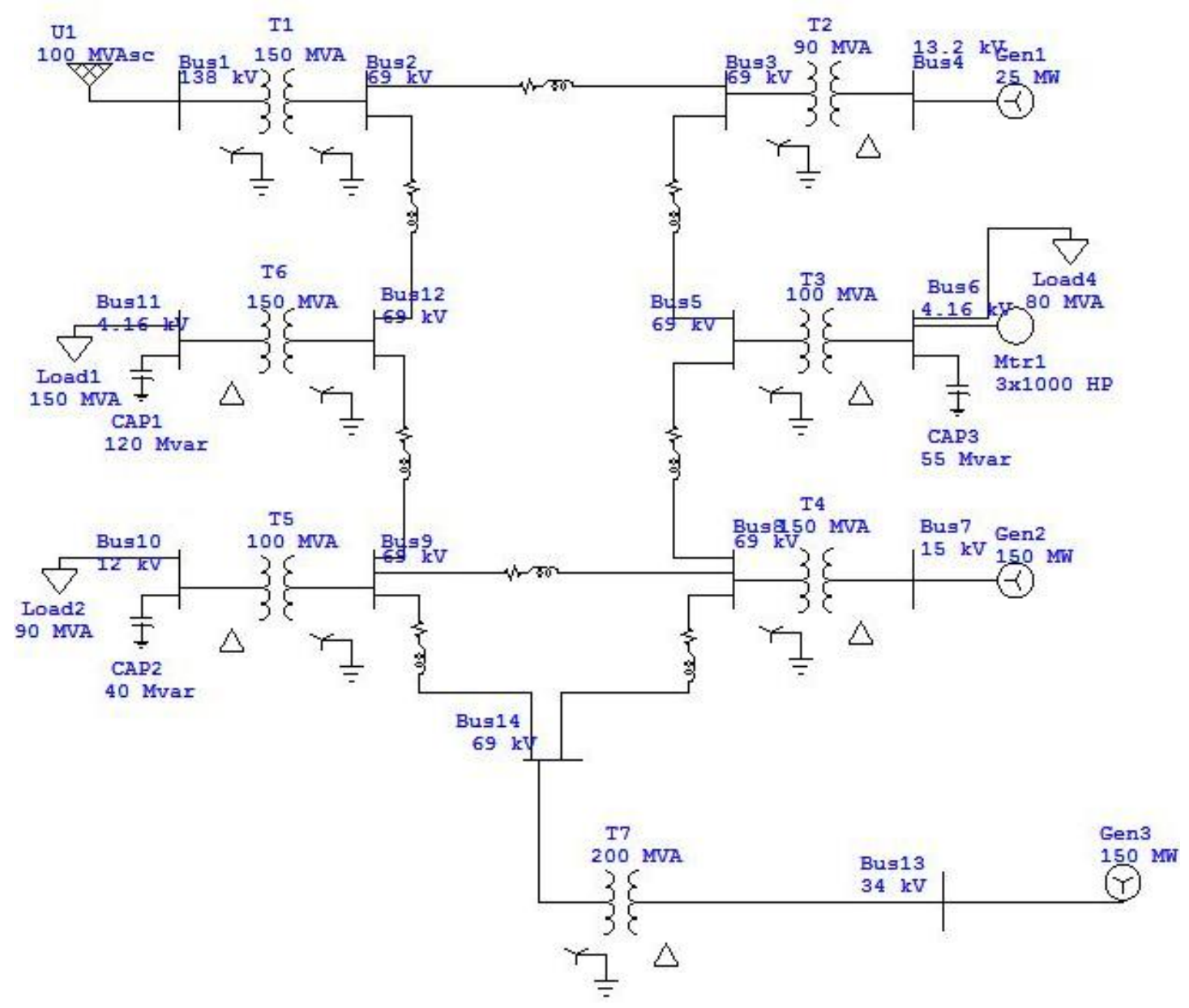

Figure 3-4: Power System with 150MW PV Plant

For the purposes of this study a 150MW PV generator was chosen. This value is on the high end of the power range for current PV arrays, but is well in the range of currently proposed facilities in the state of California, including the 550MW Topaz Solar Farm in the Carrizo Plain [16]. ETAP was chosen as the test environment for this circuit based on its transient stability abilities. Figure 3-4 shows a generic power system with a 150MW PV plant represented as Gen3. At this time ETAP is not available with a proper PV array module, so the generator was modeled following the guidelines provided by ETAP for simulating a PV Array with Maximum Power Point Tracking (MPPT) Inverter 
[17]. Transient analysis is to be performed on this power system for various cloud cover conditions. Backup power generation, or ancillary generation, is provided by generator 2 in the power system. Due to the limitations of ETAP transient analysis it is not possible to add disconnected generation to the system during simulation. In order to work around this limitation, the generation ramp function was used to increase the generation at bus 2 from $75 \mathrm{MW}$ to $150 \mathrm{MW}$ as needed.

Another crucial element to the simulation of a large PV power system is the timescale involved. As previously mentioned, the effects of shading a large PV systems are 'smoothed', or slowed, as the plant increases in size resulting in a time frame on the order of minutes rather than seconds. A test was performed to determine the effects of shaderamping speeds on the power system voltage and frequency stability. In ETAP, the maximum positive power ramp is limited to 200 percent, so the maximum cloud coverage studied is 50 percent to fit within this stipulation.

Initially, the power system is tested in a kind-of worst-case scenario lacking ancillary generation for three different scenarios: moderate, quick, and slow cloud shading speeds.

For the case of moderate cloud cover ramping, a negative ramp of 50 percent generation power over a 50 second period was used. Figures 3-5 through 3-7 demonstrate this scenario. 


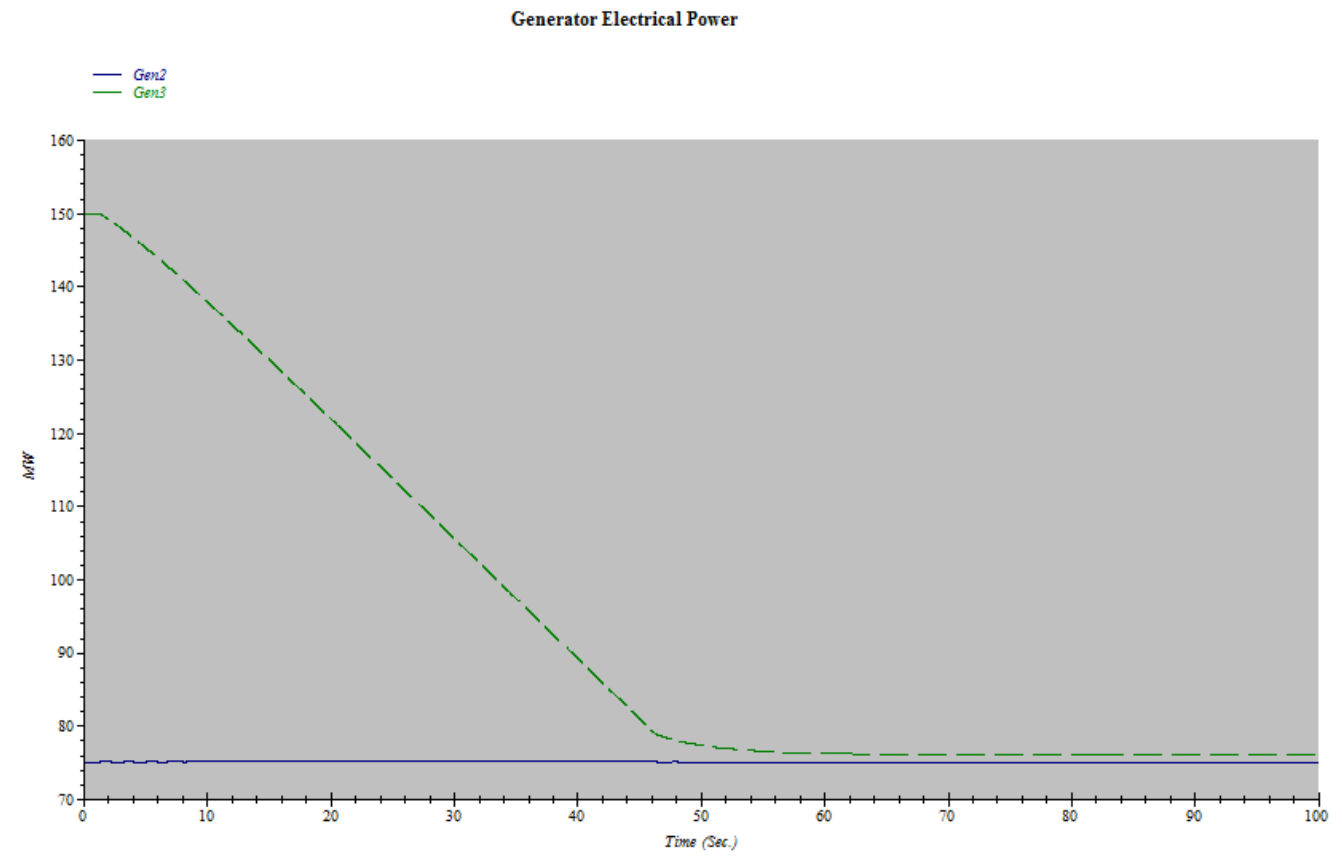

Figure 3-5: Moderate Cloud Ramping Generator Power

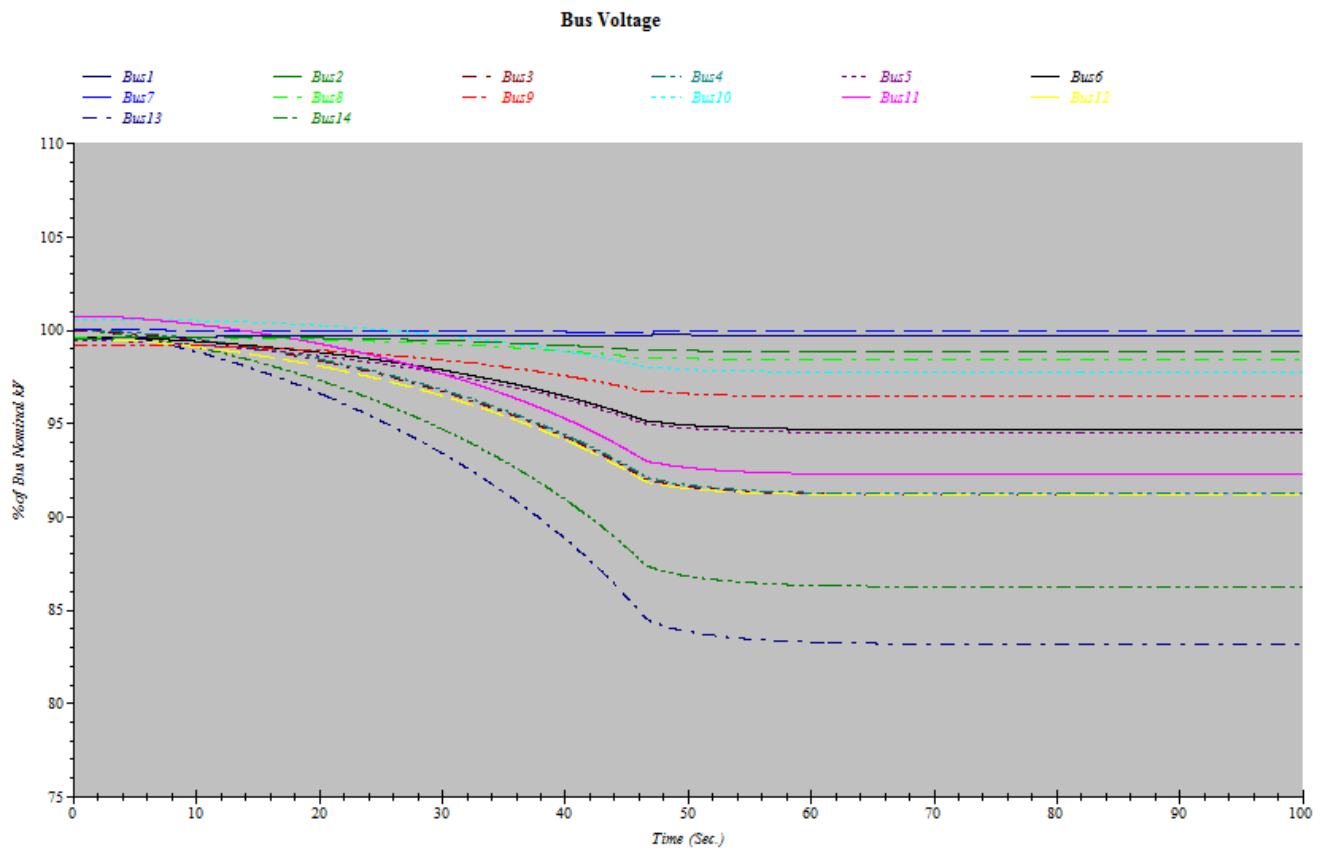

Figure 3-6: Moderate Cloud Ramping Bus Voltages 


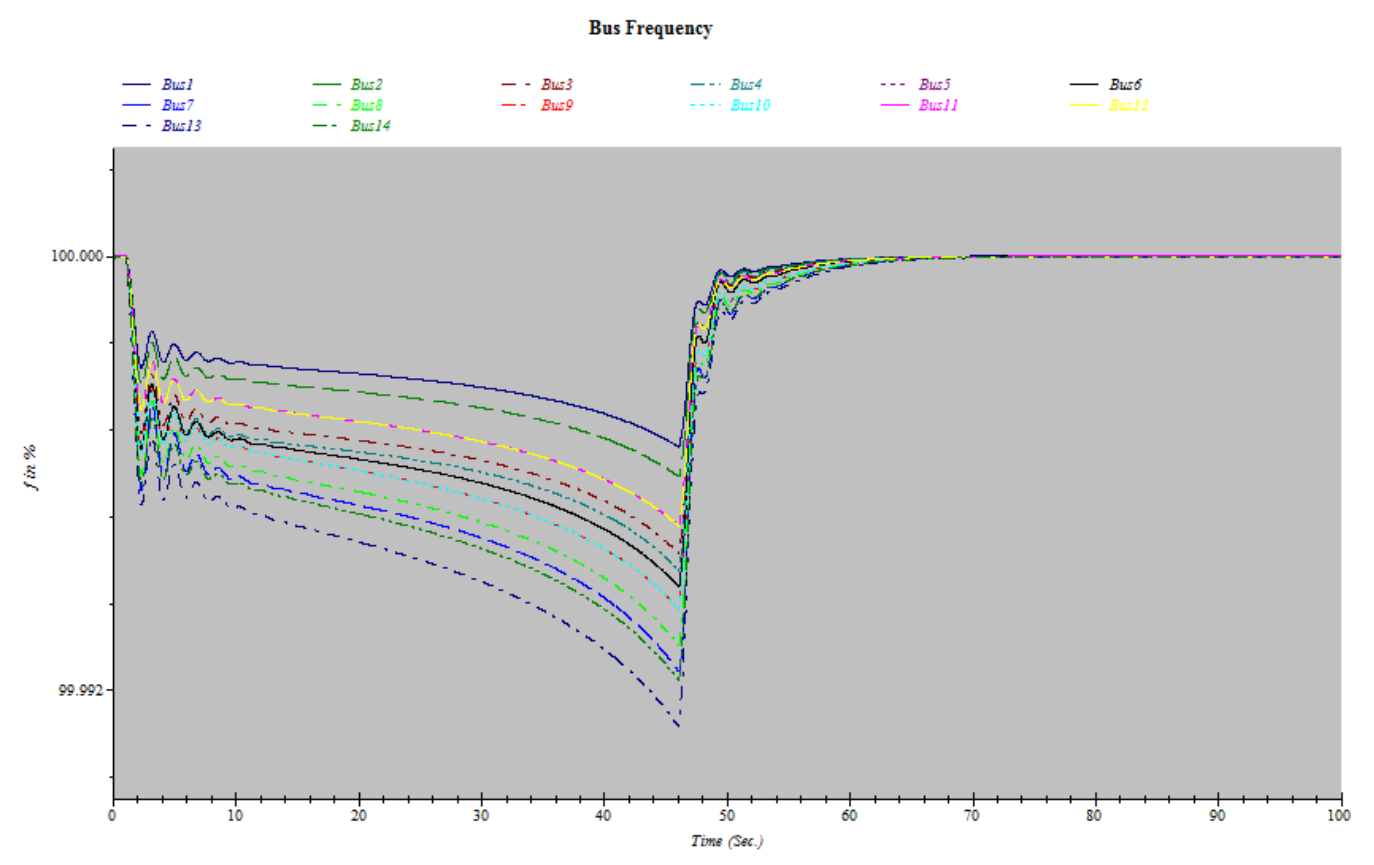

Figure 3-7: Moderate Cloud Ramping Bus Frequencies

For the case of quick cloud cover, a negative power generation ramp of 50 percent was used over 10 seconds to demonstrate the effects. Figures 3-8 through 3-10 demonstrate this case. 


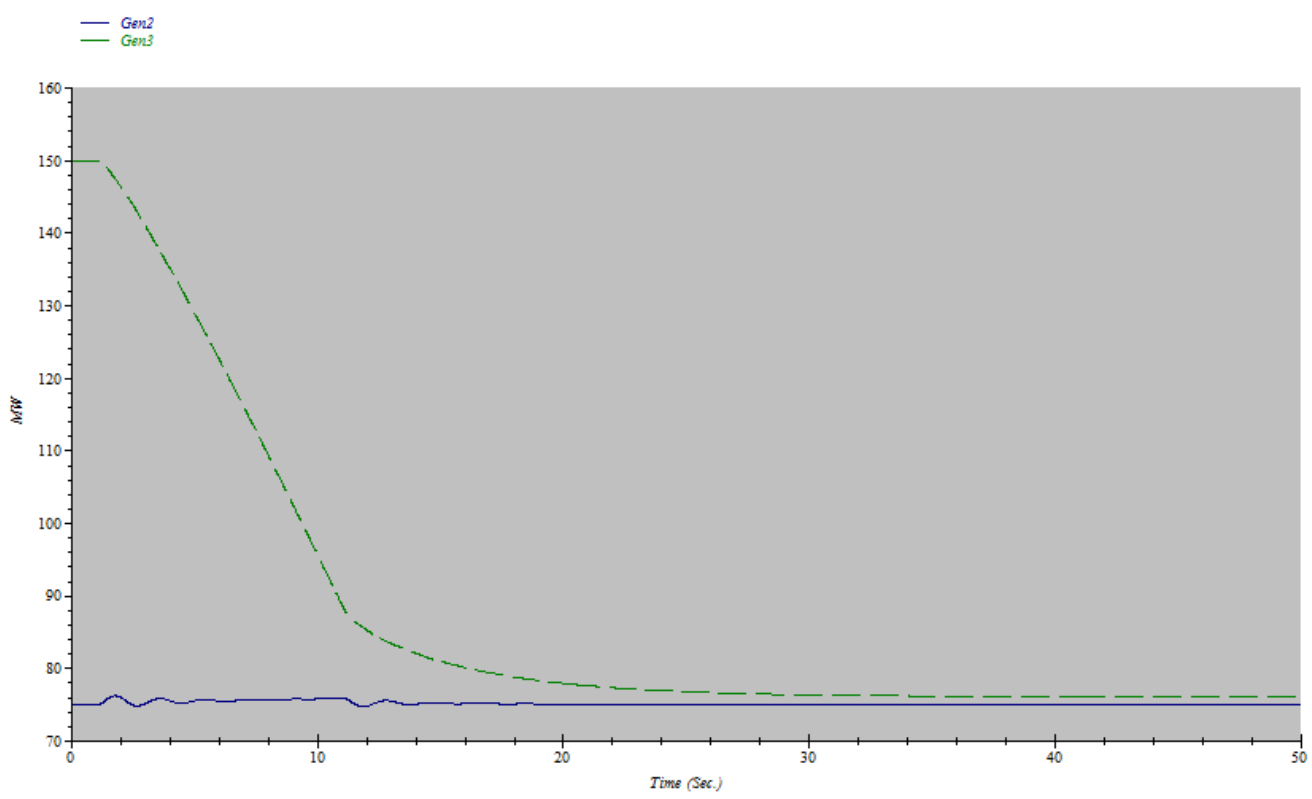

Figure 3-8: Quick Cloud Ramping Generator Power

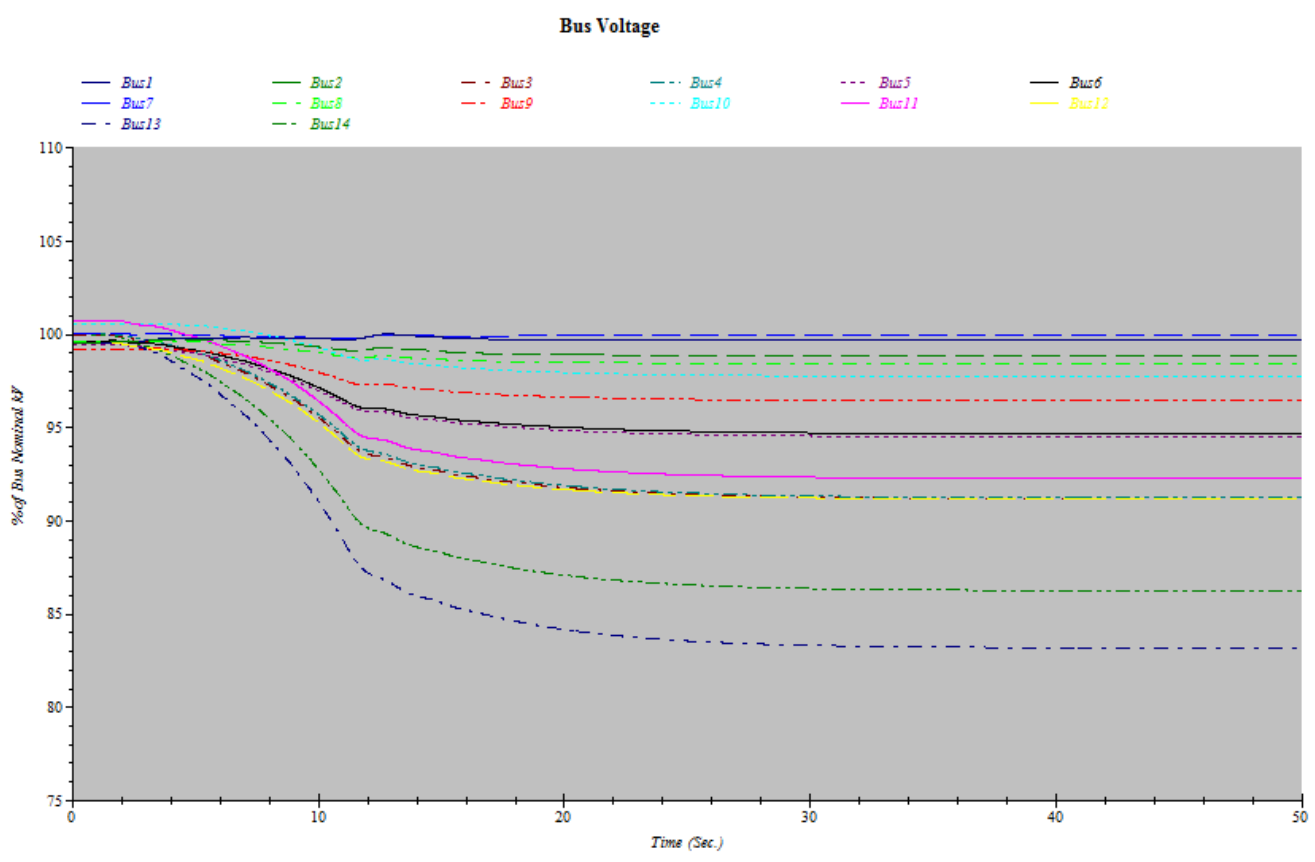

Figure 3-9: Quick Cloud Ramping Bus Voltages 


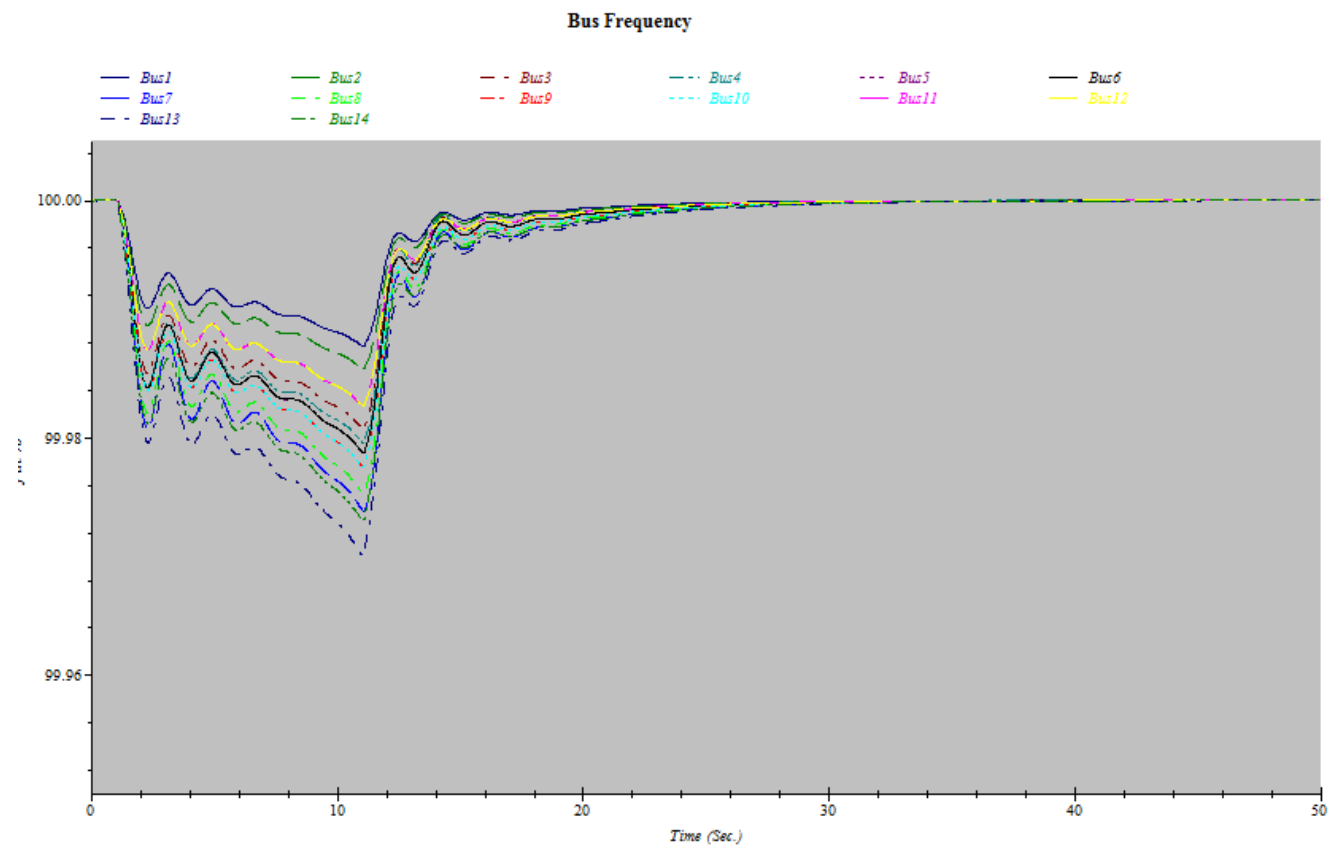

Figure 3-10: Quick Cloud Ramping Bus Frequencies

Finally, for a slower cloud ramping scenario, a negative power generation ramp of 50 percent over 100 seconds was used. Figures 3-11 through 3-13 demonstrate this test.

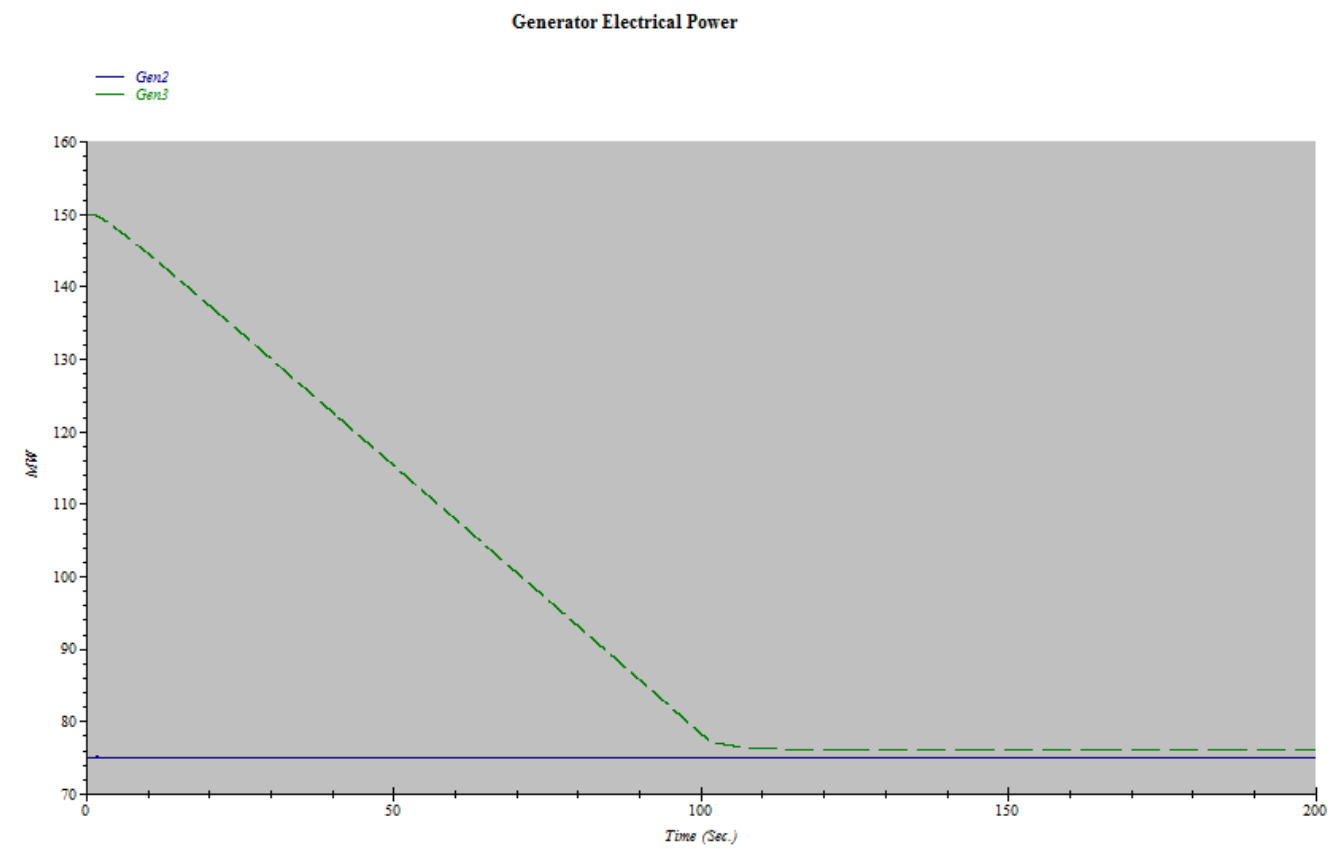

Figure 3-11: Slow Cloud Ramping Generator Power 


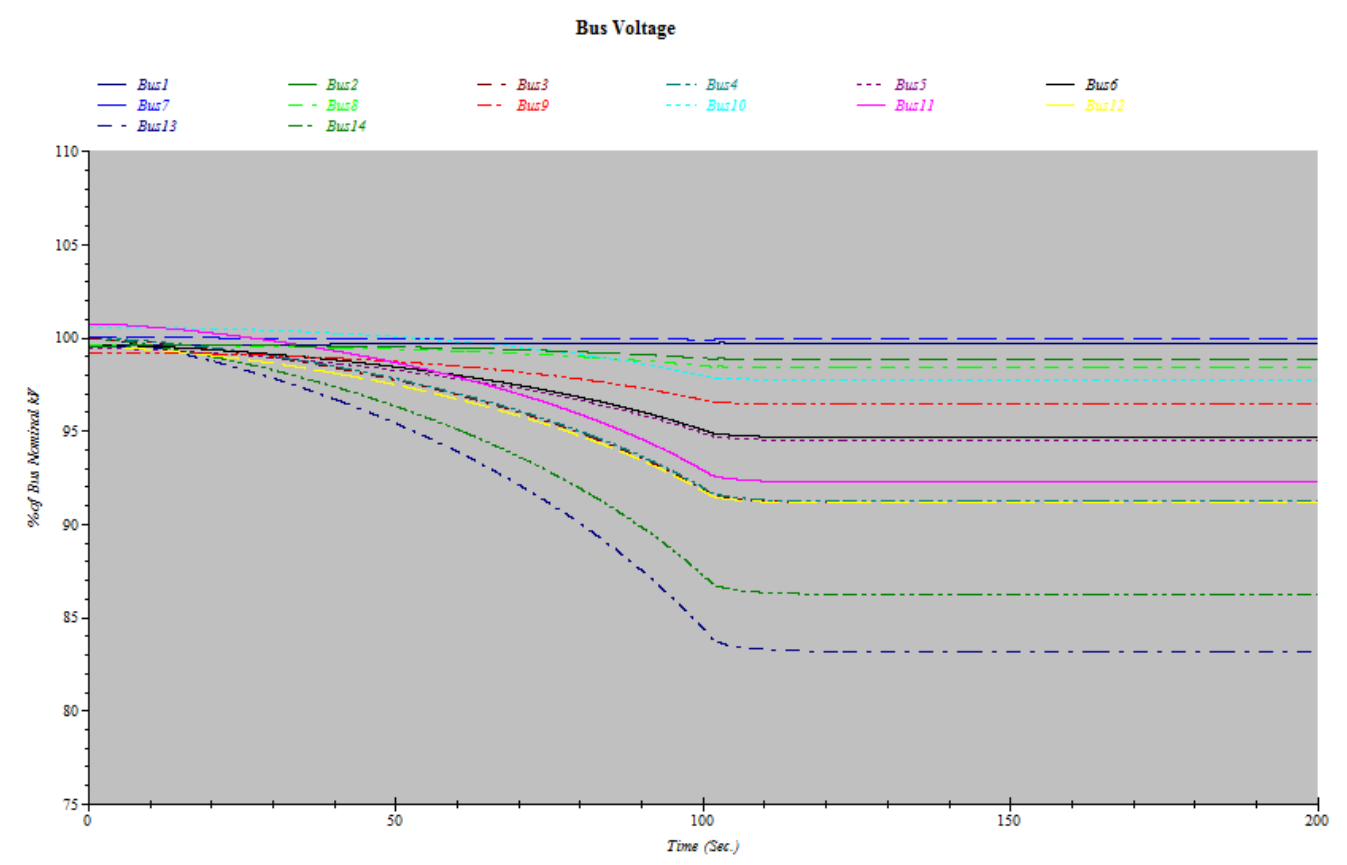

Figure 3-12: Slow Cloud Ramping Bus Voltages

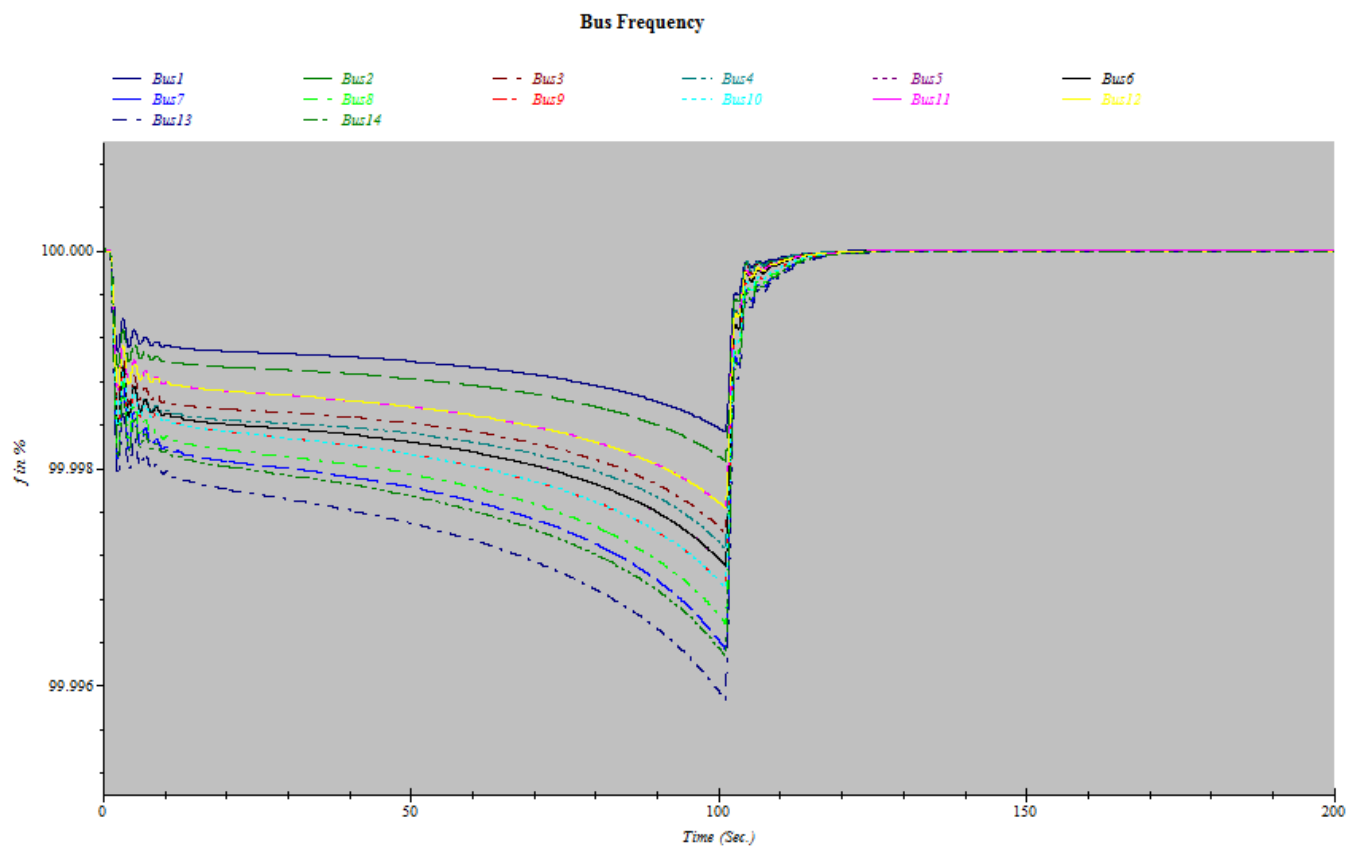

Figure 3-13: Slow Cloud Ramping Bus Frequencies

Before proceeding into analysis, an understanding of these voltages and frequencies within the larger context of grid interconnected voltage and frequency stability is needed. 
IEEE 1547 lays out the over-frequency and under-frequency ranges for devices with grid interconnections. It determines the maximum allowable amount of time to operate grid connected devices that are in abnormal or even harmful frequency conditions. Table 3-1 below provides acceptable frequency ranges for grid interconnected devices.

Table 3-1: Frequency Ranges and Corresponding Trip Times [14]

Table 8-Interconnection system response to abnormal frequencies

\begin{tabular}{|c|c|c|}
\hline DR size & Frequency range $(\mathbf{H z})$ & Clearing time ${ }^{\mathbf{a}}$ (s) \\
\hline \multirow{3}{*}{$\leq 30 \mathrm{~kW}$} & $>60.5$ & 0.16 \\
\hline & $<59.3$ & 0.16 \\
\hline \multirow{3}{*}{$>30 \mathrm{~kW}$} & $>60.5$ & 0.16. \\
\cline { 2 - 3 } & $\begin{array}{c}<\{59.8 \text { to } 57.0\} \\
\text { (adjustable set point) }\end{array}$ & Adjustable 0.16 to 300 \\
\cline { 2 - 3 } & $<57.0$ & 0.16 \\
\hline
\end{tabular}

${ }^{\mathrm{a}} \mathrm{DR} \leq 30 \mathrm{~kW}$, maximum clearing times; $\mathrm{DR}>30 \mathrm{~kW}$, default clearing times.

As can be seen from the preceding images corresponding to frequency (3-7,3-10,and 3-13), the quickly moving cloud cover has a more substantial frequency deviation from the ideal $100 \%$, or $60 \mathrm{~Hz}$. Table $3-2$ shows the minimum observed frequencies in percent and in hertz.

Table 3-2: Observed Minimum Frequency within the Grid

\begin{tabular}{|l|l|l|}
\hline Slow Cloud Cover & $\mathbf{9 9 . 9 9 6 \%}$ & $\mathbf{5 9 . 9 9 7 6 H z}$ \\
\hline Moderate Cloud Cover & $\mathbf{9 9 . 9 9 2 \%}$ & $\mathbf{5 9 . 9 9 5 2 H z}$ \\
\hline Quick Cloud Cover & $\mathbf{9 9 . 9 7 \%}$ & $\mathbf{5 9 . 9 8 2 H z}$ \\
\hline
\end{tabular}

These frequencies, as seen in comparison to Table 3-1, all fall within an acceptable range of operation, assuming that the conditions are only temporary. Some simple calculations verify the insignificance of these minor changes in frequency for even the worst-case scenario of quick cloud cover. 


$$
\% \text { error }=\left|\frac{60-59.982}{60}\right| * 100 \%=0.03 \%
$$

Based on these calculations for the maximum frequency disturbance observed, and the grid interconnection acceptable frequency ranges, it can be concluded that the effects of frequency disturbance by cloud cover are not great enough to warrant nuisance frequency relay operation.

In comparison to the previously mentioned study, these frequency deviations due to a continuous loss of power generation are significantly less than the deviations that were observed with the discrete elements being removed from the system. This is in line with the idea that quicker cloud cover will result in a more drastic change in the amount of frequency disturbance. Figure 3-2 shows a minimum frequency of 99.93 percent compared to the 99.97 percent incurred by the quickest cloud cover.

The next topic covered under the interconnection standard IEEE 1547 are the definitions of voltage stability. Table 3-3 shows the acceptable voltage ranges for the operation of over voltage and under voltage protective devices.

Table 3-3: Voltage Ranges and Corresponding Trip Times [18]

Table 7-Interconnection system response to abnormal voltages

\begin{tabular}{|l|c|}
\hline $\begin{array}{c}\text { Voltage range } \\
\text { (\% of the base voltage }{ }^{\text {}} \text { ) }\end{array}$ & $\begin{array}{c}\text { Clearing time } \\
\text { (s) }\end{array}$ \\
\hline $\mathrm{V}<50$ & 0.16 \\
\hline $50 \leq \mathrm{V}<88$ & 2.00 \\
\hline $110<\mathrm{V}<120$ & 1.00 \\
\hline $\mathrm{V} \geq 120$ & 0.16 \\
\hline
\end{tabular}

\footnotetext{
${ }^{\text {a }}$ Base voltages are the nominal system voltages stated in ANSI C84.1 Table 1.

${ }^{\mathrm{b}} \mathrm{DR} \leq 30 \mathrm{~kW}$, maximum clearing times; $\mathrm{DR}>30 \mathrm{~kW}$, default clearing times.
} 
Again, looking back to the three different cloud cover scenarios, conclusions about voltage stability can be made. Unlike the case for frequency deviation, voltage deviations are seemingly unaffected in magnitude by the relative speed of the cloud cover. This can be seen by comparing the corresponding bus voltages between the three scenarios in Figures 3-6, 3-9, and 3-12. For bus 13, the bus relating to the pretransformed PV voltage, the voltage drops as low as 84 percent in each of the three cases.

It is also useful to note the similarities here between the previous study done, and this study. Namely, both PV generators are similarly susceptible to cloud cover when on the topic of voltage stability. The case of a $40 \%$ drop in generation in that study, shown in Figure 3-3, resulted in a voltage drop to $86 \%$ [15]. Both of these voltage scenarios lead to issues with protective device operation. Table 3-3 shows that bus voltages under 88 percent of their nominal value (base voltage) should be cleared within 2 seconds. This scenario is encountered for each of these demonstrations. For smaller losses of power generation, there is a smaller amount of voltage loss. Similarly for even larger losses of generation the voltage at the respective buses will drop.

\subsection{Individual Scenarios for Ancillary Generation Support}

The following studies will demonstrate a few of the more poignant examples of the many possible cloud cover and ancillary service ramping scenarios. For the sake of simulation time, the moderate cloud cover ramping speed is used for each of the following studies.

The first scenario to be studied deals with backup generation that comes online in the midst of a negative power ramp from the PV plant. The oncoming generation has a slightly slower power ramp rate, $75 \mathrm{MW}$ in 70 seconds, compared to the moderately 
paced cloud cover power ramp of negative $75 \mathrm{MW}$ in 50 seconds. Figures 3-14 through 3-16 highlight this first case.

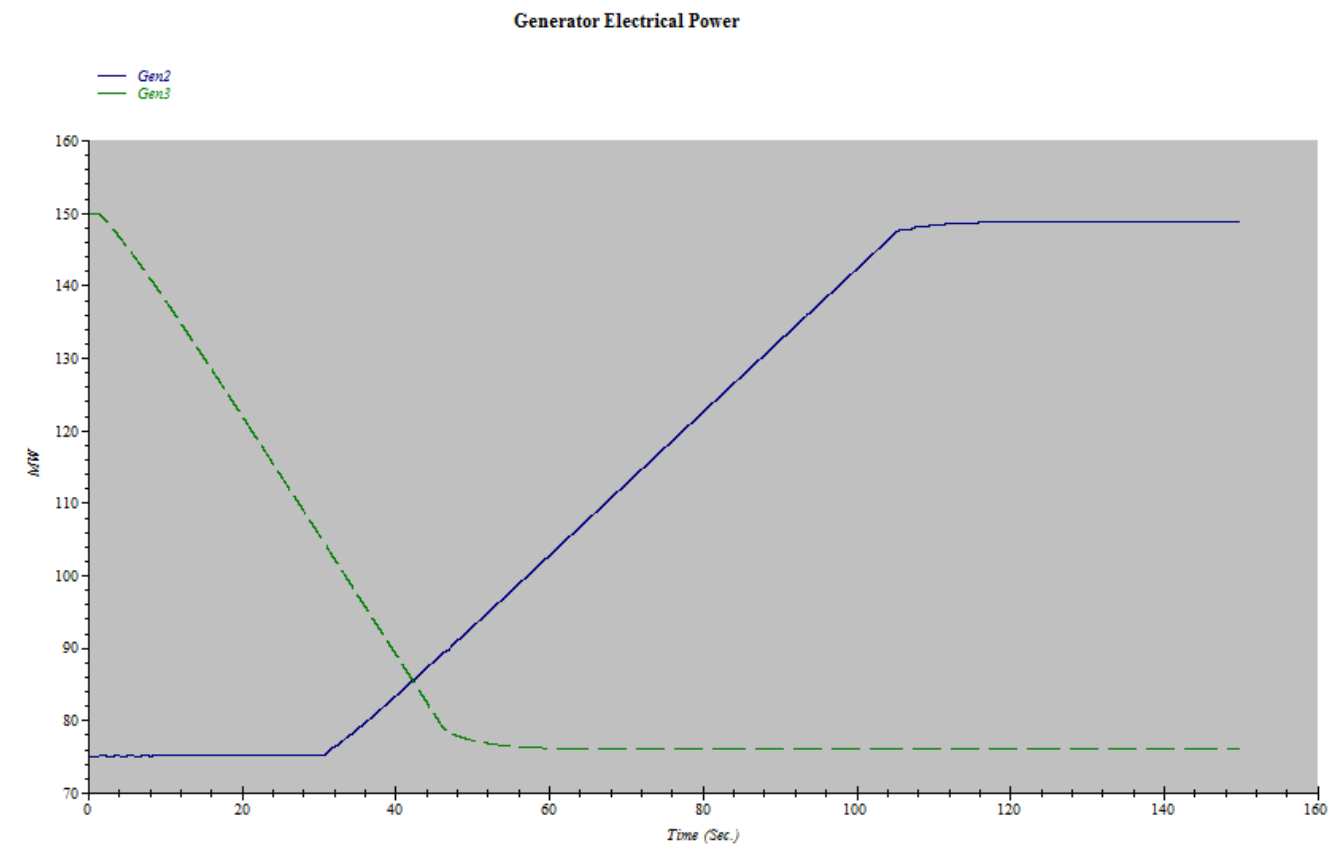

Figure 3-14: Power Generation Ramps for Case 1 


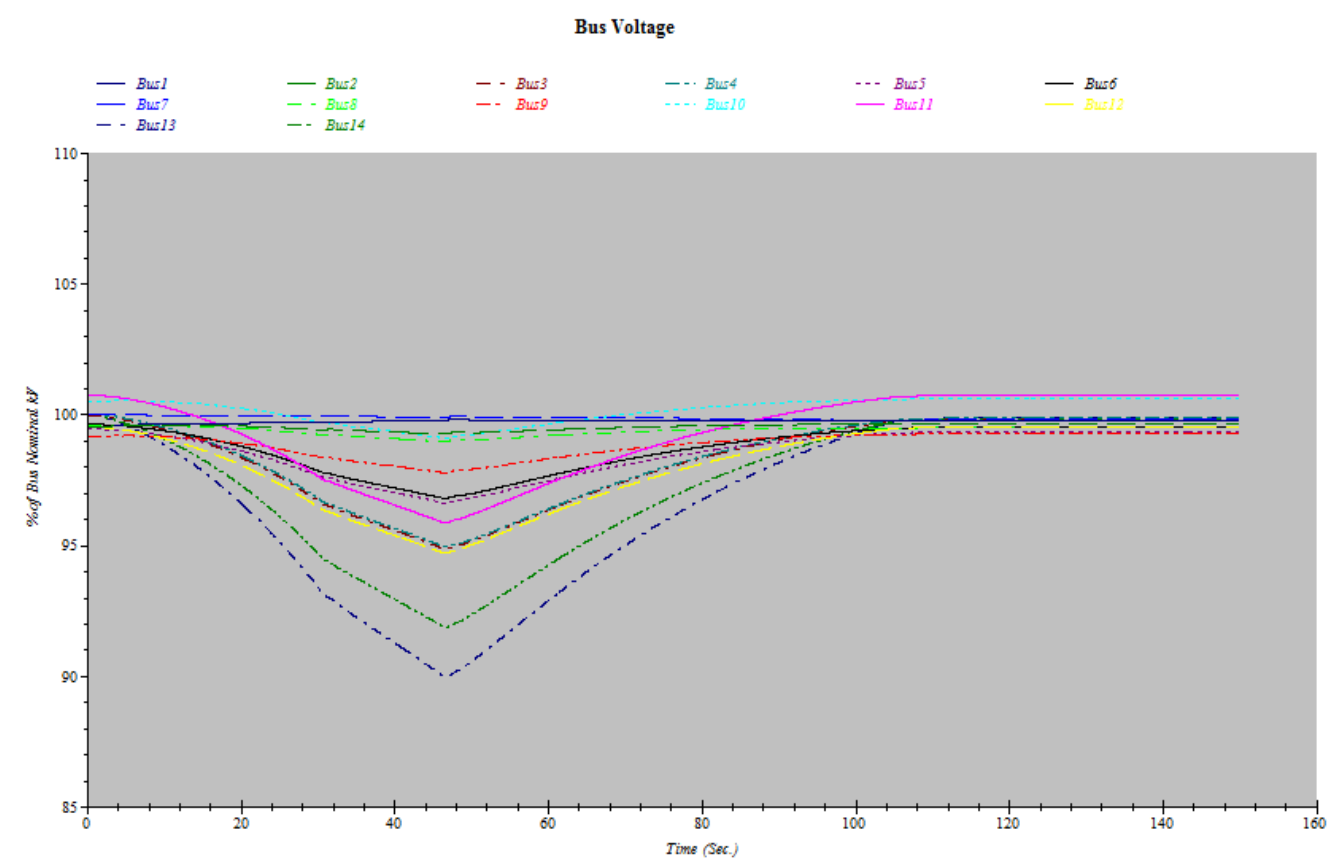

Figure 3-15: Bus Voltages for Case 1

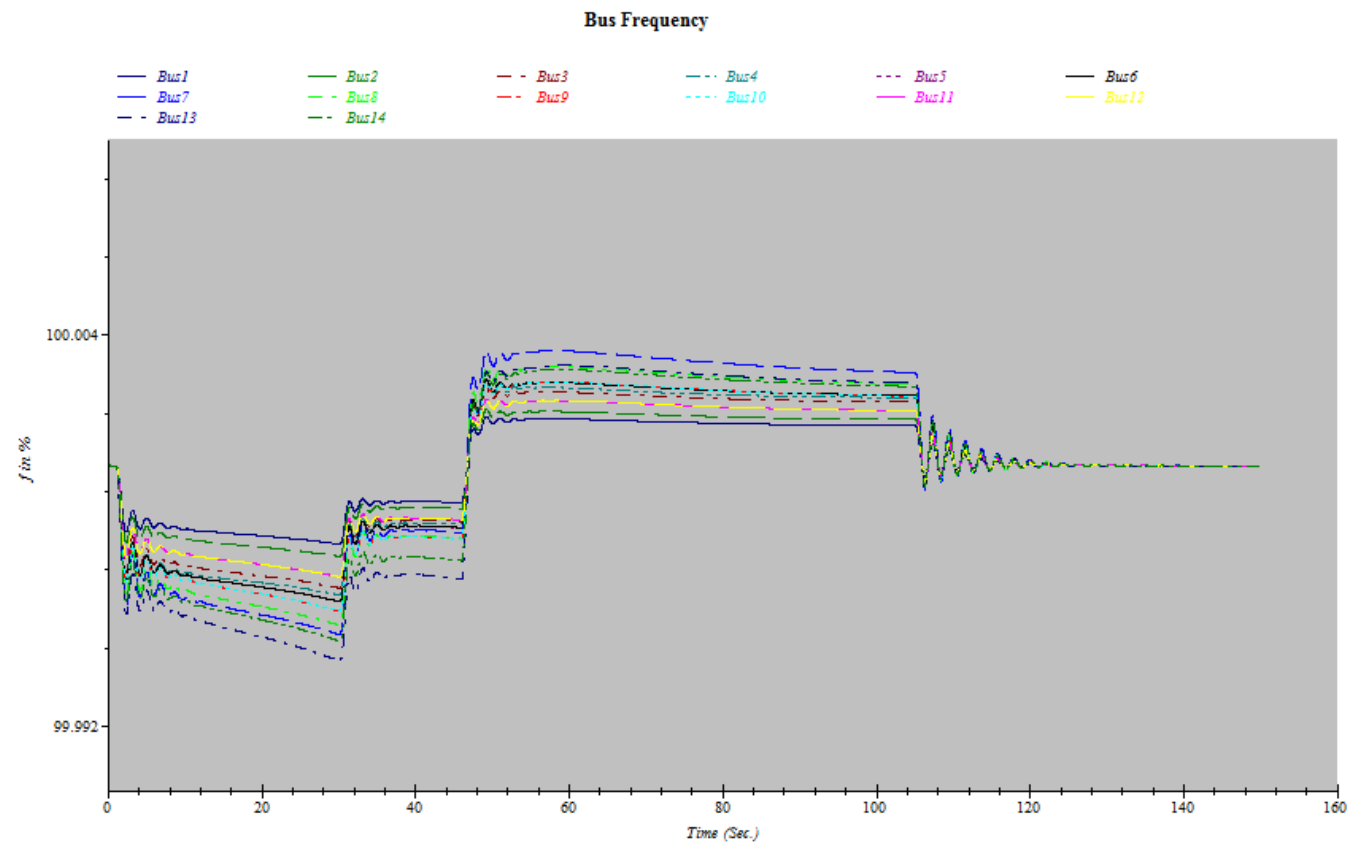

Figure 3-16: Bus Frequencies for Case 1 
There are a couple things that can be gleaned from this study. As the period for dropping generation and adding generation overlap, the loss of total voltage magnitude is not nearly as severe as the case without backup generation, dropping to only 90 percent compared to 84 percent. The frequency is also supported in this case allowing a drop of only 99.994 percent compared to 99.992 percent.

The second scenario examined is for more timely, or responsive, backup generation. In this case the generation ramp rate is the same as in Case 1. The only change is that the operators were able to bring ancillary generation online in a more immediate time frame. Figures 3-17 through 3-19 correspond to Case 2.

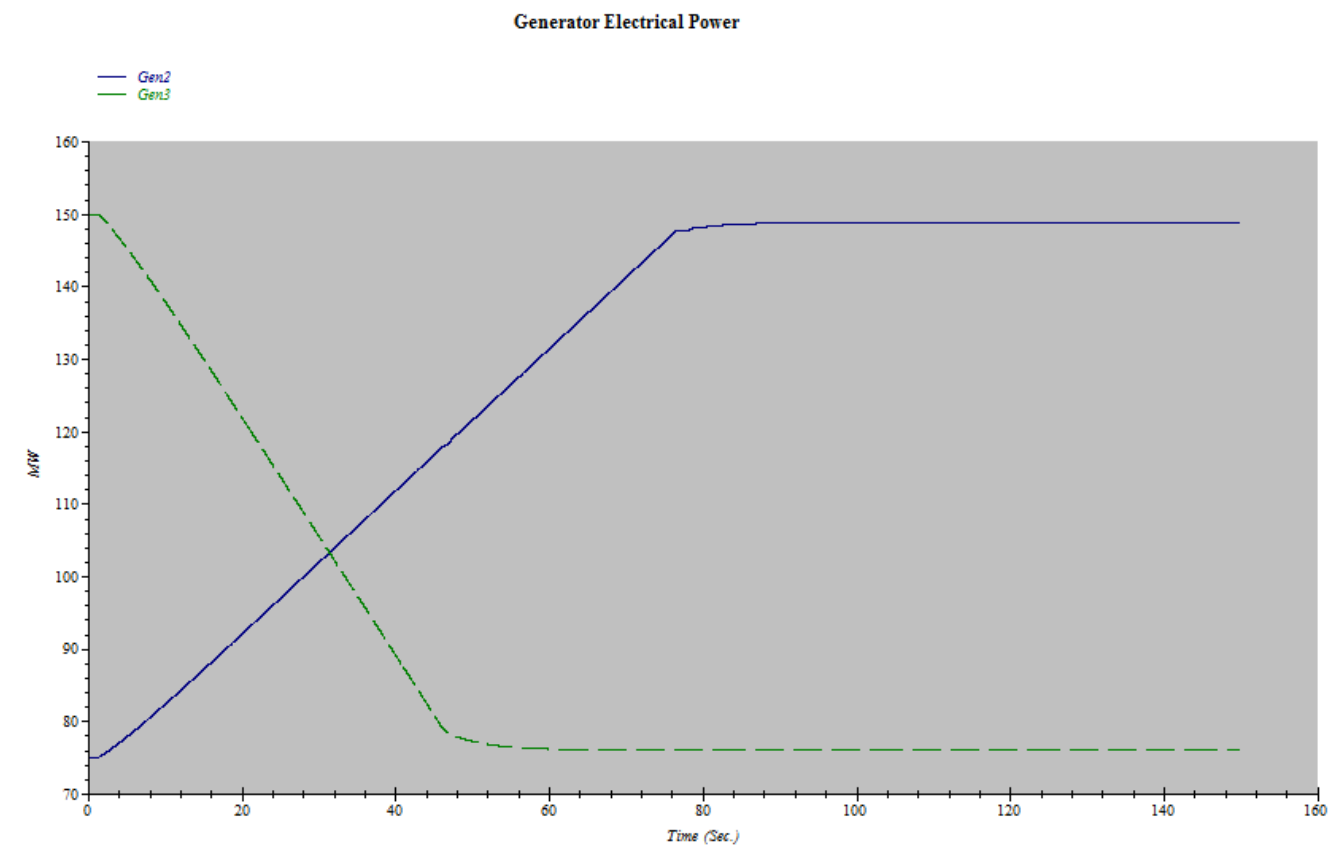

Figure 3-17: Power Generation Ramps for Case 2 


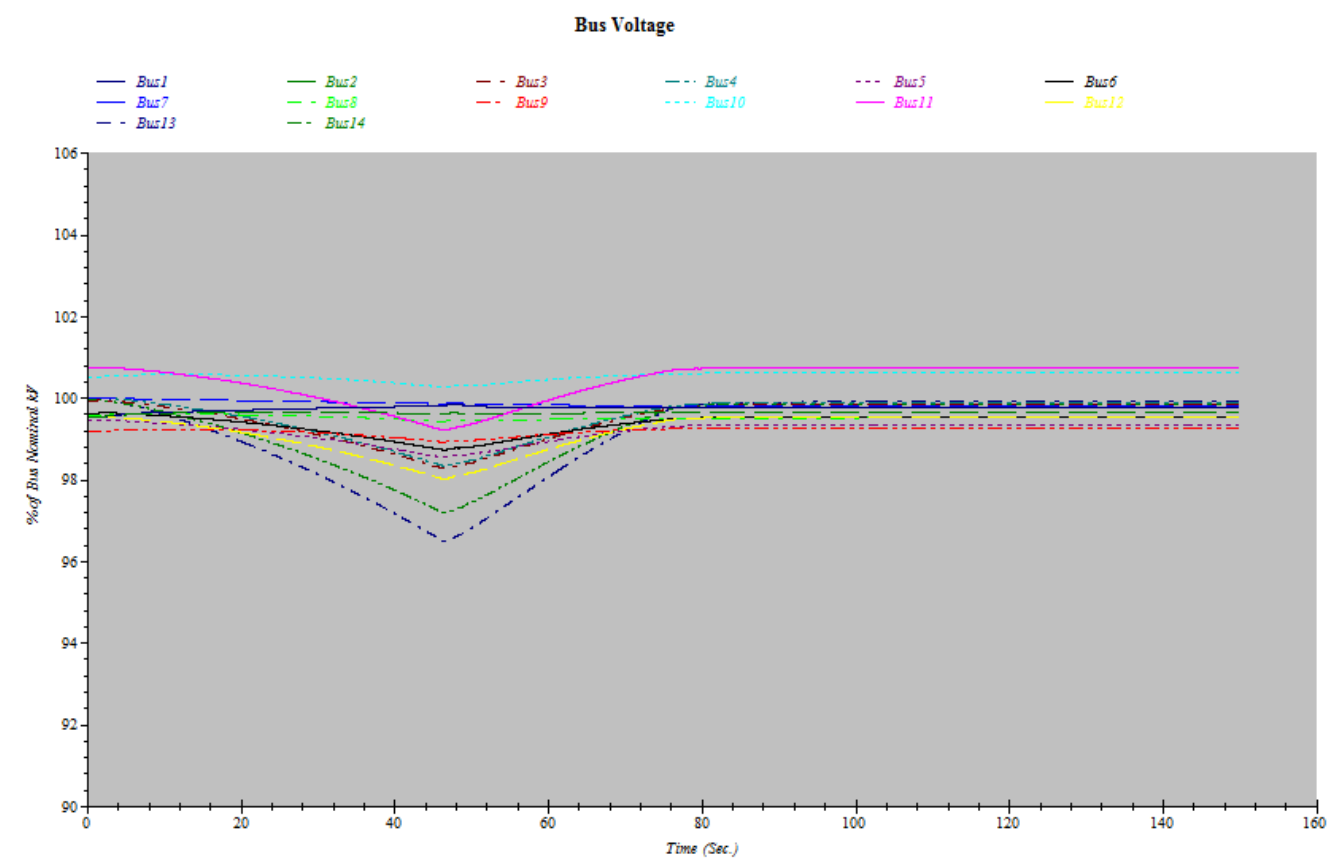

Figure 3-18: Bus Voltages for Case 2

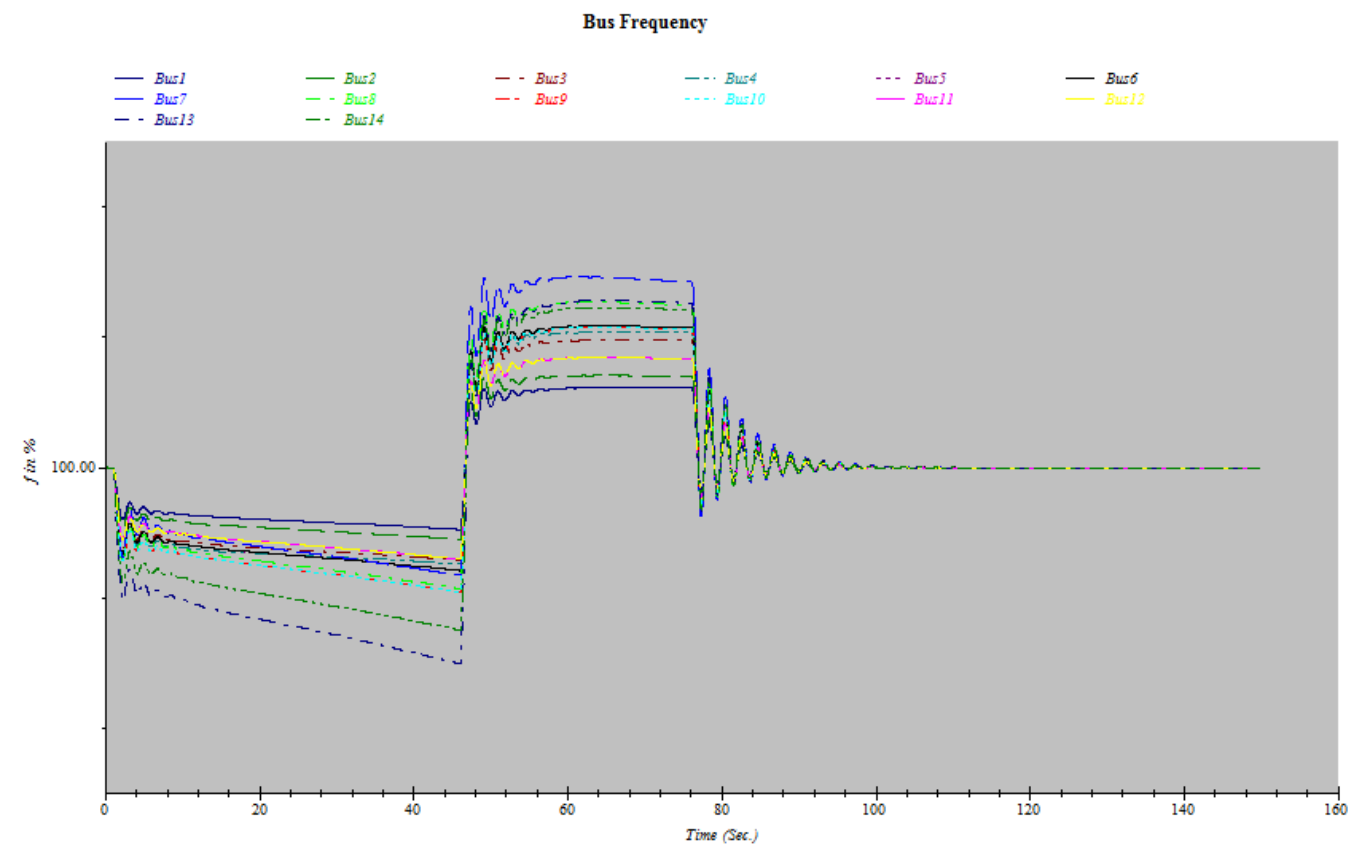

Figure 3-19: Bus Frequencies for Case 2 (Range 99.995 to 100.005) 
It can clearly be seen that as the backup generation is brought online in a more immediate fashion, both the bus voltages and frequencies remain closer to their ideal values.

The third scenario is nearly the same as this scenario, but involves matching the speed of the ancillary generation power ramp with that of the cloud cover-induced impact. Figures 3-20 through 3-22 correspond to Case 3.

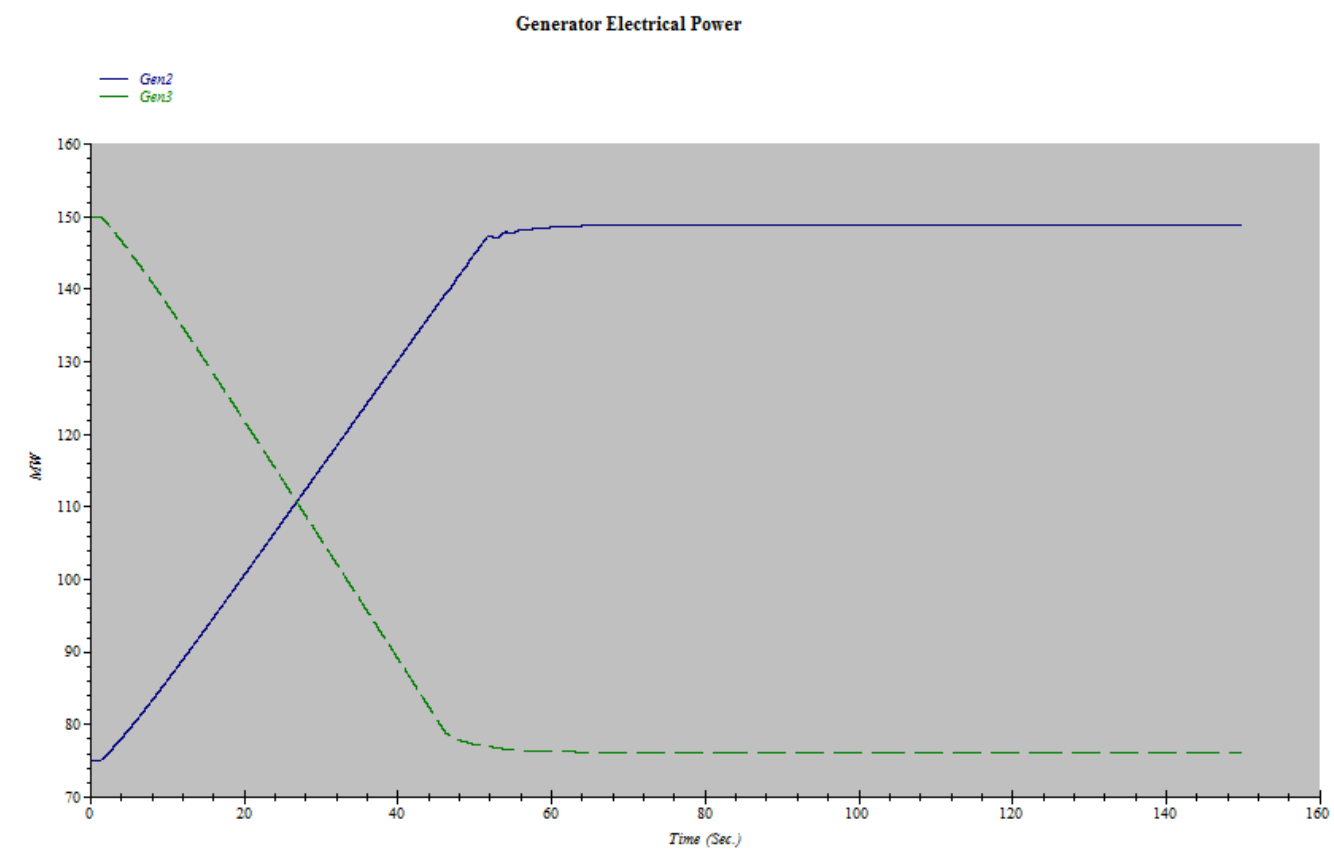

Figure 3-20: Power Generation Ramps for Case 3 


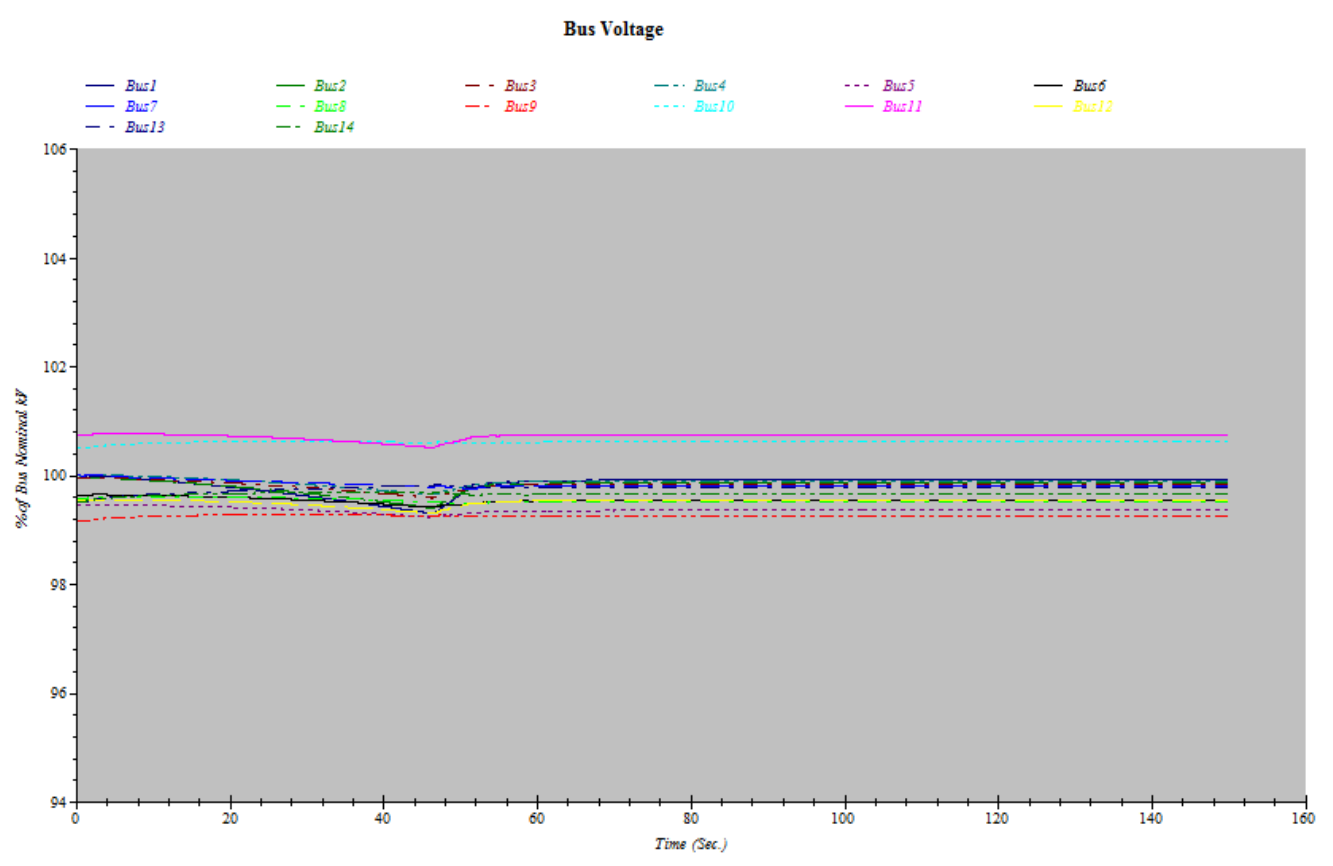

Figure 3-21: Bus Voltages for Case 3

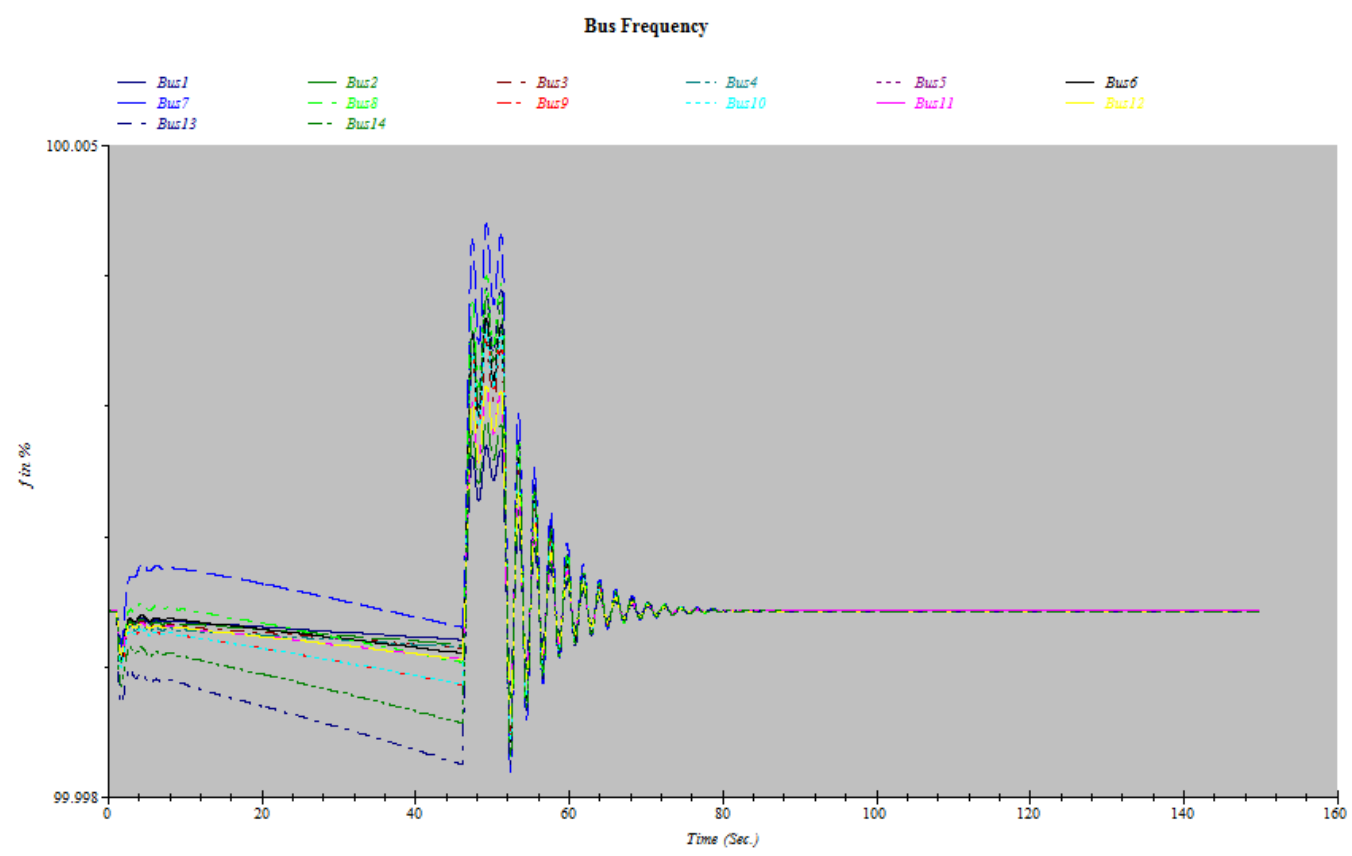

Figure 3-22: Bus Frequencies for Case 3

This case demonstrates the best-case scenario where generation loss and recovery are perfectly in line. The margin for difference between observed and ideal bus voltages are 
clearly both at a minimum. The remaining disturbances to voltage and frequency can be attributed to the layout of the system and location of the ancillary generation with respect to the PV generation. As the oncoming ancillary generation is moved further from the receding PV generation the disturbances would be expected to increase.

In case 4, the effect of slowed cloud cover and generation is explored. This case is timed such that the oncoming generation matches the time the when the negative ramp of the PV plant is complete. Figures 3-23 through 3-25 cover this fourth case.

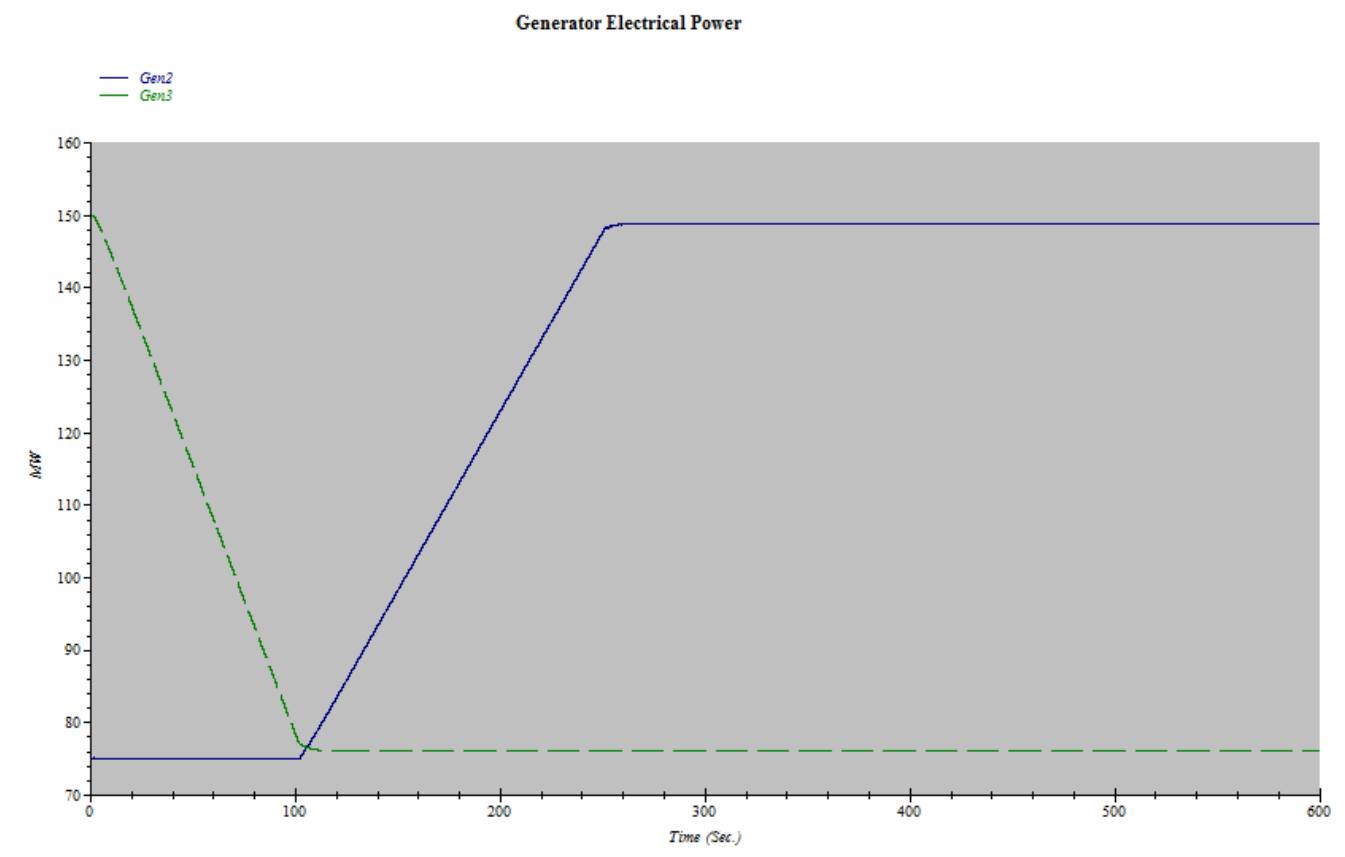

Figure 3-23: Generation Power Ramps for Case 4 


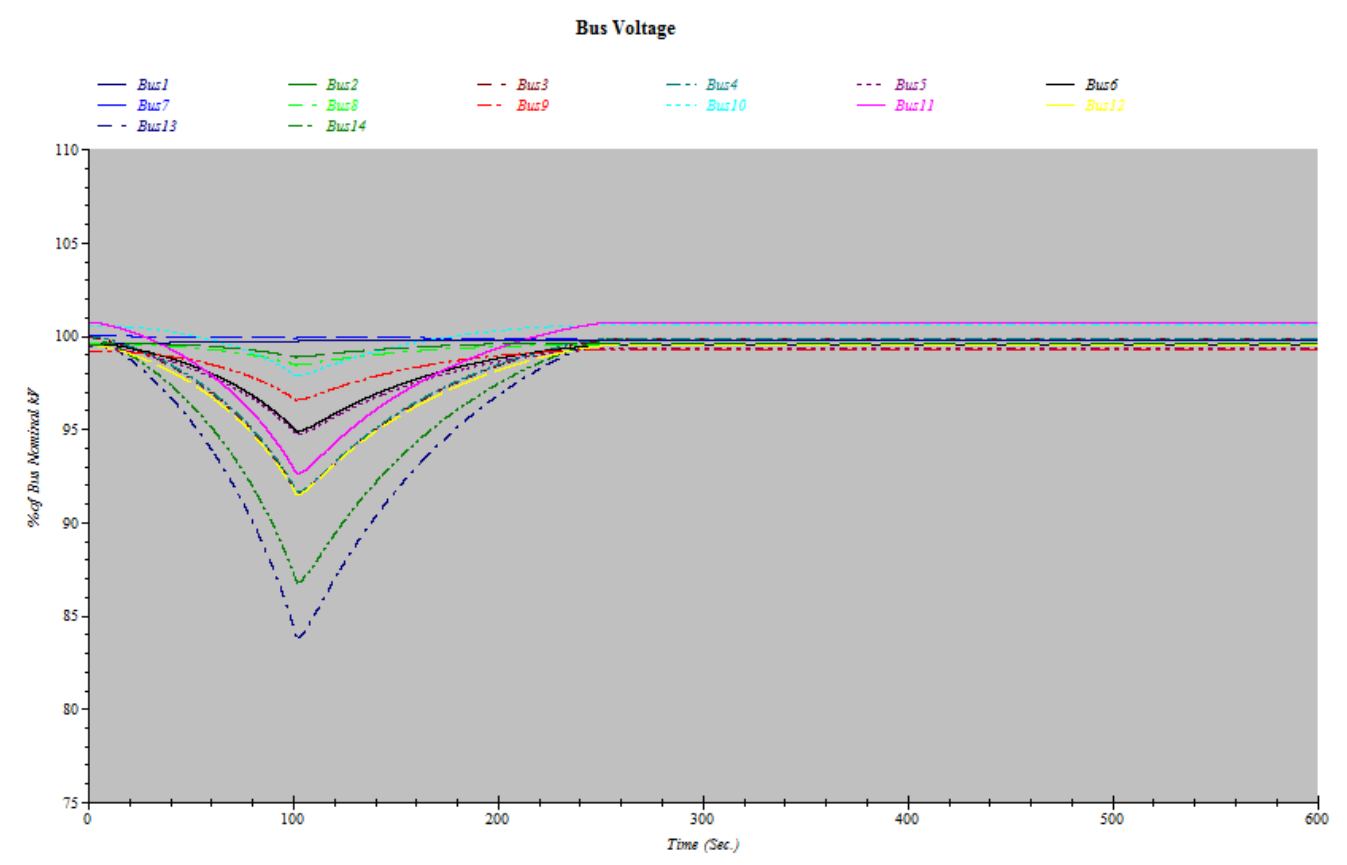

Figure 3-24: Bus Voltages for Case 4

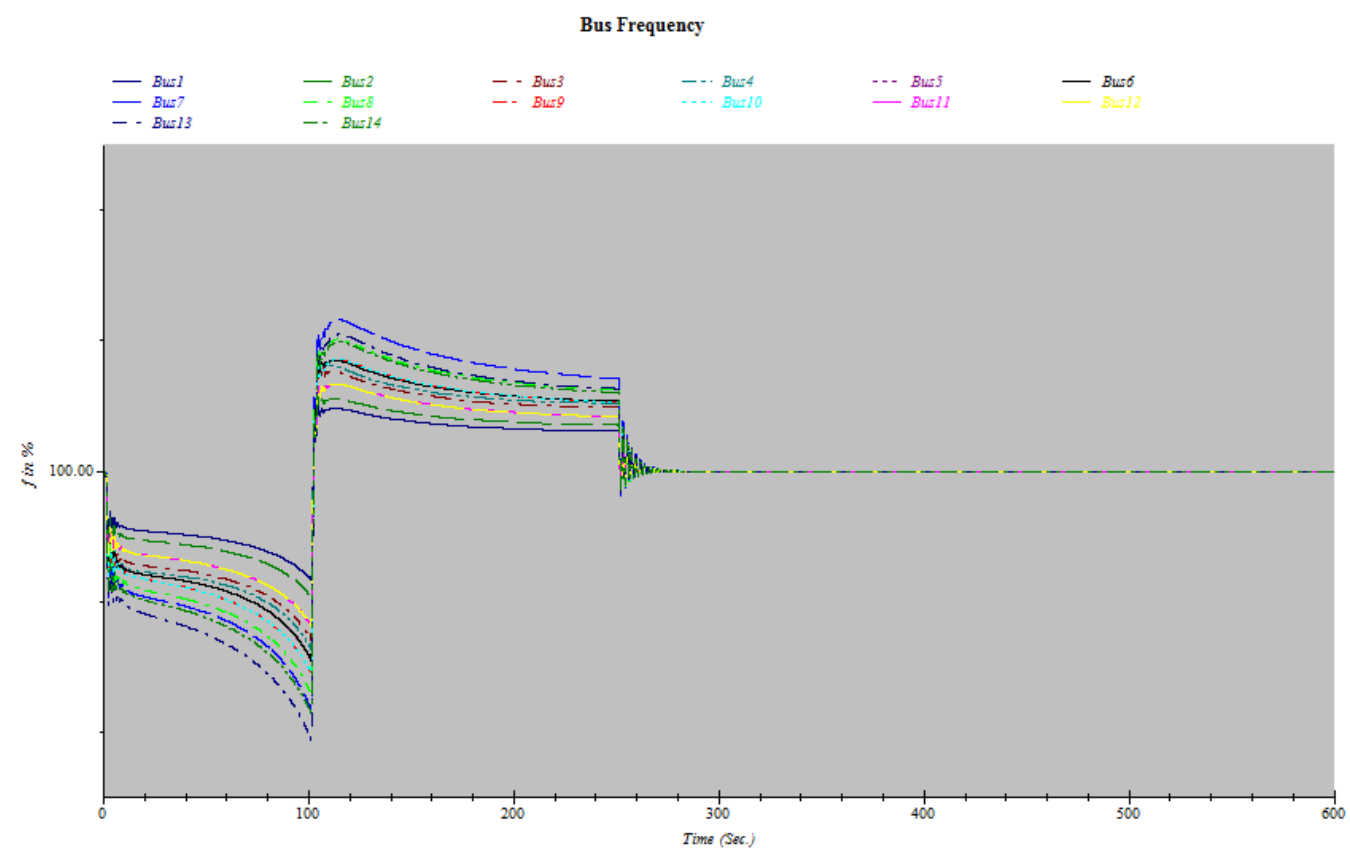

Figure 3-25: Bus Frequencies for Case 4

This case demonstrates the importance of timely backup generation. As no ancillary generation was brought on-line before the generation was removed from the system, the 
bus voltage is disturbed to its highest magnitude, which would for this example require its removal from the system as the disturbance lasts longer than the allowed 2 seconds.

At this point, the remaining cases look into the potential downsides pertaining to generation forecasting. Two of the many possible cases will be shown to cover incorrect generation consideration.

The first of these cases looks into the scenario of partial cloud coverage that quickly removes itself from the system. The oncoming generation is unresponsive to the change in generation and continues to ramp up to its full generation capacity. Figures 3-26 through 3-28 cover this first problematic case.

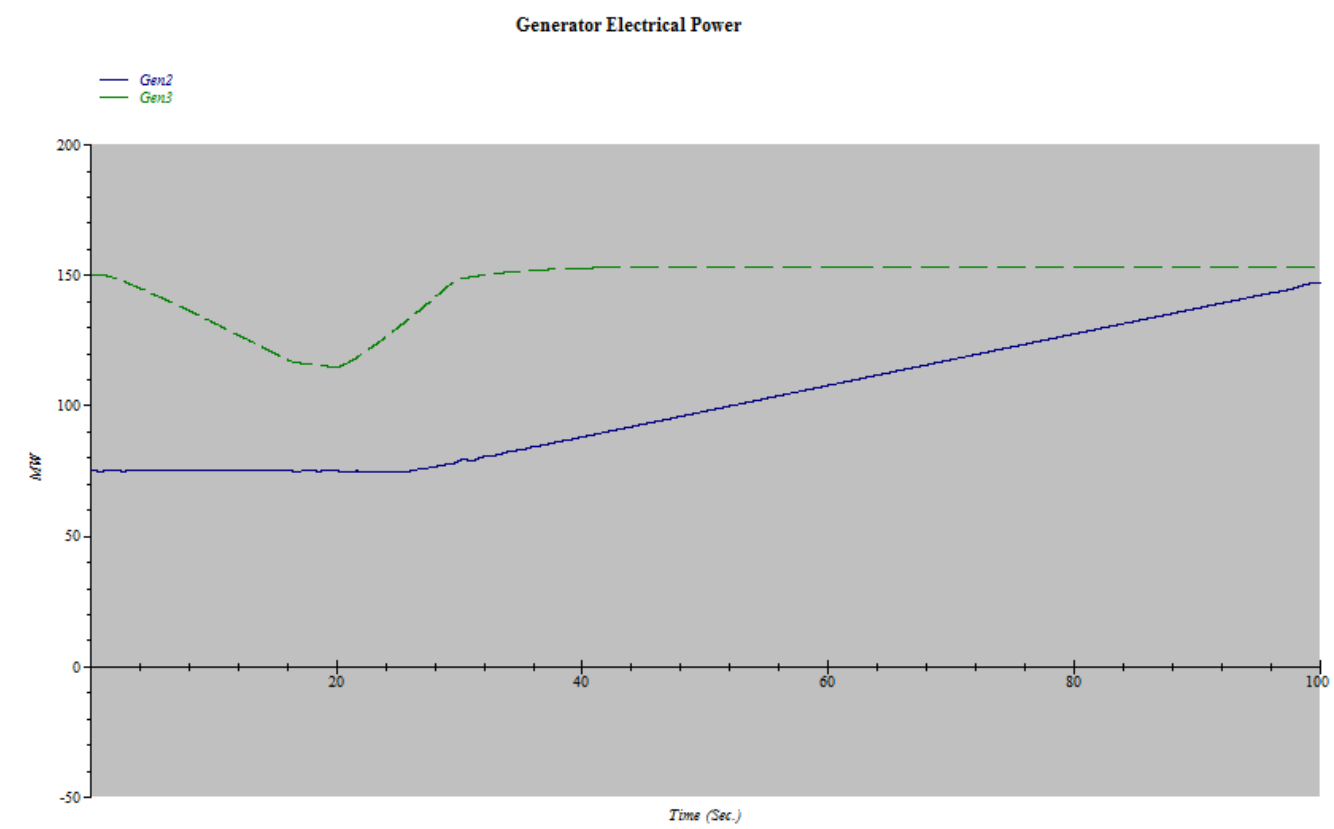

Figure 3-26: Power Generation Ramps for Problematic Case 1 


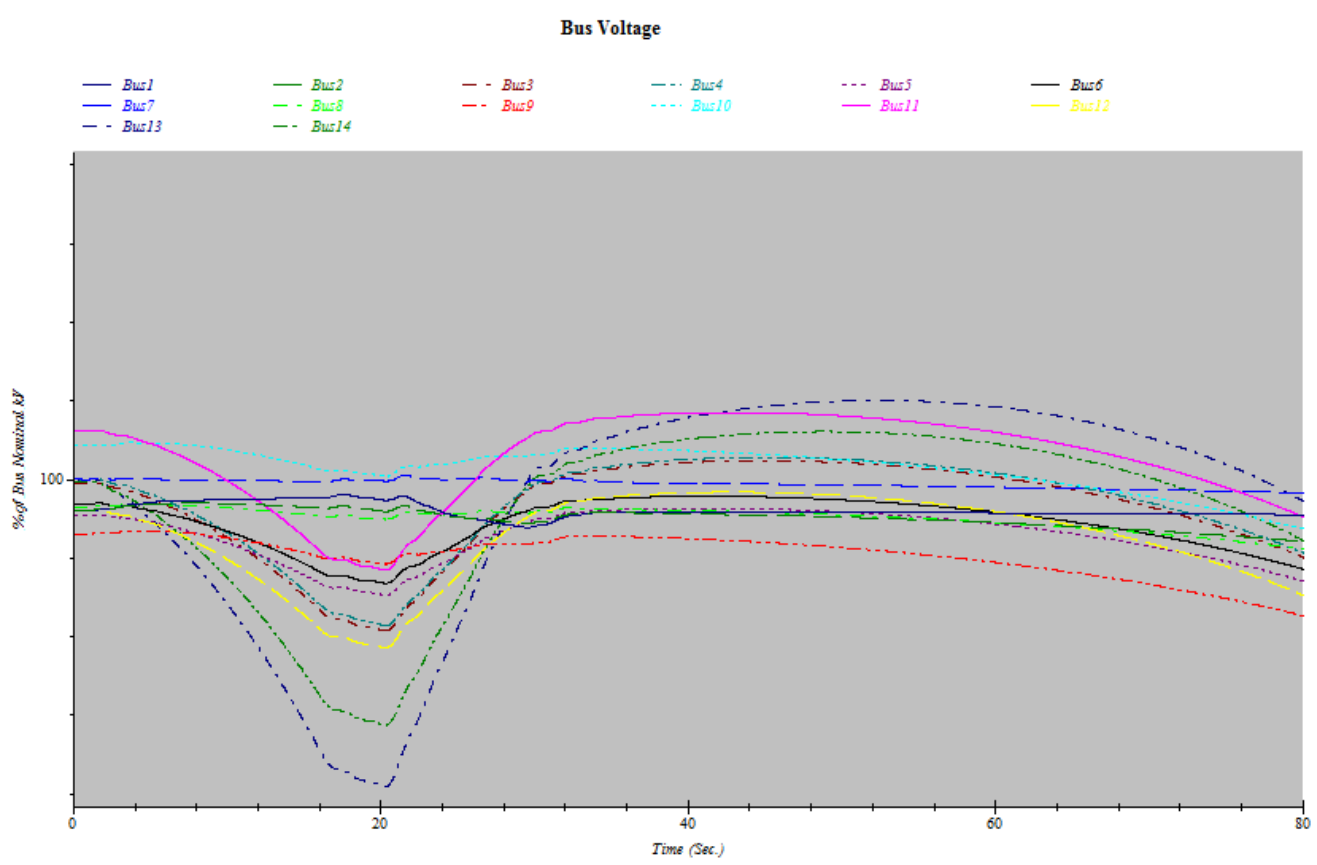

Figure 3-27: Bus Voltages for Problematic Case 1 (Range: 95 to 105)

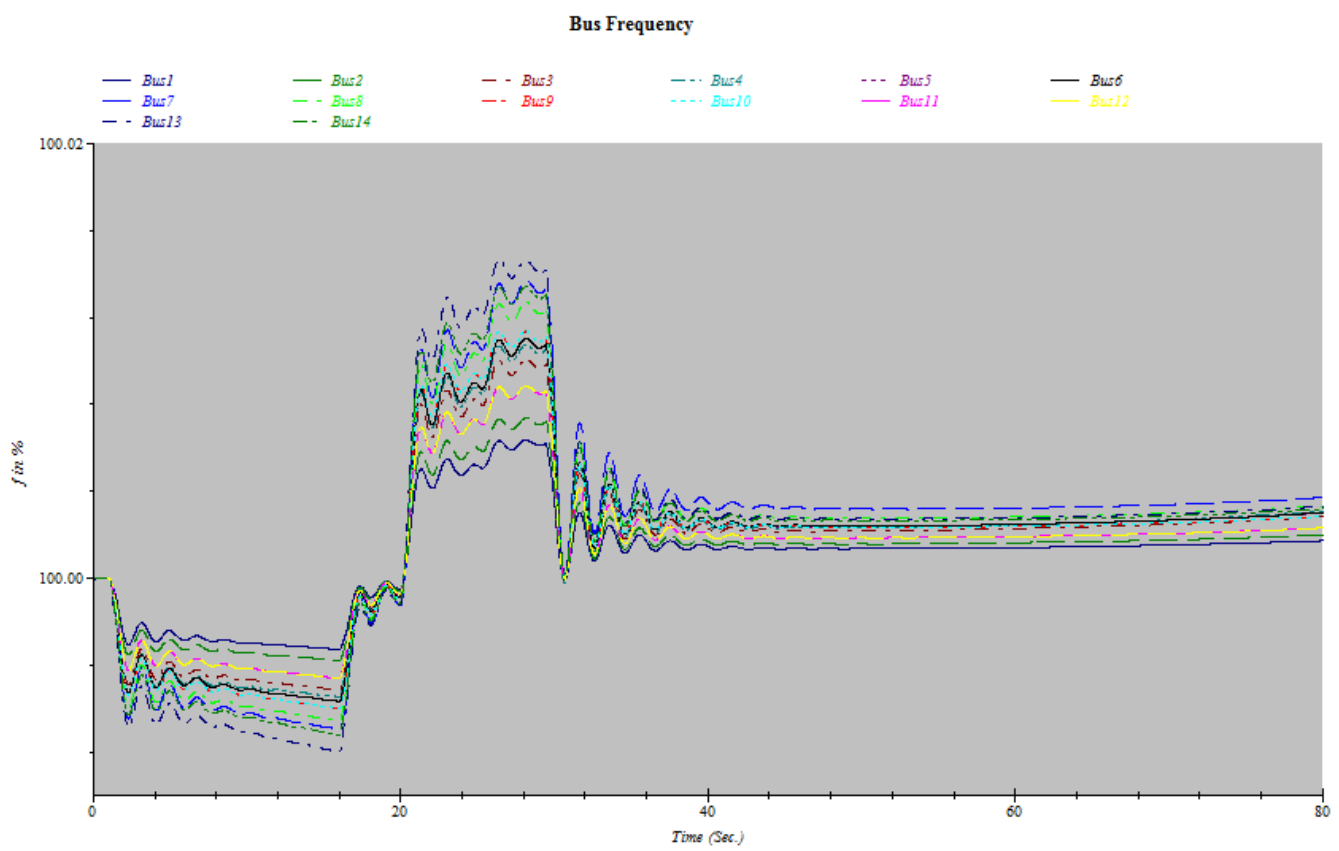

Figure 3-28: Bus Frequencies for Problematic Case 1

As expected, the addition of unnecessary generation results in overvoltage for many of the buses within the system. This could have been remedied somewhat by having the 
capacitors at the respective buses turn off for this period of time, or by having load-tap changing transformers at the most impacted buses. Despite the seemingly large voltage spikes, none of these warrant isolation from the grid.

The second problematic case is nearly the same as this first case. The change is in having more responsive oncoming generation. When the system realizes that the cloud coverage was only temporary it works to drop the oncoming generation back to its pre cloud cover levels. Figures 3-29 through 3-31 correspond to this case.

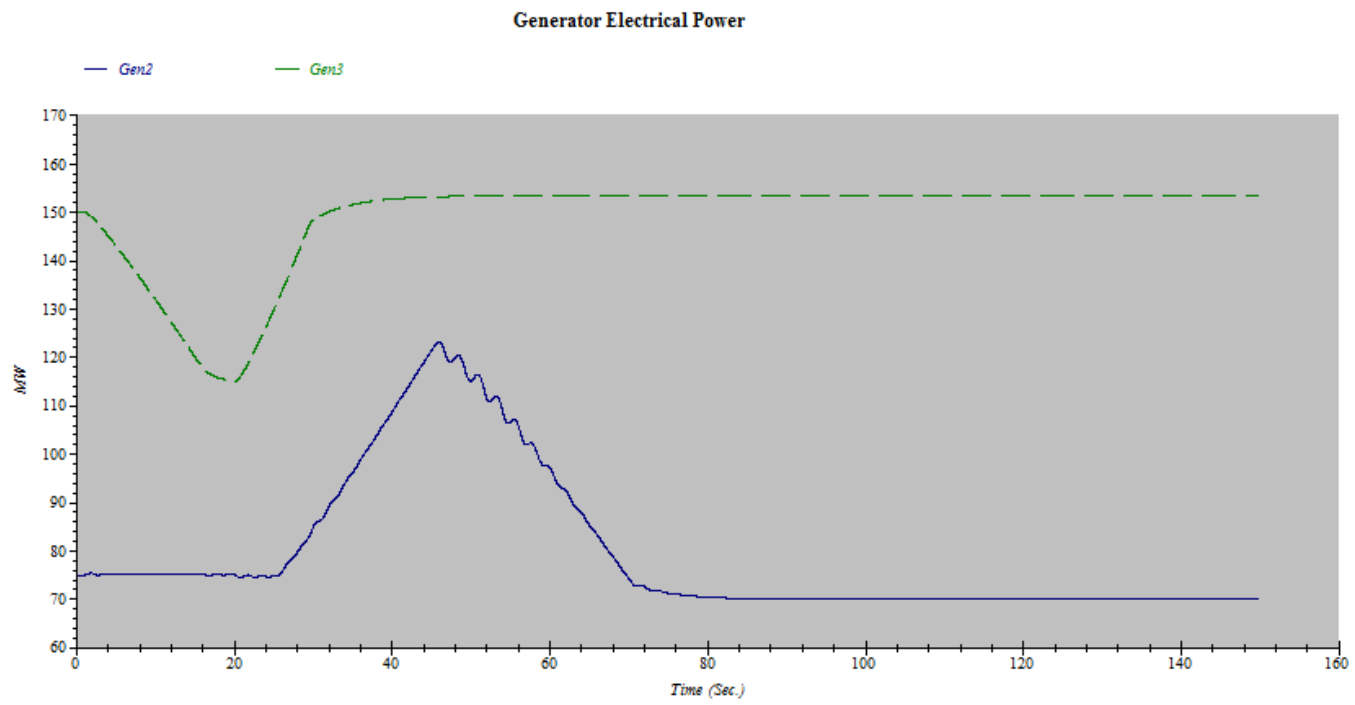

Figure 3-29: Power Generation Ramps for Problematic Case 2 


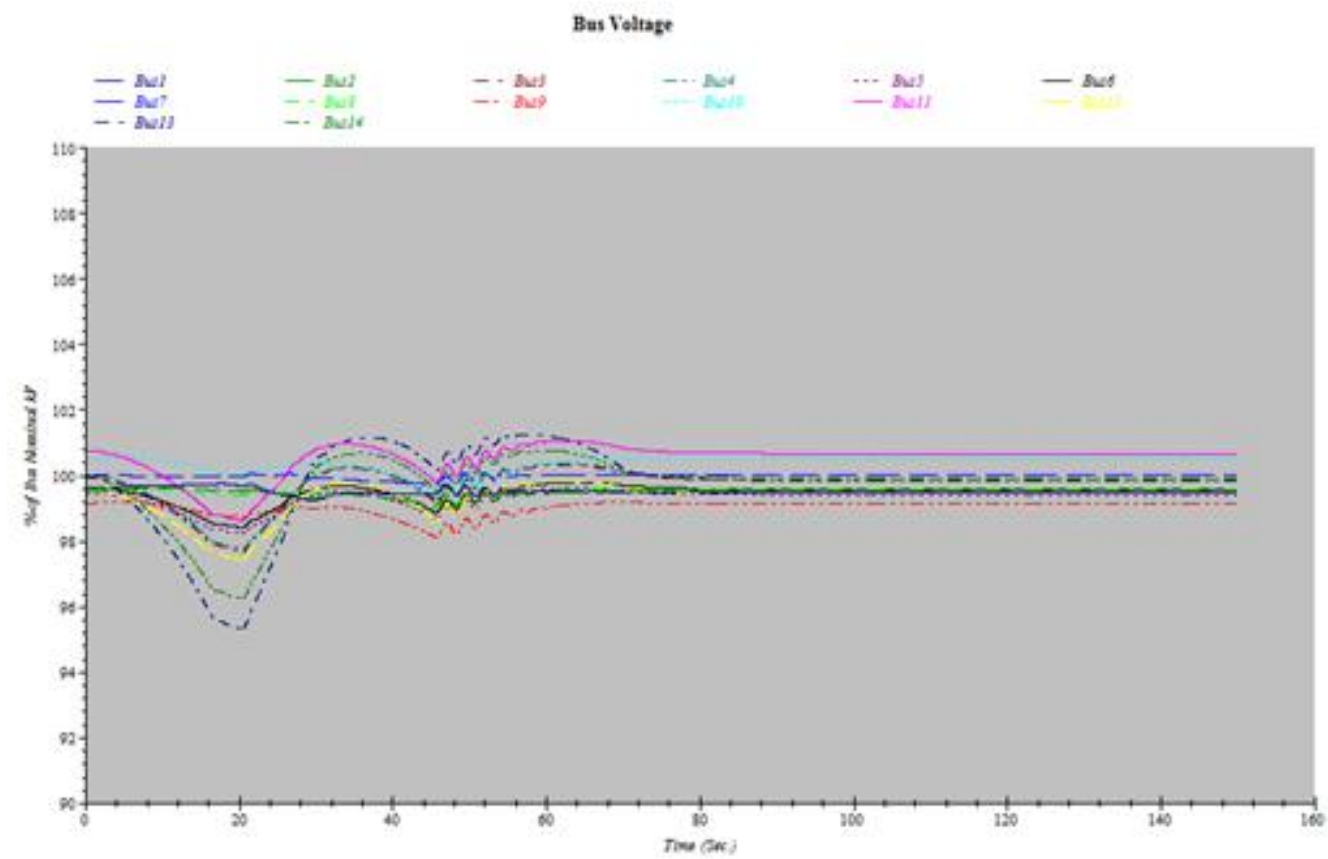

Figure 3-30: Bus Voltages for Problematic Case 2

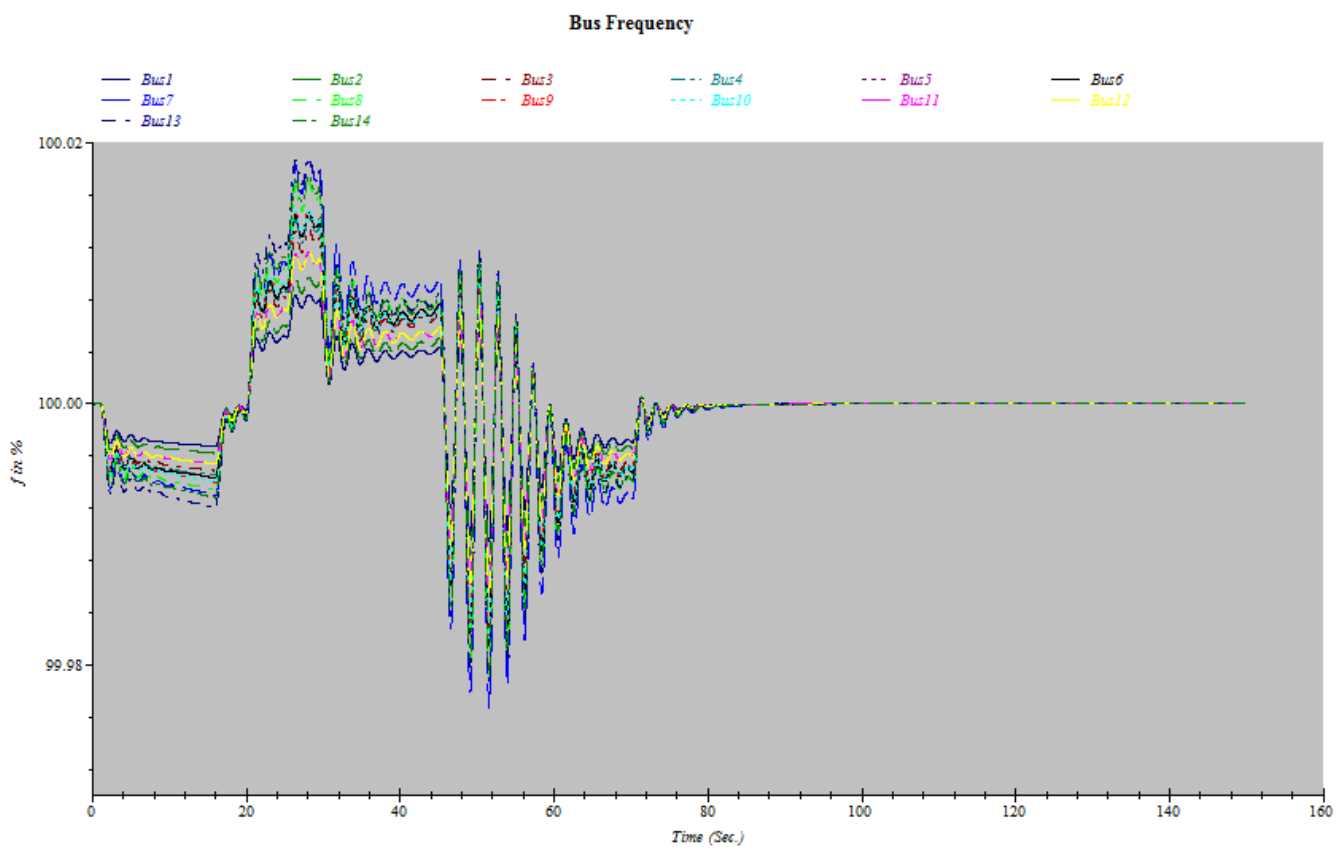

Figure 3-31: Bus Frequencies for Problematic Case 2 
The scenario results are much better than the previous study. For this case, the voltages and frequencies return to their nominal values in a much more expedient manner. Again, none of these disturbances warrant isolation from the power grid. 


\section{Chapter 4 : Economic Impacts}

The economics of near-term cloud location forecasting is not a simple case. There are at least three interested parties in the operation of PV plants. The first interested parties are PV plant operators seeking to get the best financial gain possible out of their large investment. The second interested parties are the utilities themselves. The utilities are most concerned with making sure that the negative impacts of renewable generation to their locale on the grid are kept to an absolute minimum. Similarly, the Independent System Operators (ISOs) are seeking to minimize the amount of uncertainty in the use of unpredictable renewable generation. For the ISOs, any removal of uncertainty is a costsaving effort as the amount of ancillary generation available at any time can be lowered.

\subsection{Potential Economic Benefits for Independent System Operators or PV Plant}

\section{Operators Based on More Adaptive Economics}

The largest economic challenge facing the renewable energy market is that the anticipated renewable energy forecasts have a high degree of variability compared to the total load forecasts which come much closer to anticipated targets. For this reason, some advantages for more accurate and timely renewable energy forecasting include: a better means to reduce operational uncertainty, a more efficient way to operate energy market and grid, and a reduction in need for regulating reserves or ancillary generation.

As mentioned earlier, the major driving forces behind renewable energy growth are politically passed legislation that determines how much renewable energy needs to be included in the mix of energy. In California this is known as a Renewable Portfolio Standard (RPS). In an effort to prepare themselves for the 33\% RPS that has been mandated for the year 2020 by AB32, Pacific Gas and Electric (PG\&E) has worked with 
the California Independent System Operators (CAISO) to study the many aspects of integrating new renewable energy generation [19]. The focus of the study was on PG\&E's Renewable Integration Model (RIM), a model used to improve the awareness of the associated constraints associated with the integration of renewable energy. Figures41 and 4-2 show the different scenarios that PG\&E chose to study using their RIM. In the year 2009, California utilities had an average of $15.4 \%$ renewable energy used in their energy mix [19].

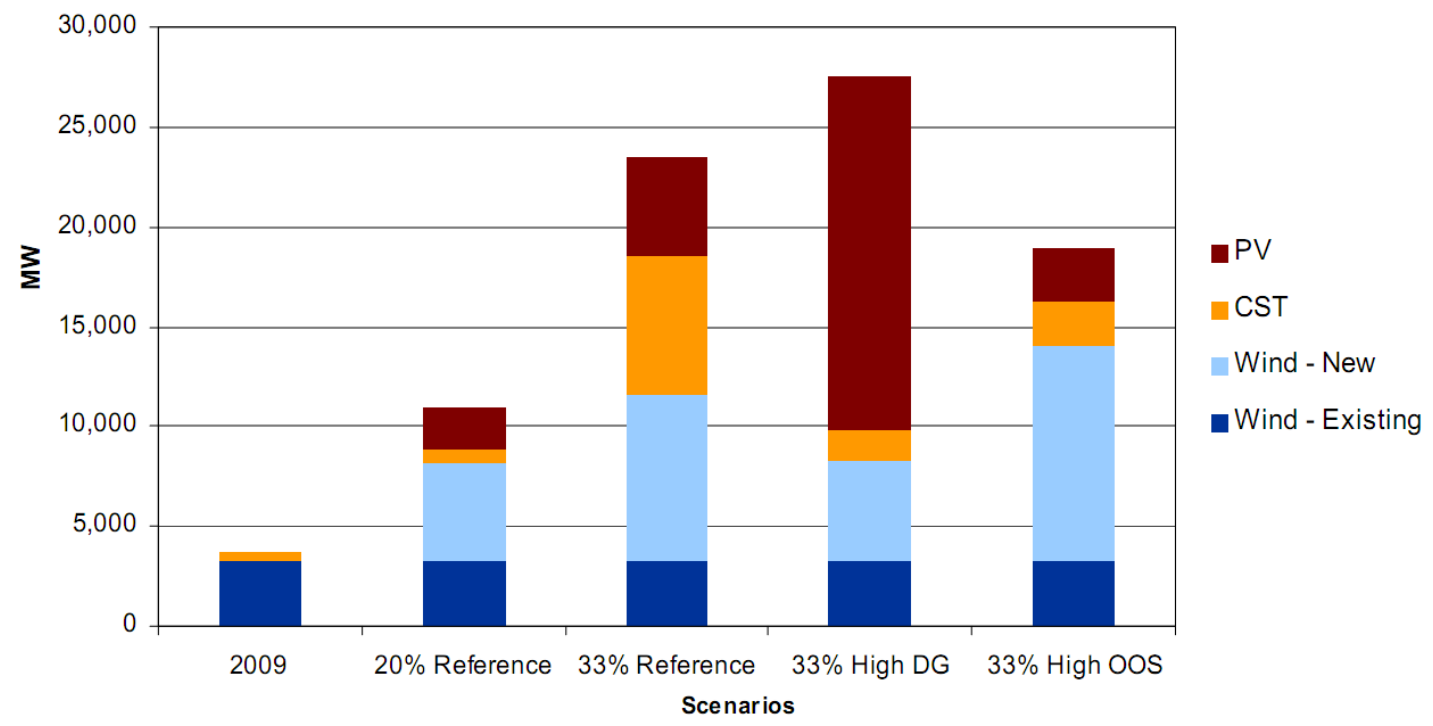

Figure 4-1: Scenarios for Intermittent Renewable Resource Generation [19] 


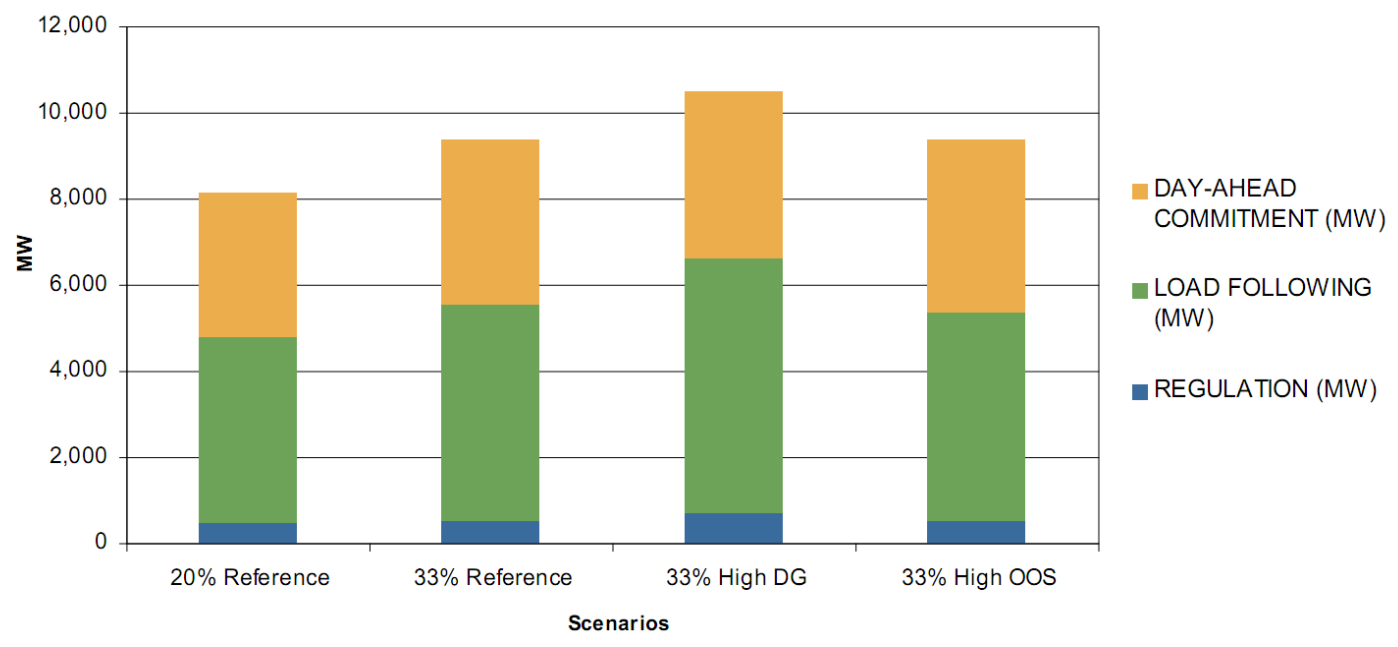

Figure 4-2: Operating Flexibility Requirements [19]

As Figure 4-1 shows, PG\&E looked at a few different options for meeting the $33 \%$ RPS. The reference includes a somewhat even distribution of new intermittent energy sources, while the high distributed generation allows for more PV. The final scenario looks into integrating large amount of out-of-state wind energy. Figure 4-2 can be assisted by Figure 4-3 in explaining the timescales involved with day-ahead commitment, load following, and load regulation. 


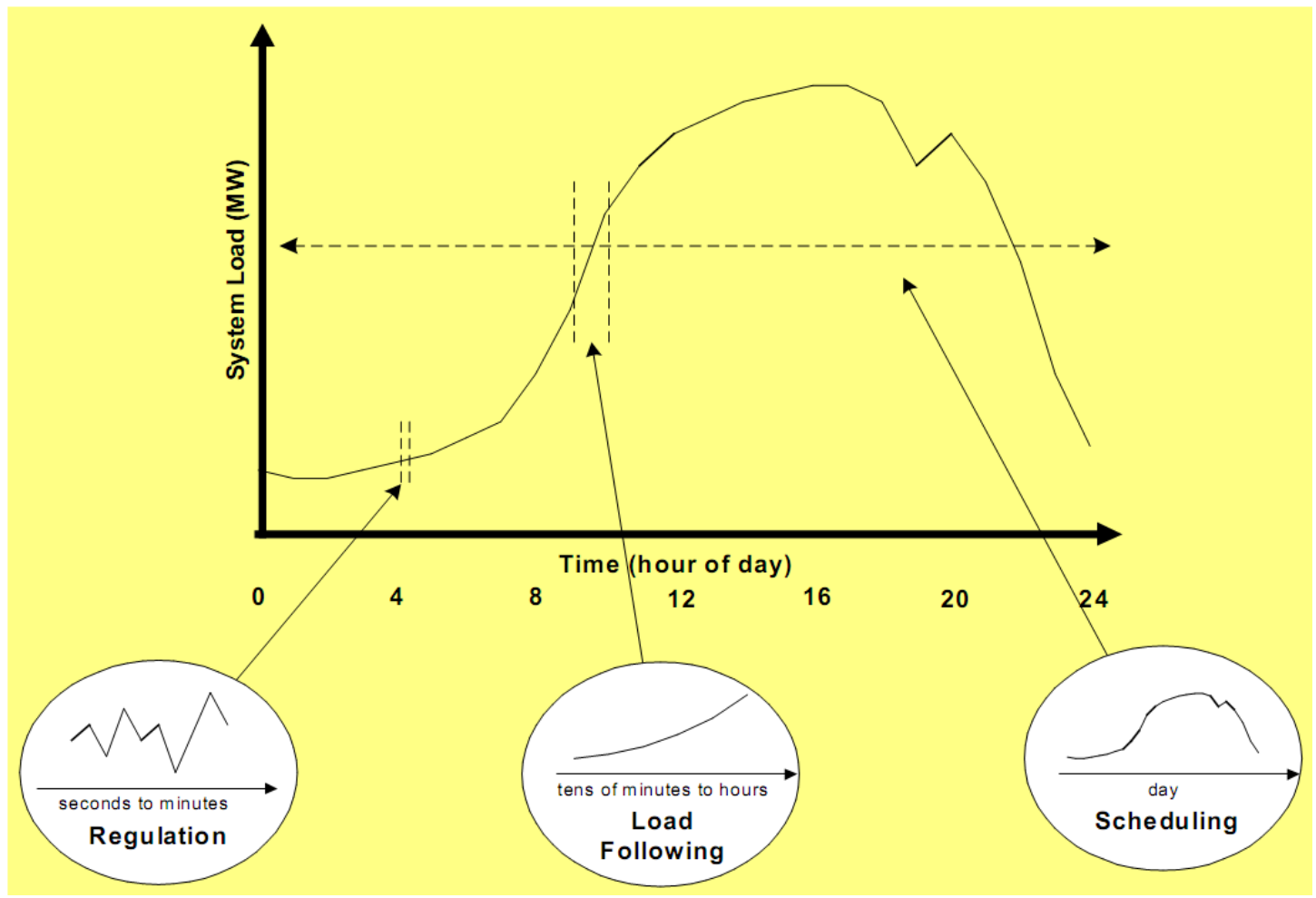

Figure 4-3: Time Scales Relevant to Operating Power Systems [4]

It can be seen that the amount of generation that is required to be available for load following is significant compared to the amount of generation that is scheduled a day in advance. The major reason for this is the inherent uncertainty in generation. The most significant need for load following and regulation needs comes for the case of high PV and distributed generation penetration. Any reduction in the uncertainty of predictions would result in a similar reduction of needs for ancillary generation or resources committed to load following and regulation.

A study by the National Renewable Energy Lab (NREL) on solar resource variability and forecasting done in Hawaii confirmed earlier assumptions that the best sources of information for sub-hourly forecasting were ground based observations, whether from radiometers or TSI. The models they used were either related to persistence of operating 
conditions using irradiance meters at select sites, or cloud-fraction based using TSI. The method used was similar to the previously discussed TSI based method used by UCSD. Moving to larger time frames they found that cloud motion vectors from satellites and Numerical Weather Prediction (NWP) models were more accurate due to the distances and wind profiles involved. The NREL found that for the sake of accurate forecast models both of these techniques, sub-hourly and hours-to-day, are necessary to accommodate minimized ancillary services for load following and regulation. Figure 4-4 shows one of their ground based irradiance meters, similar in design to the second proposed structure for insolation recordings discussed earlier in the chapter [20]. 


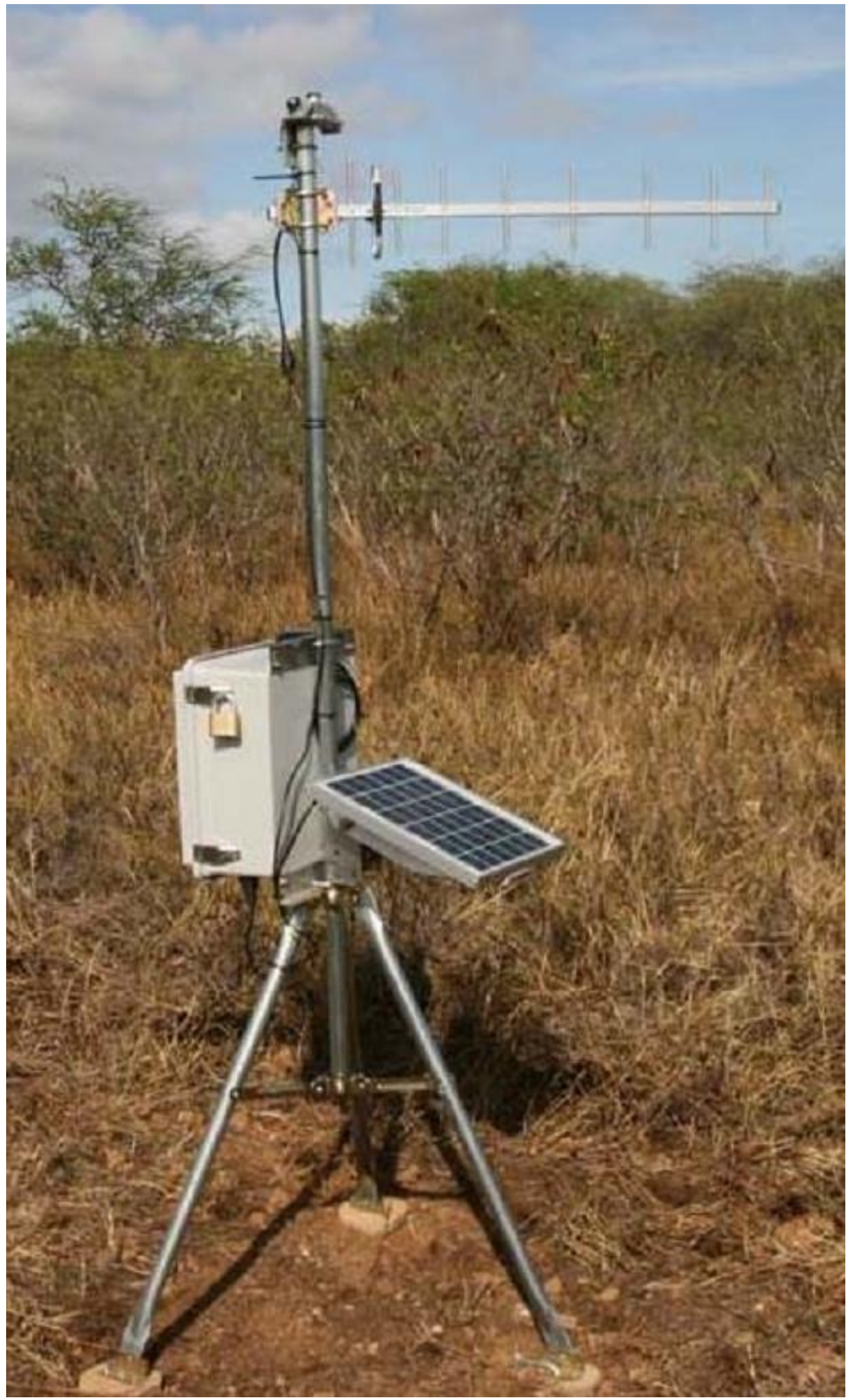

Figure 4-4: NREL Ground Based Sensor [20] 
Economically speaking, both variability and uncertainty increase the requirement for ancillary services. More accurate forecast models have a large effect on the uncertainty of renewable generation. Both variability and uncertainty are modeled with meansquared error or using standard deviations. The more accurate your forecast model is the smaller the error term becomes, lowering the requirements for ancillary services and the associated costs [21, 22, 23].

As both PV and wind are highly intermittent renewable energy sources, similarities in forecasting and ancillary services can be drawn. Unfortunately due to a larger installation base, as well as a higher number of in-depth forecasting studies, wind energy has been the recipient of more favorable ISO treatment. The CAISO, like all ISOs, schedules generation in advance. Like solar, wind energy production is typically deviates from the scheduled amount of production. In the early years of wind, the CAISO would impose large "grid-imbalance" fees upon wind generators due to this mismatch in generation and forecasted generation. Due to the stifling effects of these fees, investments in new wind energy facilities dwindled. Recently the CAISO implemented a new program to retool the payment schemes to accommodate the characteristics highly volatile wind energy production. These new tools allow for closer to-real-time, hourly, changes in predicted load with less economic downside to the wind energy producers. They have implemented this cost saving effort by requiring all new wind projects to install meters and share the costs associated with forecasting [24].

Table 4-1 shows just how helpful it is to be able to predict generation from hourahead rather than day ahead forecasts. 
Table 4-1: Average Wind Production Forecast Error [25]

\begin{tabular}{cccc}
$\begin{array}{c}\text { Forecast } \\
\text { Time Frame }\end{array}$ & Percentage Base & $\begin{array}{c}\text { Forecast Error } \\
\text { for a Single Plant }\end{array}$ & $\begin{array}{c}\text { Forecast Error } \\
\text { for a Region }\end{array}$ \\
\hline $\begin{array}{c}\text { Hour-Ahead } \\
\text { Forecast }\end{array}$ & Actual Output & $10-15 \%$ & $6-11 \%$ \\
Installed Capacity & $4-6 \%$ & $3-6 \%$ \\
$\begin{array}{c}\text { Day-Ahead } \\
\text { Hourly } \\
\text { Forecast }\end{array}$ & Actual Output & $25-30 \%$ & $15-18 \%$ \\
\hline \hline
\end{tabular}

Similarly, the CAISO has concluded that the hour-ahead forecasts have a significantly lower error compared to that of the day-ahead forecasts. That being said, wind and solar both are recipients of short duration changes that hour-ahead forecasting only helps so much. The CAISO is in the process of rolling out a 15 minute based persistence model to automatically accumulate multiple short term forecasts for use in intra-hour forecasts for wind energy [23].

Another potential solution to handling the variability of intermittent energy resources, though not cost-effective to any degree yet, is energy storage. The advantage of energy storage for handling of fluctuation of renewable energy is that it can be very responsive. Potential Energy Storage technologies and applications are shown in Table 4-2. 
Table 4-2: Energy Storage Technologies and Applications [26]

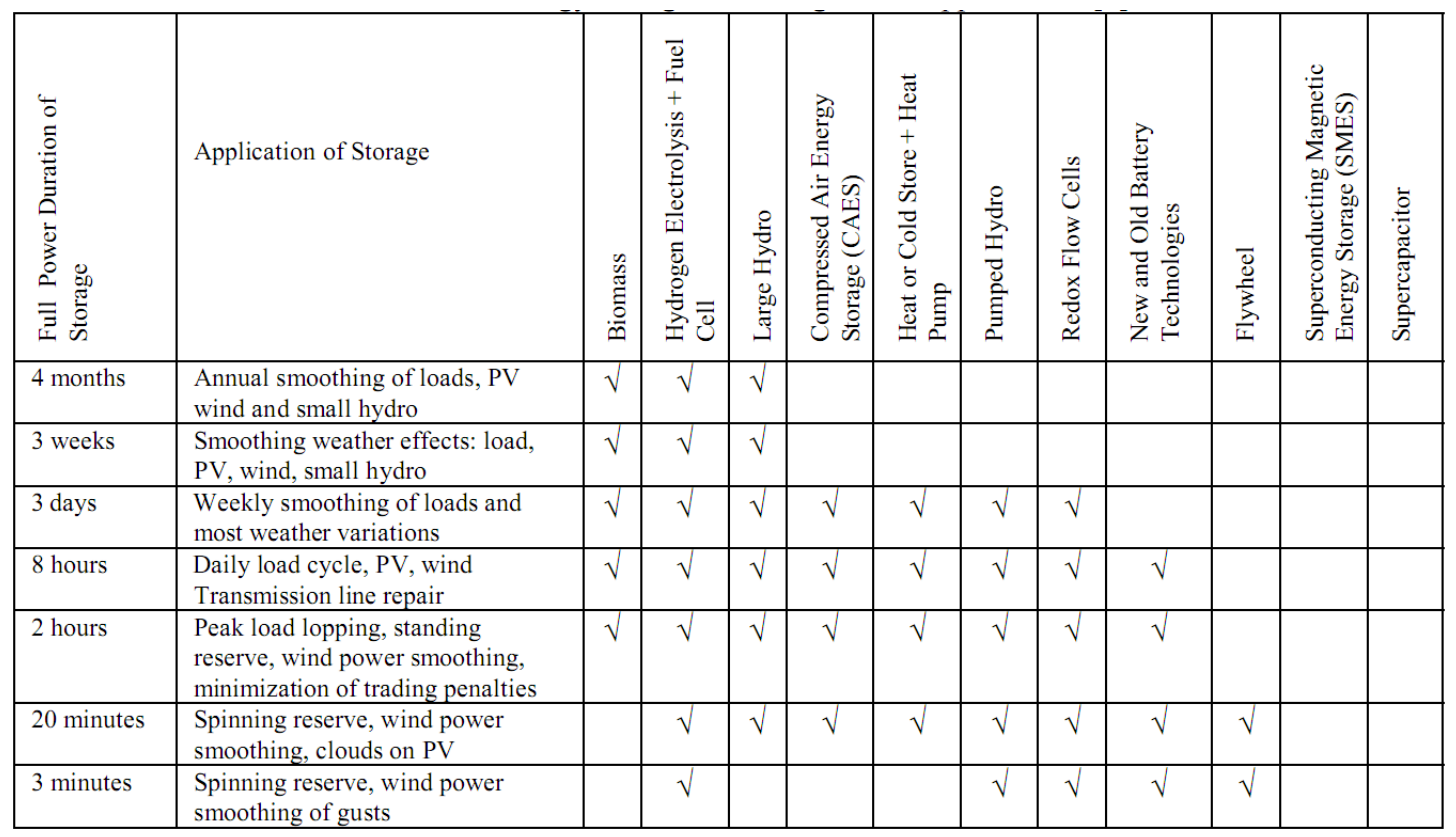

This table shows the many potential storage mediums that can be used for varying applications and time scales. It can be seen that the quickest responding mediums are fuel cells, pumped hydro, redox flow cells, batteries, and flywheels. The study of energy storage for suppressing fluctuations in renewable energy performed by the Pacific Northwest National Laboratory, determined that the benefits for energy storage are the fast response and improved regulation, as well as producing no carbon dioxide emissions. Unfortunately, due to the high associated costs, the power and energy capacity should be minimized to save high investment and capital costs [26]. Perhaps as new technologies emerge, and prices move downward, energy storage will be an economical regulation method for renewable energy. 


\section{Chapter 5 : Conclusion}

This thesis had a couple large objectives; to ascertain the benefits of near-term cloud location based forecasting and to look into the potential of ground based insolation meters to meet this challenge of near-term forecasting. Chapter 1 introduced the need for addressing and understanding the reliability and variability of renewable energy.

Chapter 2 provided a background on the effects of meteorological changes to PV generation. In addition it described the use of insolation meters or total sky imagers for forecasting cloud coverage, and the estimated costs for each solution. It was found that both ground based insolation meters and TSI are capable of providing enough information to be useful for forecasting future cloud based coverage. The limitations for close-to real-time forecasting included the time frame for forecasts, and level of resolution to be sought. The forecast time frame was limited by how far the sensors are from the corresponding facility. As the intended forecast period grows, the number of sensors required similarly increases. The level of resolution refers to what the maximum cloud coverage with respect to facility size is allowable without causing concern. As a higher resolution is required the spacing of the arrangement of solar sensors decreases, and hence the number of sensors increases. Both of these limitations have an effect on the number of sensors and thus the associated costs of such solutions. An advantage of TSI comes in the higher resolution due to the characteristics of photography. Since the device characterizes close to 3 miles of sky above it there is reduced uncertainty between the devices, and significantly fewer devices are required. TSI became a drastically cheaper option when looking at solutions for forecasting at the case-example of the future Topaz Solar Farm. It also showed that as facilities increased above 5MW, the investment 
made by the installers included significantly more spending for radar based weather stations. It is somewhere above this 5MW threshold that ground based metering whether image or insolation based starts to make sense.

Chapter 3 looked into detailed simulations of how close-to real-time forecast information could be used, and the effects it would have. It was found that the speed of cloud coverage had a larger effect on frequency stability than on voltage stability. Also, it was seen that even minimally delayed responses in ancillary generation produced significant voltage stability benefits.

Chapter 4 looked into the economic challenges facing the adoption of insolation metering or TSI solutions. It showed the economic challenges facing the wide-spread adoption of new renewable energy sources, as well as the benefits wind energy is reaping from its larger installation and research base. Unfortunately, aside from political incentives, for solar energy to become more attractive to investors and utilities, changes like shared cost-forecasting, and short interval output predictions, that are starting to occur within the wind energy infrastructure will need to also take place in the solar industry.

\subsection{Future Considerations and Recommendations}

This thesis opens up many avenues for continued studies relating to the near-term cloud location forecasting, as well as understanding and quantifying PV variability. Some future proposed studies directly relating to this thesis include, but are not limited to:

- Comparison of predicted and experienced solar production from a fully implemented fixed location insolation metering scheme. 
- An in-depth investigation of balancing generation and loads, and how sudden changes in irradiance can be handled.

- Investigation into the effects of catastrophic generation isolating events caused by frequency or voltage instability.

- Research focused on remediation and maintenance for localized power and voltage stability issues due to photovoltaic variability.

- There is a need to study and find more accurate models for cloud location forecasting, whether the information comes from satellites or ground based meters. This information will lead to the adoption of more favorable economic rules similar to those being implemented for wind energy. 


\section{Bibliography}

[1] California Air Resources Board. "Assembly Bill 32: Global Warming Solutions Act." (2006) http://www.arb.ca.gov/cc/ab32/ab32.htm (June 6, 2011).

[2] Office of the Governor. "EXECUTIVE ORDER S-14-08." (2008) http://www.drecp.org/documents/2008-11-17_Exec_Order_S-14-08.pdf (June 6, 2011).

[3] Recurrent Energy. "The San Francisco Sunset Reservoir Solar Project.” (2009) http://www.recurrentenergy.com/resources/sfsunset.php (January 21, 2011).

[4] Mills, A., Ahlstrom, M., Brower, M., Ellis, A., George, R., Hoff, T., Kroposki, B., Lenox, C., Miller, N., Stein, J., Wan, Y.. "Understanding Variability and Uncertainty of Photovoltaics for Integration with the Electric Power System." Ernst Orlando Lawrence Berkley National Laboratory: Environmental Energy Technologies Division, December 2009.

[5] Messenger, Roger, et al. Photovoltaic Systems Engineering. Boca Raton: CRC Press, 2010. Print.

[6] Rohde, Robert. "Solar Spectrum." (2007) http://www.globalwarmingart.com/wiki/File:Solar_Spectrum_png (May 1, 2011).

[7] Glossary of Meteorology, AMS. "Cloud." http://amsglossary.allenpress.com/glossary/search?id=cloud1 (May 5, 2011).

[8] Hostetter, John (REC Solar). "Cal Poly Masters Thesis Related Inquiry." Email to Tim Rudd. 25 May 2011.

[9] Hobby Boards: Complete 1-Wire Solutions. "Solar Radiation Detector." http://www.hobbyboards.com/catalog/product_info.php?cPath=22\&products_id=82 (January 20, 2011).

[10] Automation X: Automation Made Simple. "Main Store." http://www.automationX.com/Automation-X-Home (March 15, 2011).

[11] Kleissl, J., Huang, R.

"Using a Sky Imager to Forecast Cloud Motion in Order to Efficiently Control Ph otovoltaic Systems." University of California San Diego: CalIT2 Project, Summer 2010.

[12] Chow, C., Urquhart, B., Lave, M., Kleissl, J., Shields, J.. "Intra-hour Forecasting With a Total Sky Imager at the UC San Diego Solar Energy Testbed." University of California San Diego, Department of Mechanical and Aerospace Engineering, November 2010.

[13] Climate Research Facility, US Department of Energy. "Instrument: Total Sky Imager." http://www.arm.gov/instruments/tsi (May 17, 2011).

[14] Yankee Environmental Systems. "TSI-440." http://www.yesinc.com/products/data/tsi440/index.html (January 20, 2011).

[15] Nelson, Joel. (2010) "Effects of Cloud-Induced Photovoltaic Power Transients on Power System Protection.” Master's Thesis. California Polytechnic State University.

[16] Morse, Lisa. "First Solar Agrees to Acquire Multi Gigawatt Utility Scale Photovoltaic Pipeline." (2009) 
http://investor.firstsolar.com/phoenix.zhtml?c=201491\&p=irolnewsArticle \&ID=1261676\&highlight=topaz (May 5, 2011).

[17] ETAP Knowledge Base. "Simulating a PV Array with MPPT Inverter." (2010). Operation Technology, Inc.

[18] Farret, Felix, and Simoes, M. Integration of Alternative Sources of Energy. New Jersey: IEEE Press, 2006. Print.

[19] Middlekauff, Charles. "Notice of Availability of Pacific Gas and Electric Company's Renewable Integration Model and Results." Pacific Gas and Electric Company, August 2010.

[20] Renne, D., George, R., Sengupta, M. "Recent Advances in Solar Resource Variability and Forecasting." National Renewable Energy Laboratory, November 2010.

[21] Patwa, Daidipya (PG\&E). "RE: Masters Thesis Related Inquiry." Email to Timothy Rudd. 10 May 2011.

[22] Gul, T., Stenzel, T. "Variability of Wind Power and Other Renwables: Management Options and Strategies." International Energy Agency, June 2005.

[23] Kehler, J., Hu, M., McMullen, M., Blatchford, J. "ISO Perspective and Experience with Integrating Wind Power Forecasts into Operations." Electric Reliability Council of Texas, April 2010.

[24] Asmus, Peter. "Introduction to Energy in California." Berkeley, CA: University Press, 2009. Print.

[25] Liang, J., Grijalva, S., Harley, R. "Increased Wind Revenue and System Security by Trading Wind Power in Energy and Regulation Reserve Markets." IEEE and National Science Foundation, USA, January 2011.

[26] Makarov, Y., Kintner-Mayer, M., Jin, C., Illian, H. "Optimal Size of Energy Storage to Accommodate High Penetration of Renewable Resources in WECC System." Pacific Northwest National Laboratory: Energy Science and Technology Division, July 2010. 
Appendix A : 1-Wire DataSheet

\section{DALLAS}

\section{$M / X I M$}

S2438

\section{wuw.maxim-ic.com}

FEATURES

- Unique $1 . \mathrm{Wire}^{\mathrm{v}}$ interface requires only one port pin for communication

- Provides unique 64-bit serial number

- Eliminates thermistors by sensing battery temperature on-chip

- On-board AV converter allaws monitoring of hattery voltage for end-of charge and end. of-discharge determination

- On-board integrated current accumulator facilitates fuel gauging

- Elapsed time meter in binary format

- 40-byte nonvolatile user memory available for storage of bantery-specific data

- Reverts to low-power sleep mode on battery pack disconnect (feature disabled on DS2438AZ)

- Operating range $-40^{\circ} \mathrm{C}$ to $+85^{\circ} \mathrm{C}$

- Applications include portable computers, portable/cellular phones, consumer electronics, and handheld instrumentation

\section{PIN ASSIGNMENT}

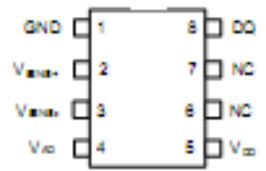

DS243日Z, DS2 439AZ

BPin SOIC (150.mil)

\section{PIN DESCRIPTION}

DQ - Data In/Out

VAD - General A/D input

$V_{\text {SEVs- - Battery current monitor input }(+)}$

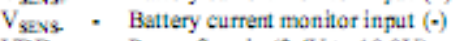

VDD - Power Supply (2.4V to 10.0V)

GND - Ground

NC - No connect

\section{DESCRIPTION}

The DS2438 Smart Battery Monitor provides several funcions that are desirable to carry in a battery pack: a means of tagging a battery pack with a unique serial number, a dired-10-digital temperature sensor which eliminales the need for thermistors in the battery pack, an $A / D$ converter which measures the battery voltage and current, an integrated current accumulator which keeps a running total of all current going into and out of the battery, an elapsed time meter, and 40 byles of nonvolatile EEPROM memory for storage of important parameters such as battery chemistry, battery capacity, charging methodology and assembly date. Information is sent to/from the DS2438 over a 1.Wire interface, so that only one wire (and ground) needs to be connected from a central microprocessor to a DS2438. This means that battery packs need only have three output connectors: battery power, ground, and the 1-Wire interface.

Because each DS2438 contains a unique silicon serial number, multiple DS2438s can exist on the same $1-$ Wire bus. This allows multiple battery packs to be charged or used in the system simultanecusly.

Applications for the smart bantery monior include portable computers, cellular telephones, and handheld insirumentation battery packs in which it is critical to monitor real-time battery performance. Used in conjunction with a microcontroller in the host system, the DS2438 provides a complete smart battery pack solution that is fully chemistry-independent. The customization for a particular battery chemistry and capacity is realized in the code programmed into the microcontroller and DS2438 EEPROM, and only a software revision is necessary should a designer wish to change battery pack chemistry. 


\section{Appendix B : Hobby-Boards Solar Radiation Detector Schematic}

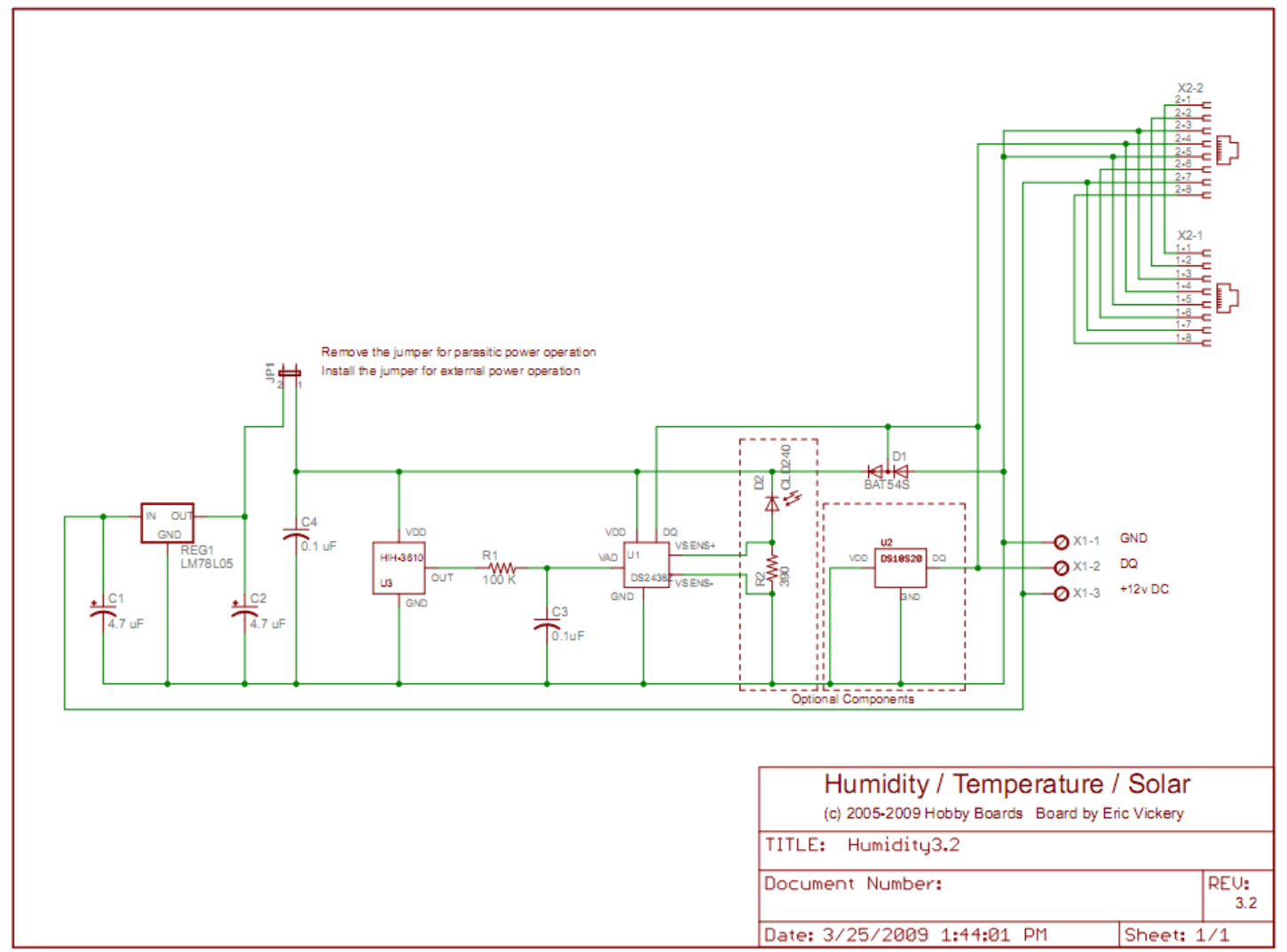




\section{Appendix C : Raw Measurements from Insolation Meter}

Table C-1 : Insolation Readings Taken on 5/16 at 1pm

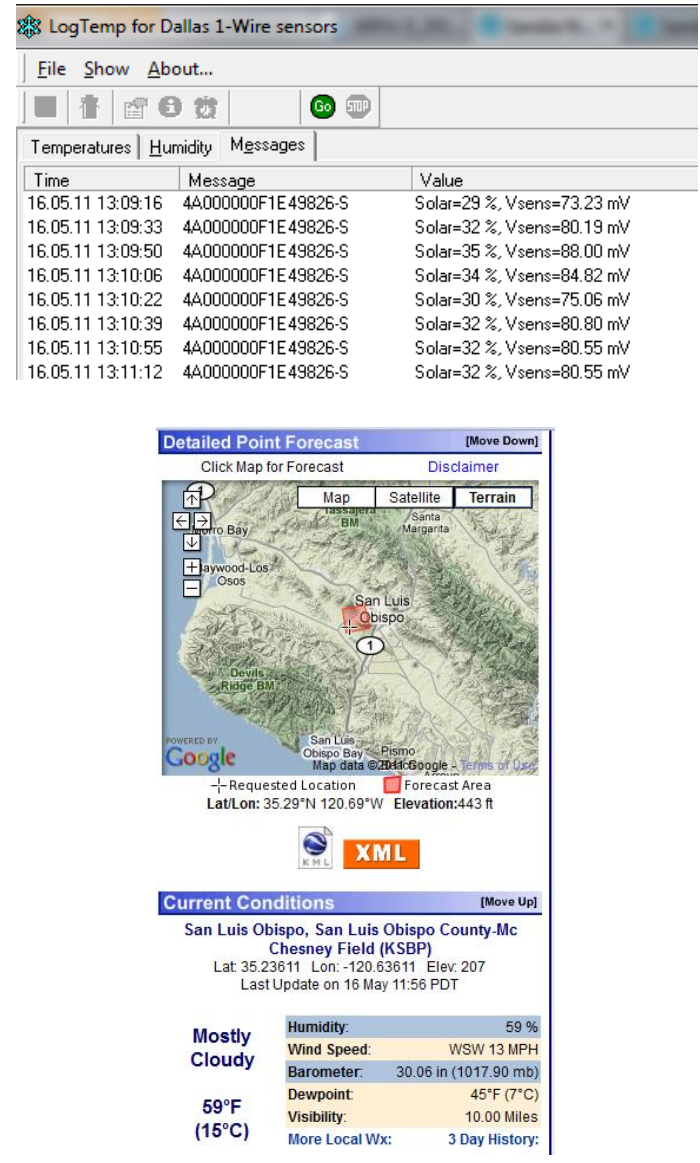

Figure C-1: Weather Conditions on 5/16 
Table C-2: Insolation Readings Taken on 5/17 at 1pm

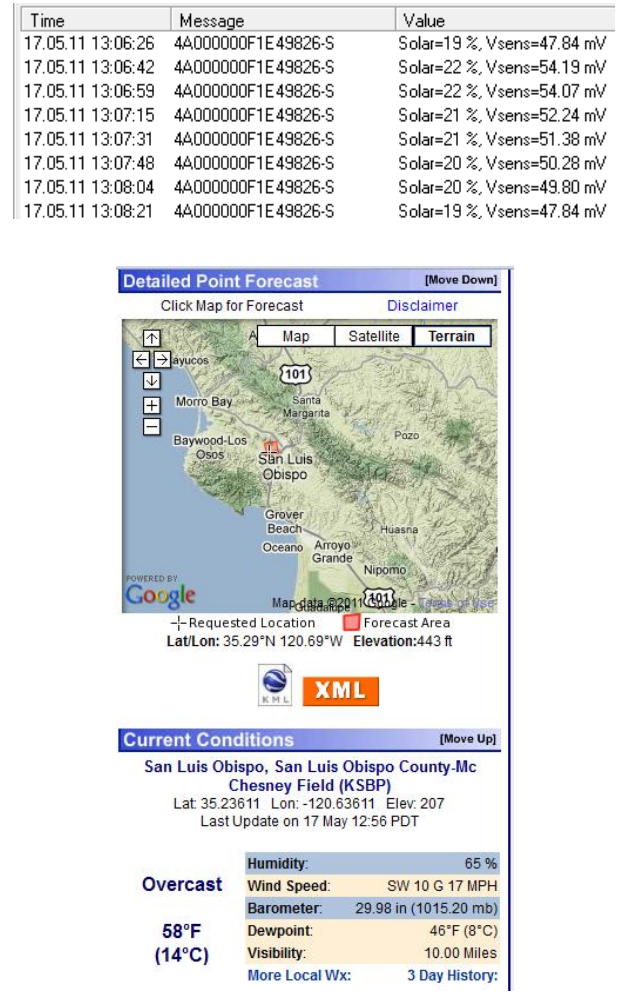

Figure C-2: Weather Conditions on 5/17 
Table C-3: Insolation Readings Taken on 5/18 (1 of 3)

\begin{tabular}{|c|c|c|}
\hline & & \\
\hline $111305-10$ & 8826-S & $\mathrm{m}=73 \%$, $V_{\text {sens }}=181.49 \mathrm{mV}$ \\
\hline 05.11 13:06:26 & 4A000000F1E $49826-\mathrm{S}$ & Solar $=85 \%, V_{\text {sens }}=211.76 \mathrm{mV}$ \\
\hline $05.1113: 06: 42$ & $44000000 F 1 E 49826-S$ & Solar $=59 \%, V_{\text {sens }}=146.70 \mathrm{mV}$ \\
\hline $05.1113: 06: 59$ & 4A.000000F1E49826-S & Solar $=46 \%$, V sens $=115.09 \mathrm{mV}$ \\
\hline $05.1113: 07: 15$ & 44.000000F1E49826-S & 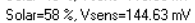 \\
\hline 18.05.11 13:07:32 & 44.000000F1E49826-S & Solar $=73 \%$, V sens $=182.59 \mathrm{mv}$ \\
\hline 18.05.11 13:07:48 & $44000000 F 1 E 49826-S$ & Solar $=79 \%$, Vsens $=198.45 \mathrm{mv}$ \\
\hline 18.05.11 13:08:05 & 440000000F1E $49826-\mathrm{S}$ & Solar $=45 \%, V_{\text {sens }}=112.77 \mathrm{~m}$ V \\
\hline 18.05.11 13:08:21 & 440000000F1E49826-S & Solat $=80 \%$, Vsens $=200.89 \mathrm{mV}$ \\
\hline $1113: 08: 37$ & 44000000F1E $49826-\mathrm{S}$ & Solar $=89 \%$, Vsens $=223.72 \mathrm{mV}$ \\
\hline 05.11 13:08:54 & $=1 E 49826-S$ & 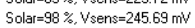 \\
\hline 18.05.11 13:09:11 & 44000000F1E $49826-\mathrm{S}$ & 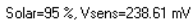 \\
\hline 18.05.11 13:09:27 & 44.000000F1E49826-S & Solar $=96 \%$, V $V_{\text {sens }}=239.22 \mathrm{mv}$ \\
\hline 18.05.11 13:09:43 & $1 E 49826-\mathrm{S}$ & olar=86\%, Vsens $=214.56 \mathrm{~m}$ V \\
\hline $10: 00$ & & ala $=96 \%$ V Vens $=240.93 \mathrm{~m}$ V \\
\hline 18.05.11 13:10:16 & $44,000000 F 1 E 49826-\mathrm{S}$ & Solat $=95 \%$, V Vens $=236.65 \mathrm{~m} /$ \\
\hline 18.05.11 13:10:33 & 44.000000F1E $49826-\mathrm{S}$ & Solar $=97 \%, V_{\text {sens }}=241.90 \mathrm{mV}$ \\
\hline 18.05.11 13:10:49 & F1E $49826-S$ & Solat $=95 \%$ V Vens $=238.24 \mathrm{mV}$ \\
\hline & & 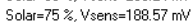 \\
\hline 18.05.11 13:11:22 & $=49826-\mathrm{S}$ & Solar $=67 \%$, V $V_{\text {sens }}=166.72 \mathrm{mV}$ \\
\hline 18.05.11 13:11:38 & E49826-S & Solar $=63 \%$, $V_{\text {sens }}=157.81 \mathrm{mV}$ \\
\hline 18.05.11 13:11:55 & E 49826-S & Solat $=0 \%, V_{\text {sens }}=0.00 \mathrm{mV}$ \\
\hline 13:12:11 & 4A,000000F 1 E $49826-\mathrm{S}$ & Solat $=0 \%, V_{\text {sens }}=0.00 \mathrm{~m} V$ \\
\hline 13:12:28 & & Solar $=77 \%$ V Vens $=192.35$ \\
\hline 18.05.11 13:12:44 & 440 & Solat $=85 \%$ V V \\
\hline 18.05.11 13:13:00 & 440 & Solar $=84 \%, V_{\text {sens }}=210.17 \mathrm{mV}$ \\
\hline 18.05.11 13:13:17 & 4A.000000F1E49826-S & Solar $=91 \%$, V $V_{\text {sens }}=226.40 \mathrm{mV}$ \\
\hline 13:13:33 & F1E $49826-\mathrm{S}$ & Solar $=85 \%$, V sens $=211.88 \mathrm{mV}$ \\
\hline 13:13:50 & & . \\
\hline 18.05.11 13:14:06 & 440,0 & Solar $=53 \%$ V Y sens $=133$. \\
\hline 18.05.11 13:14:22 & 44.000000F1E49826-S & Solar $=31 \%$, V sens $=77.75 \mathrm{mV}$ \\
\hline & OFIE $49826-5$ & Solar $=58 \%$, V sens $=144.02 \mathrm{mV}$ \\
\hline & & $a=43 \%$ \\
\hline
\end{tabular}

Table C-4: Insolation Readings Taken on 5/18 (2 of 3)

\begin{tabular}{|c|c|c|}
\hline Time & Message & Value \\
\hline $18.05 .1113: 14: 55$ & 4A,000000F1E $49826-\mathrm{S}$ & Solar $=43 \%, V_{\text {sens }}=107.65 \mathrm{mV}$ \\
\hline 18.05.11 13:15:12 & 4A,000000F1E $49826-\mathrm{S}$ & Solar $=70 \%$ V Vens $=175.63 \mathrm{mV}$ \\
\hline 18.05.11 13:15:28 & 4A,000000F1E $49826-S$ & Solar $=41 \%, V$ sens $=103.74 \mathrm{mV}$ \\
\hline 18.05.11 13:15:45 & 4A.000000F 1 E $49826-5$ & Solat $=46 \%, V_{\text {sens }}=114.73 \mathrm{mV}$ \\
\hline 18.05.11 13:16:01 & 44,000000F1E49826-S & Solar $=52 \%, V_{\text {sens }}=129.01 \mathrm{mV}$ \\
\hline 18.05.11 13:16:17 & 4A,000000F1E $49826-\mathrm{S}$ & Solar $=45 \%, V_{\text {sens }}=112.04 \mathrm{mV}$ \\
\hline 18.05.11 13:16:34 & 4A0000000F1E $49826-S$ & Solar $=52 \%, V_{\text {sens }}=129.01 \mathrm{mV}$ \\
\hline 18.05.11 13:16:50 & 4A,000000F1E $49826-\mathrm{S}$ & Solar $=39 \%, V_{\text {sens }}=97.52 \mathrm{mV}$ \\
\hline 18.05.11 13:17:07 & 4A,000000F1E $49826-S$ & Solar $=37 \%, V_{\text {sens }}=92.64 \mathrm{mV}$ \\
\hline 18.05.11 13:17:23 & 4A,000000F1E $49826-S$ & Solar $=33 \%, V_{\text {sens }}=81.65 \mathrm{mV}$ \\
\hline 18.05.11 13:17:40 & 4A0000000F1E $49826-\mathrm{S}$ & Solar $=27 \%$ V V sens $=68.10 \mathrm{mV}$ \\
\hline 18.05.11 13:17:56 & 4A,000000F1E $49826-S$ & Solar $=26 \%$, Vsens $=64.44 \mathrm{mV}$ \\
\hline 18.05.11 13:18:12 & 4A0000000F1E $49826-\mathrm{S}$ & Solar $=27 \%$, V sens $=66.27 \mathrm{mV}$ \\
\hline 18.05.11 13:18:29 & 4A,000000F1E $49826-S$ & Solar $=27 \%, V_{\text {sens }}=66.64 \mathrm{mV}$ \\
\hline 18.05.11 13:18:45 & 4A0000000F1E $49826-S$ & Solar $=25 \%, V_{\text {sens }}=63.47 \mathrm{mV}$ \\
\hline 18.05.11 13:19:02 & 4A,000000F1E $49826-\mathrm{S}$ & Solar $=25 \%, V_{\text {sens }}=62.00 \mathrm{mV}$ \\
\hline 18.05.11 13:19:18 & 4A,000000F1E $49826-5$ & Solar $=24 \%, V_{\text {sens }}=60.05 \mathrm{mV}$ \\
\hline 18.05.11 13:19:34 & 4A.000000F 1 E $49826-\mathrm{S}$ & Solat $=24 \%, V_{\text {sens }}=60.05 \mathrm{mV}$ \\
\hline 18.05.11 13:19:51 & 4A0000000F1E $49826-S$ & Solar $=25 \%, V_{\text {sens }}=61.88 \mathrm{mV}$ \\
\hline 18.05.11 13:20:07 & 4A,000000F1E $49826-\mathrm{S}$ & Solar $=25 \%, V_{\text {sens }}=63.22 \mathrm{mV}$ \\
\hline 18.05.11 13:20:24 & 4A0000000F1E $49826-5$ & Solar $=26 \%, V_{\text {sens }}=65.30 \mathrm{mV}$ \\
\hline 18.05.11 13:20:40 & 4A.000000F1E $49826-\mathrm{S}$ & Solar $=27 \%, V_{\text {sens }}=66.64 \mathrm{mV}$ \\
\hline 18.05.11 13:20:57 & 4A0000000F $1 E 49826-5$ & Solar $=27 \%$ V Vens $=67.86 \mathrm{mV}$ \\
\hline 18.05.11 13:21:13 & 4A,000000F1E $49826-S$ & Solar $=28 \%, V_{\text {sens }}=69.20 \mathrm{mV}$ \\
\hline $18.05 .1113: 21: 29$ & 4A,000000F1E $49826-5$ & Solar $=29 \%, V_{\text {sens }}=71.28 \mathrm{mV}$ \\
\hline 18.05.11 13:21:46 & 4A,000000F1E $49826-\mathrm{S}$ & Solar $=30 \%, V_{\text {sens }}=76.16 \mathrm{mV}$ \\
\hline 18.05.11 13:22:02 & 4A.000000F1E $49826-5$ & Solar $=32 \%$ V Vens $=80.43 \mathrm{mV}$ \\
\hline 18.05.11 13:22:19 & 4A,000000F1E $49826-\mathrm{S}$ & Solar $=34 \%$, V sens $=84.58 \mathrm{mV}$ \\
\hline 18.05.11 13:22:35 & 4A,000000F1E $49826-S$ & Solar $=36 \%$ V $V_{\text {sens }}=89.83 \mathrm{mV}$ \\
\hline 18.05.11 13:22:52 & 4A,000000F1E49826-S & Solar $=36 \%$ V Vens $=90.81 \mathrm{mV}$ \\
\hline 18.05 .11 & 4A.0000000F1E $49826-5$ & Solar $=36 \%$ V Vsens $=90.44 \mathrm{mV}$ \\
\hline 18.05.11 13:23:24 & 4A,000000F1E49826-S & Solar $=35 \%$, V sens $=88.73 \mathrm{mV}$ \\
\hline 18.05.11 13:23:41 & 4A,000000F1E $49826-5$ & Solar $=36 \%, V_{\text {sens }}=90.32 \mathrm{mV}$ \\
\hline
\end{tabular}

Table C-5: Insolation Readings Taken on 5/18 (3 of 3) 

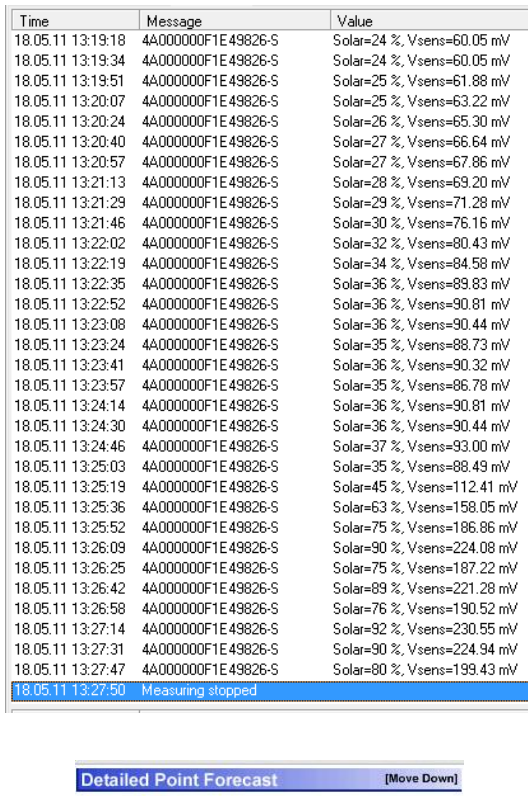

Click Map for Forecast Disclaimer

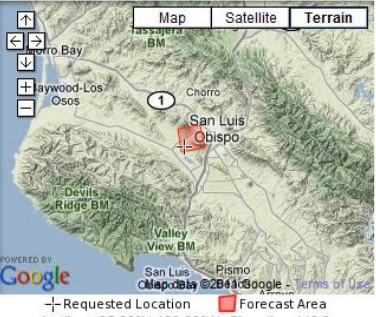

I- Requested Location $\square$ Forecast Area
LatLlon: $3529^{\circ} \mathrm{N} 120.69^{\circ} \mathrm{W}$ Elevation:443

8 $\mathrm{XML}$

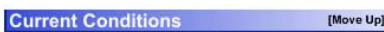

San Luis Obispo, San Luis Obispo County-Mc

Chesney Field (KSBP)
Lat. 35.23611 Lon: - 120.63611 Elev: 207
Last Update on 18 May 13:03 PDT

Mostly Cloudy Humidity: $\quad 63 \%$

$61^{\circ} \mathrm{F} \quad$ Barometer. 29.87 in (N/A mb)

$\begin{array}{rlr}\left(16^{\circ} \mathrm{C}\right) & \text { Dewpoint: } & 48^{\circ} \mathrm{F}\left(9^{\circ} \mathrm{C}\right) \\ & \text { Visibility: } & 10.00 \text { Miles }\end{array}$

More Local Wx: 3 Day History:

Figure C-3: Weather Conditions on 5/18 
Table C-6: Insolation Readings Taken Morning of 5/21

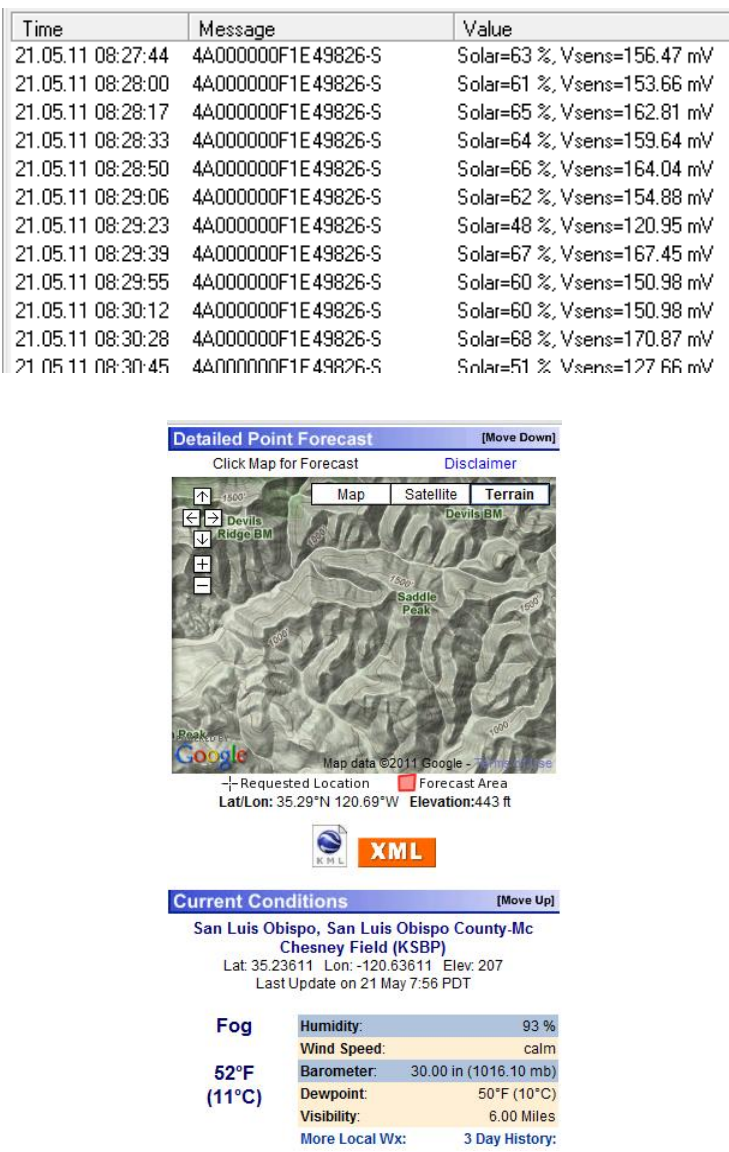

Figure C-4: Weather Conditions on 5/21 (Note Fog Had Already Burned Off) 
Table C-7: Insolation Readings Taken Evening of 5/24

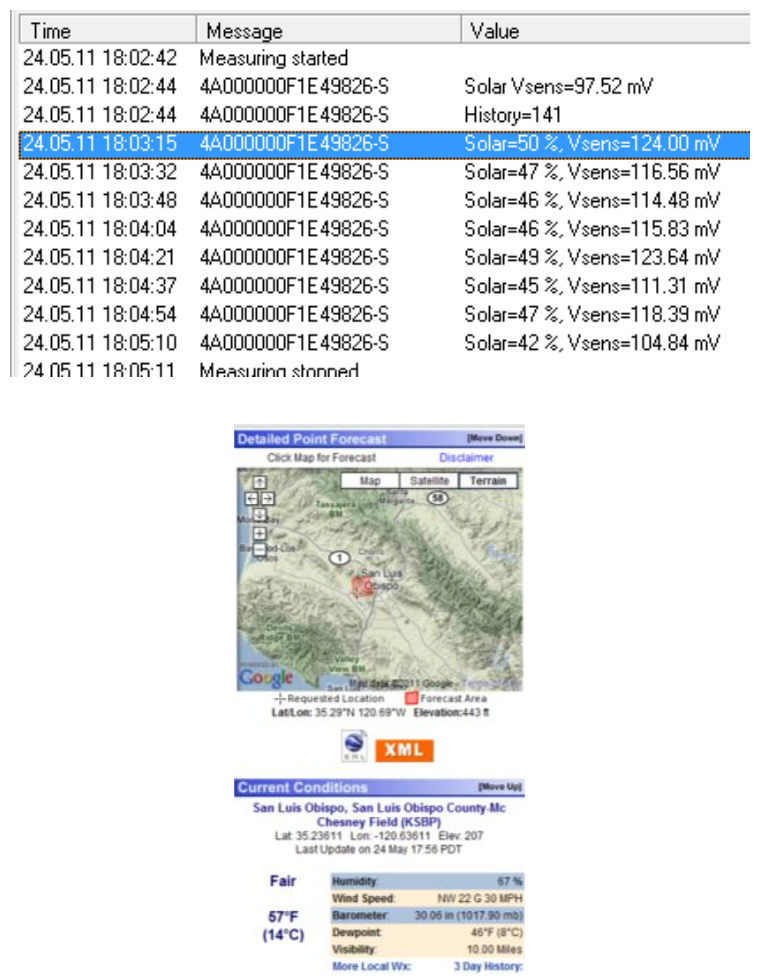

Figure C-5: Weather Conditions on 5/24 


\section{Appendix D : PG\&E SCADA Estimated Costs}

Table D-1 : PG\&E SCADA Cost Estimate

\begin{tabular}{|c|c|c|c|c|c|c|}
\hline Item & & & & & Unit & Extended \\
\hline \multirow[t]{3}{*}{ No. } & Qty. & Unit & Description & Part\# & Price & Price \\
\hline & & & & & & \\
\hline & & & Repeater & & & \\
\hline & & & & & & \\
\hline 1 & 1 & ea & $\begin{array}{l}\text { Universal Package, MDS P-70, Radio Support = 2; } \\
120 \text { AC input, NEMA 4X Housing, 2-Lightning } \\
\text { Protectors, } 12 \text { AH Batt. Back-up, Heater, Fan, Tail-End } \\
\text { Link Operation Mode, Host=9710B (1200bps), } \\
\text { Remote=Transnet E } 805 \text { (1200bps) }\end{array}$ & P702NA220F141_ & $\$ 965.90$ & $\$ 965.90$ \\
\hline 2 & 1 & ea & \begin{tabular}{|l|} 
Radio, MDS 9710B 800-960 MHz Transceiver, \\
Interoperable, $12.5 \mathrm{KHz}$, up to 9600 bps. TX: 928.6875 \\
MHz, RX: $952.6875 \mathrm{MHz}$. Install in Item 1
\end{tabular} & $9710 \mathrm{~B}$ & $\$ 846.30$ & $\$ 846.30$ \\
\hline 3 & 1 & ea & Diagnostics Softw are, MDS InSite Radio Management & 9710-DIAG & $\$ 66.30$ & $\$ 66.30$ \\
\hline 4 & 1 & ea & $\begin{array}{l}\text { Radio, MDS Trans Net 900, adjustable RF output, } \\
\text { synthesized, 902-928 MHz, } 1.2 \text { to } 115.2 \text { kbps } \\
\text { RS232/RS485 VF. Install in Item } 1\end{array}$ & 트805 & $\$ 715.00$ & $\$ 715.00$ \\
\hline 5 & 1 & ea & TransNET 900 Diagnostic & El805-DIAG & $\$ 66.30$ & $\$ 66.30$ \\
\hline 6 & 2 & ea & Bracket, P-Model to Pole Mount VF & $82-1743 \mathrm{~A} 01$ & $\$ 33.15$ & $\$ 66.30$ \\
\hline 7 & 1 & ea & Battery Back-Up, with 12 AH Battery. Install in Item 1 & 28-1575A04 & $\$ 76.05$ & $\$ 76.05$ \\
\hline 12 & 1 & ea & Heater for P70. Install in item 1 & 03-3960A01 & $\$ 146.25$ & $\$ 146.25$ \\
\hline 13 & 2 & ea & Lightning Arrestor for P70 & $97-1678 \mathrm{~A} 15$ & $\$ 42.50$ & $\$ 85.00$ \\
\hline 14 & 1 & ea & Engineering for Item 1 & ENGR-SYS6 & $\$ 350.00$ & $\$ 350.00$ \\
\hline 1 & 1 & ea & Antenna, Yagi, 10dB. Kathrein SCALA P/N:RY-900B & SCARY-900B & $\$ 452.00$ & $\$ 452.00$ \\
\hline 2 & 1 & ea & Mounting Kit for Antenna & SCAMKPS-1 & $\$ 54.00$ & $\$ 54.00$ \\
\hline 3 & 1 & ea & Pipe, Plain End 2-3/8" x 48" & MTSMT-650 & $\$ 23.09$ & $\$ 23.09$ \\
\hline 4 & 4 & ea & Cold Shrink Kit 1/4-1/2" to TY900 Ant. & AND245174 & $\$ 14.35$ & $\$ 57.40$ \\
\hline 7 & 1 & ea & Antenna, Omni, 3dB, 902-928 MHz, Antennex & ANXFG-9023 & $\$ 75.24$ & $\$ 75.24$ \\
\hline 8 & 1 & ea & Pipe to Pipe Kit by Antennex & ANXFM2 & $\$ 19.76$ & $\$ 19.76$ \\
\hline 9 & 2 & Asbly & $\begin{array}{l}\text { Coaxial Cable Assembly, 50' long, NM-NM, made w/ } \\
\text { LDF4-50A Heliax (1/2"). }\end{array}$ & ANDL4-PNMNM-XX & $\$ 116.07$ & $\$ 232.14$ \\
\hline 10 & 2 & ea & RF Connector, $1 / 2$ Male for LDF4 & ANDL4PNM-RC & $\$ 16.08$ & $\$ 32.16$ \\
\hline 11 & 2 & Kit & Hoisting Grip for LDF4 & ANDL4SGRIP & $\$ 13.60$ & $\$ 27.20$ \\
\hline 12 & 2 & ea & Grounding Kit for LDF4 & AND241088-1 & $\$ 14.93$ & $\$ 29.86$ \\
\hline 14 & 1 & ea & Clamps, Pipe to Pipe, Set of Tw o (1-2-7/8") & CEL 46 & $\$ 33.00$ & $\$ 33.00$ \\
\hline 15 & 1 & ea & RF Connector, N Right Angle MF. Andrew & ANDCA-TNRNF & $\$ 18.78$ & $\$ 18.78$ \\
\hline 19 & 2 & ea & Antenna Support Mount & & $\$ 21.76$ & $\$ 43.52$ \\
\hline & & & & & & \\
\hline & & & Switch & & & \\
\hline & & & & & & \\
\hline 15 & 1 & ea & $\begin{array}{l}\text { Radio, MDS 9710B 800-960 MHzTransceiver, } \\
\text { Interoperable, } 12.5 \mathrm{KHz} \text {, up to } 9600 \text { bps. TX: } 928.6875 \\
\text { MHz, RX: } 952.6875 \mathrm{MHz} \text {. }\end{array}$ & $9710 \mathrm{~B}$ & $\$ 986.35$ & $\$ 986.35$ \\
\hline 1 & 1 & ea & Antenna, Yagi, 10dB. Kathrein SCALA P/N:RY-900B & SCARY-900B & $\$ 452.00$ & $\$ 452.00$ \\
\hline 2 & 1 & ea & Mounting Kit for Antenna & SCAMKPS-1 & $\$ 54.00$ & $\$ 54.00$ \\
\hline 3 & 1 & ea & Pipe, Plain End 2-3/8" x 48" & MTSMT-650 & $\$ 23.09$ & $\$ 23.09$ \\
\hline 4 & 2 & ea & Cold Shrink Kit 1/4-1/2" to TY900 Ant. & AND245174 & $\$ 14.35$ & $\$ 28.70$ \\
\hline 9 & 1 & Asbly & $\begin{array}{l}\text { Coaxial Cable Assembly, 50' long, NM-NM, made w/ } \\
\text { LDF4-50A Heliax ( } 1 / 2 ") \text {. }\end{array}$ & ANDL4-PNMNM-XX & $\$ 116.07$ & $\$ 116.07$ \\
\hline 10 & 1 & ea & RF Connector, $1 / 2$ Male for LDF4 & ANDL4PNM-RC & $\$ 16.08$ & $\$ 16.08$ \\
\hline 11 & 1 & Kit & Hoisting Grip for LDF4 & ANDL4SGRIP & $\$ 13.60$ & $\$ 13.60$ \\
\hline 12 & 1 & ea & Grounding Kit for LDF4 & AND241088-1 & $\$ 14.93$ & $\$ 14.93$ \\
\hline 14 & 1 & ea & Clamps, Pipe to Pipe, Set of Tw o (1-2-7/8") & CEL 46 & $\$ 33.00$ & $\$ 33.00$ \\
\hline 15 & 1 & ea & RF Connector, N Right Angle MF. Andrew & ANDCA-TNRNF & $\$ 18.78$ & $\$ 18.78$ \\
\hline 16 & 1 & ea & Protector, Polyphaser & POLIS-B50LN-C2 & $\$ 55.25$ & $\$ 55.25$ \\
\hline 18 & 1 & ea & Cbl. Assmbly. NM-NM, 2feet,Andrew: & ANDF1A-PNMNM-2 & $\$ 30.32$ & $\$ 30.32$ \\
\hline 19 & 1 & ea & Antenna Support Mount & & $\$ 21.76$ & $\$ 21.76$ \\
\hline L01 & 1 & ea & Cbl. RS232 (DB9F/DB25M) 5801/9710B & CSTM Fig B P/N\# 200143-3 & $\$ 16.60$ & $\$ 16.60$ \\
\hline & & & Remole Sites & & & \\
\hline & & & Rem ote Sites & & & \\
\hline 8 & 3 & ea & RF Adaptor TNC-M to NF & 97-1677A161 & $\$ 20.40$ & $\$ 61.20$ \\
\hline 9 & 3 & ea & Cable, Programming (TransNet) & $03-3246 \mathrm{~A} 01$ & $\$ 21.25$ & $\$ 63.75$ \\
\hline 10 & 3 & ea & $\begin{array}{l}\text { Radio, MDS Trans Net 900, adjustable RF output, } \\
\text { synthesized, 902-928 MHz, } 1.2 \text { to } 115.2 \text { kbps } \\
\text { RS232/RS485 VF. }\end{array}$ & 트805 & $\$ 715.00$ & $\$ 2,145.00$ \\
\hline 11 & 3 & ea & TransNET 900 Diagnostic & Ele05-DIAG & $\$ 66.30$ & $\$ 198.90$ \\
\hline 4 & 4 & ea & Cold Shrink Kit 1/4-1/2" to TY900 Ant. & AND245174 & $\$ 14.35$ & $\$ 57.40$ \\
\hline 5 & 2 & KT & Support/Hoisting Grip for $1 / 4^{\prime \prime}$ or $3 / 8^{\prime \prime}$ coax & ANDL1SGRIP & $\$ 11.38$ & $\$ 22.76$ \\
\hline 6 & 2 & Asbly & $\begin{array}{l}\text { Coaxial Cable Assembly, 25' long, NM-NM, made w/ } \\
\text { LDF2-50 Heliax ( } 3 / 8 " \text { ). }\end{array}$ & ANDL2-PNMNM-XX & $\$ 82.31$ & $\$ 164.62$ \\
\hline 7 & 2 & ea & Antenna, Omni, 3dB, 902-928 MHz, Antennex & ANXFG-9023 & $\$ 75.24$ & $\$ 150.48$ \\
\hline 8 & 2 & ea & Pipe to Pipe Kit by Antennex & ANXFM2 & $\$ 19.76$ & $\$ 39.52$ \\
\hline 13 & 2 & ea & Grounding Kit for LDF2 & 223158 & $\$ 1.00$ & $\$ 2.00$ \\
\hline 16 & 2 & ea & Protector, Polyphaser & POLIS-B50LN-C2 & $\$ 55.25$ & $\$ 110.50$ \\
\hline 17 & 2 & ea & RF Adaptor. TNC-M to NF. Right Angle & R/FRFT1234-11 & $\$ 9.36$ & $\$ 18.72$ \\
\hline 18 & 2 & ea & Cbl. Assmbly. NM-NM, 2feet,Andrew : & ANDF1A-PNMNM-2 & $\$ 30.32$ & $\$ 60.64$ \\
\hline 19 & 2 & ea & Antenna Support Mount & & $\$ 21.76$ & $\$ 43.52$ \\
\hline L01 & 2 & ea & Cbl. RS232 (DB9F/DB9M) 5801/Transnet & CSTM Fig A, P/N\# 200142-3 & $\$ 15.20$ & $\$ 30.40$ \\
\hline
\end{tabular}


Table D-2 : PG\&E PT Cost Estimate

\begin{tabular}{|c|c|c|c|c|}
\hline PG\&E & 1630 & & & \\
\hline Qty & Unit & Code & \multicolumn{2}{|c|}{ Description } \\
\hline \multirow[t]{2}{*}{1} & $E A$ & 253058 & + TRAN & FORMER POTENTIAL 10 \\
\hline & & PG\&E & $=1630$ & Misc Items \\
\hline Subtotal for & & PG\&E & $=1630$ & \\
\hline
\end{tabular}

$\begin{array}{rrrr}\text { Rate } & \text { Direct } & & \\ 739 & \text { Cost } & \text { Gross } & \text { JT Pole } \\ & 739 & 890 & 0 \\ 0 & 0 & 0 \\ 739 & 890 & 0 \\ 739 & \mathbf{8 9 0} & \mathbf{0}\end{array}$

